Check for updates

Cite this: RSC Adv., 2019, 9, 39743

Received 20th September 2019 Accepted 25th November 2019

DOI: $10.1039 / c 9 r a 09389 c$

rsc.li/rsc-advances

\title{
Synthesis, cytotoxicity and anti-inflammatory activity of rhamnose-containing ursolic and betulinic acid saponins $\uparrow$
}

\begin{abstract}
Balla Sylla, ${ }^{a}$ Serge Lavoie, ${ }^{b}$ Jean Legault, ${ }^{a}$ Charles Gauthier (DD *ac and André Pichette*a
Betulinic acid and ursolic acid are ubiquitous, naturally-occurring triterpenoids exhibiting various pharmacological activities including cytotoxic and anti-inflammatory activities. However, these triterpenoids display unfavorable pharmacokinetic properties as well as low aqueous solubility. It has been shown that the presence of $\alpha$-L-rhamnose moieties positively modulates the anticancer activity of secondary metabolites. Herein we report the synthesis and in vitro evaluation of cytotoxic and antiinflammatory activities of a series of rhamnose-containing ursolic and betulinic acid saponins. Relying on Schmidt's normal and inverse procedures, monorhamnosides, $(1 \rightarrow 4)$-linked dirhamnosides as well as branched trirhamnosides and tetrarhamnosides were synthesized in high yields with full control of stereoselectivity. A betulinic acid saponin bearing a 3-O- $\alpha$-L-rhamnopyranosyl-(1 $\rightarrow 4)-\alpha-L-$ rhamnopyranosyl residue was found to be a potent cytotoxic agent against human colorectal adenocarcinoma cells without damaging the healthy cells (selectivity ratio $>20$ ) whereas rhamnosecontaining ursolic acid saponins potently inhibited NO overproduction induced by LPS-stimulated macrophages. Our results reveal that rhamnose-containing ursolic and betulinic acid saponins represent promising therapeutic agents.
\end{abstract}

\section{Introduction}

Betulinic acid (BA, 1) is a natural product-derived compound, and member of the lupane-type triterpenoid family. BA possesses multiple pharmacological activities including cytotoxic, anticancer, anti-inflammatory, antimalarial, and anti-HIV activities. ${ }^{1}$ Because of its low in vivo toxicity, ubiquitous natural occurrence in the plant kingdom and broad spectrum of pharmacological activities, BA and its derivatives have been thoroughly investigated in the past few years..$^{2-4}$ Ursolic acid (UA, 2) is another naturally occurring member of the triterpenoid family. UA is found in various plants, fruits, and medicinal herbs. ${ }^{5}$ UA has been shown to possess a vast spectra of pharmacological activities including anti-metastatic, antiangiogenic, antioxidant, anti-inflammatory, and antimicrobial activities. $^{6}$

${ }^{a}$ Centre de Recherche sur La Boréalie (CREB), Chaire de Recherche sur Les Agents Anticancéreux D'origine Naturelle, Laboratoire LASEVE, Département des Sciences Fondamentales, Université du Québec à Chicoutimi, 555, Boul. de L'Université, Chicoutimi, Québec, Canada, G7H 2B1.E-mail: andre.pichette@uqac.ca

${ }^{b}$ Institut des Sciences de la Forêt Tempérée, Université du Québec en Outaouais, 58, Rue Principale, Ripon, Québec, Canada, JoV 1 Vo

${ }^{c}$ Centre Armand-Frappier Santé Biotechnologie, Institut National de La Recherche Scientifique (INRS), 531, Boul. des Prairies, Laval, Québec, Canada, H7V 1 B7. E-mail: charles.gauthier@iaf.inrs.ca

$\uparrow$ Electronic supplementary information (ESI) available. See DOI: 10.1039/c9ra09389c
Although BA and UA are promising natural products from a medicinal point of view, their biopharmaceutical development has been hampered because of their low bioavailability and aqueous solubility. ${ }^{2,5}$ In order to modulate the pharmacokinetic properties and increase their absorption by the organism, polar substituents have been added on the triterpenoid core by taking advantage of the presence of C-3 hydroxyl and C-28 carboxylic acid groups. For instance, C-28 amino acid, ${ }^{7}$ C-3 phthalate, ${ }^{8}$ and C-3 carbamate ${ }^{9}$ as well as ionic derivatives ${ }^{\mathbf{1 0}}$ of BA have been synthesized and showed improved aqueous solubility and cytotoxic activities compared to BA. Recently, Baran and co-workers have developed a late-stage diversification approach for improving the pharmacokinetic properties of BA via $\mathrm{C}-\mathrm{H}$ oxidation through a combination of chemical and enzymatic reactions. ${ }^{\mathbf{1 1}}$

In parallel to these pioneering studies, $\mathrm{we}^{\mathbf{1 , 1 2 - 1 8}}$ and others $^{19-23}$ have been interested in coupling diverse hydrosoluble sugar moieties at the C-3 and/or C-28 positions of BA and other members of the lupane-type triterpenoid family such as betulin and lupeol. Among other things, we have shown that synthetic BA saponins bearing L-rhamnopyranose (Rha) residues at the C-3 position were potent cytotoxic agents ${ }^{15}$ devoid of hemolytic activity ${ }^{\mathbf{1 2}}$ as compared to oleanane-type saponins. BA 3- $O$ - $\alpha$-L-rhamnopyranoside (3) exhibited higher cytotoxic activities against lung carcinoma (A549) and colorectal adenocarcinoma (DLD-1) than BA itself while being less active against human normal skin fibroblasts (WS1). ${ }^{15}$ Furthermore, the 
anticancer activity of a bidesmosidic betulin saponin bearing Rha residues ${ }^{14}$ was demonstrated in vivo against LLC1 tumorbearing mice. ${ }^{24}$ This compound was shown to induce apoptosis in cancer cells via disturbance of mitochondrial electron transfer chain, reduced reactive oxygen species, and decreased membrane potential. ${ }^{24}$

Although not fully understood, there seems to be a correlation between the presence of Rha residues and the anticancer properties of Rha-containing secondary metabolites. The intraperitoneal administration of Rha was shown to suppress cancer growth in mice. ${ }^{25}$ Rhamnospicamycin, a Rha-containing analogue of the natural product spicamycin, was shown to be a potent cytotoxic agent against human myeloma cell lines with an $\mathrm{IC}_{50}$ of $120 \mathrm{nM}^{26}$ Rha-containing bufadienolides and cardenolides such as gamabufotalin rhamnoside and ouabain, respectively, are potent anticancer agents. ${ }^{27}$ O'Doherty and coworkers reported the synthesis of Rha-containing digitoxin derivatives that showed excellent selectivity and activity against a panel of 60 human cancer cell lines. ${ }^{28}$ Structure-activity relationship study highlighted that the $\alpha$-configuration of the glycosidic linkage as well as the presence of the L-enantiomer was a prerequisite to the anticancer activity of digitoxin glycosides. $^{29}$ Interestingly, Lou and co-workers have hypothesized that the presence of a Rha-binding lectins on human cells could play an important role in the anticancer activity of Rhacontaining solasodine saponins. ${ }^{30}$

Within this framework, we report here the synthesis of a series of rhamnose-containing (mono, di, tri, and tetra) BA and UA saponins (compounds 3-10, Fig. 1). By designing these compounds, our objective was to significantly improve the aqueous solubility of BA and UA while preserving (or enhancing) their cytotoxic and anti-inflammatory activities through the multiple presentation of rhamnose units on the triterpenoid scaffold. The synthetic saponins were prepared from corresponding naturally occurring BA and UA, which are commercially available at low prices. The saponins were synthesized following a regioselective approach aiming at minimizing the number of steps and protecting groups throughout the synthetic sequence. The Rha-containing saponins were evaluated for their cytotoxic and anti-inflammatory activities and some interesting selectivities were observed.

\section{Results and discussion}

\section{Synthesis of BA saponins 3-6}

Our work started with the synthesis of mono- and dirhamnoside-containing BA saponins (Scheme 1). Benzyl betulinate $(\mathbf{1 1})^{31}$ was reacted with Schmidt 2,3,4-tri-O-benzoyl- $\alpha$ L-rhamnopyranosyl trichloroacetimidate donor $(\mathbf{1 2})^{\mathbf{1 4}}$ under the promotion of trimethylsilyl trifluoromethanesulfonate (TMSOTf) in anhydrous DCM providing rhamnoside 13 in 76\% yield. Relying on the neighbouring participation of the C-2 benzoyl group, full control of stereoselectivity ( $\alpha$-L-rhamnopyranoside) was obtained, as expected. Then, benzoyl groups were removed through Zemplén conditions to give triol 14. Debenzylation of the latter in the presence of catalytic amounts of $10 \%$ $\mathrm{Pd} / \mathrm{C}$ in refluxing EtOAc led to the previously reported BA $3-O-\alpha-$ L-rhamnopyranoside 3 with an improved overall yield (62\% over three steps from derivative 11) without reducing the terminal alkene. ${ }^{15,32}$

Compound 14 was converted into the corresponding 2,3-di$O$-isopropylidene derivative 15 following treatment with 2,2dimethoxypropane (2,2-DMP) under the catalytic action of PTSA. The C-4' position of derivative 15 was then coupled with trichloroacetimidate (TCA) donor 12 to provide dirhamnoside $16(72 \%$ yield $)$ in exclusive $\alpha$-form. Cleavage of the isopropylidene group using $80 \%$ aqueous HOAc at $80{ }^{\circ} \mathrm{C}$ gave key intermediate 17 in $63 \%$ yield. Target BA dirhamnoside saponin 4 was obtained following hydrogenolysis and debenzoylation with $73 \%$ yield over two steps.

The synthesis of trirhamnoside BA saponin $\mathbf{5}$ was performed by taking advantage of derivative 17. As depicted in Scheme 2,
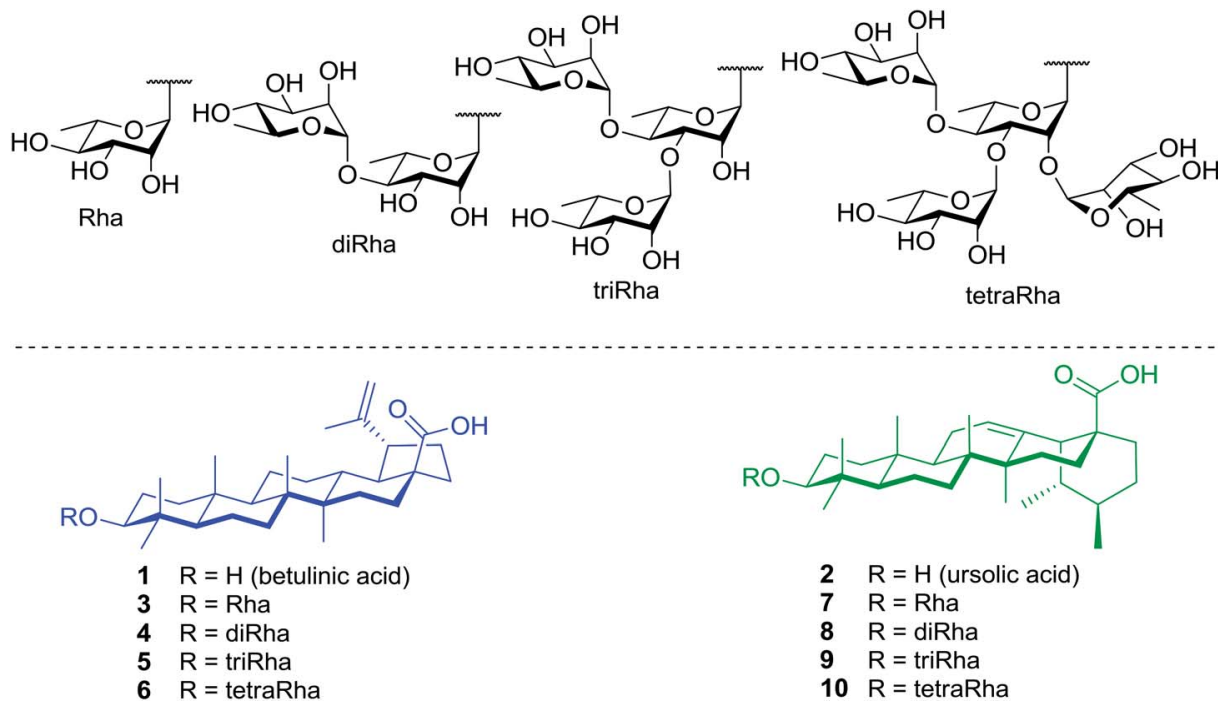

Fig. 1 Structures of target rhamnose-containing UA and BA saponins. 


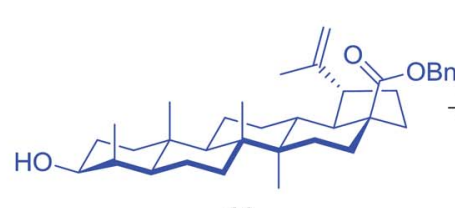

11

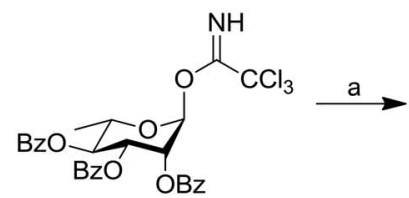

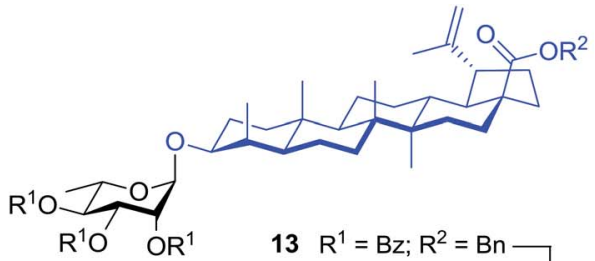

12

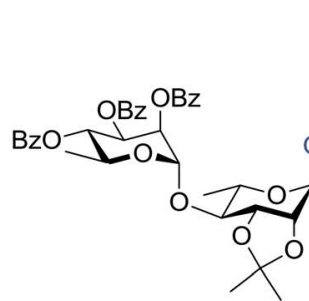

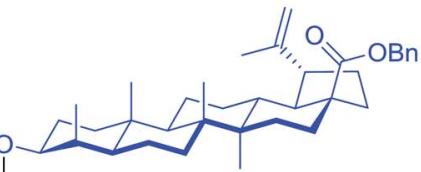<smiles>[Te][Te]</smiles>
e

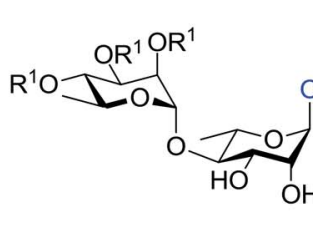<smiles>C1=CC2CCCCC=C1C2</smiles><smiles>C=CC(=O)OCCCC</smiles>
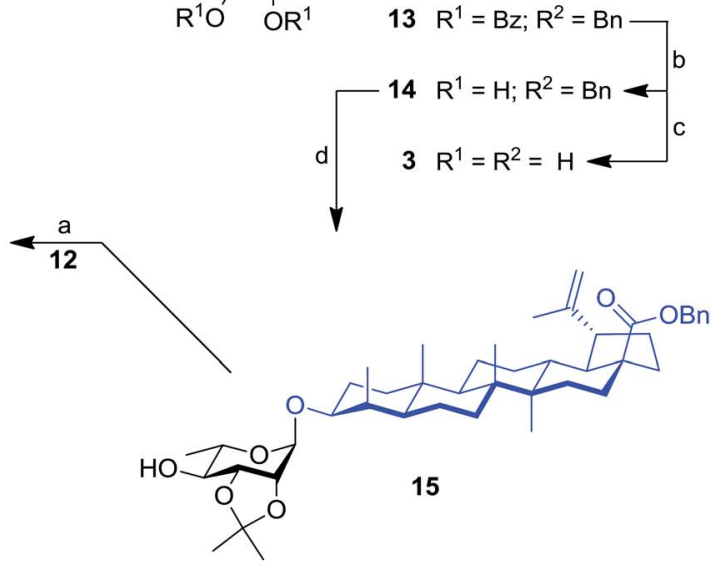

$18 R^{1}=B z ; R^{2}=H$

$4 \mathrm{R}^{1}=\mathrm{R}^{2}=\mathrm{H}$

Scheme 1 Synthesis of mono- and dirhamnoside-containing BA saponins ( 3 and 4). Reagents and conditions: (a) 12 (1.2-1.5 equiv.), TMSOTf (0.1 equiv.), $4 \AA \mathrm{ASS}, \mathrm{DCM}, 0{ }^{\circ} \mathrm{C}, 30 \mathrm{~min}, 76 \%$ (for 13), 72\% (for 16); (b) $\mathrm{NaOMe}, \mathrm{MeOH} / \mathrm{DCM} 2$ : 1, rt, $16 \mathrm{~h}, 97 \%$ (for 14), 85\% (for 4); (c) 10\% Pd/C, $\mathrm{H}_{2}$, EtOAc, $80{ }^{\circ} \mathrm{C}, 4 \mathrm{~h}, 86 \%$ (for 18), 82\% (for 3, two steps from 13); (d) 2,2-DMP (3 equiv.), PTSA (0.1 equiv.), acetone, rt, 2 h, 62\%; (e) $80 \%$ aq. HOAc, DCM, rt, 16 h, $63 \%$.

diol 17 was subjected to regioselective glycosylation ${ }^{33,34}$ with TCA donor 12 affording $\mathrm{C}-3^{\prime}$ and $\mathrm{C}-4^{\prime}$ linked trirhamnoside 19 in $63 \%$ yield. The regioselectivity of the reaction at the $\mathrm{C}-3^{\prime}$ position was confirmed via a 2D NMR HMBC experiment. A small amount of trirhamnoside at the C-2' position was also isolated at this step (data not shown). Cleavage of protecting groups in compound 19 led to target BA trirhamnoside saponin 5 in 68\% yield over two steps.

The synthesis of tetrarhamnoside 6 was our next target. Schmidt's inverse procedure (SIP) ${ }^{35}$ that is known to minimize

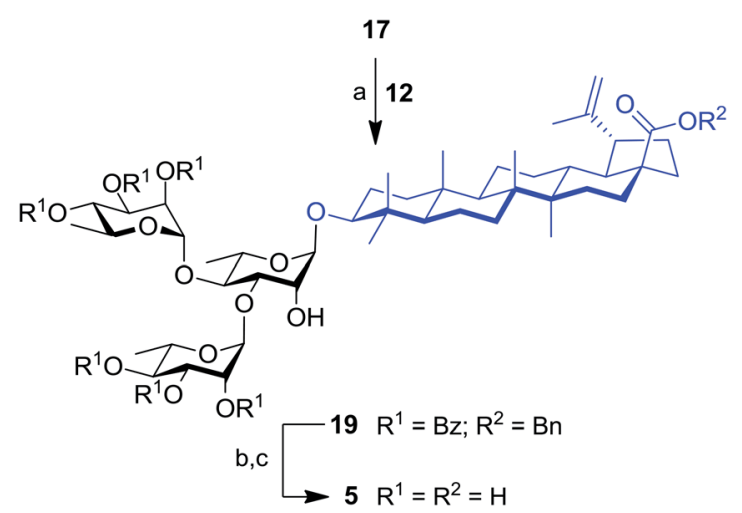

Scheme 2 Synthesis of trirhamnoside-containing BA saponin (5). Reagents and conditions: (a) 12 (1.0 equiv.), TMSOTf ( 0.1 equiv.), $4 \AA$ MS, DCM, $0{ }^{\circ} \mathrm{C}, 30 \mathrm{~min}, 63 \%$; (b) $10 \% \mathrm{Pd} / \mathrm{C}, \mathrm{H}_{2}$, EtOAc, $80^{\circ} \mathrm{C}, 4 \mathrm{~h}$; (c) $\mathrm{NaOMe}, \mathrm{MeOH} / \mathrm{DCM} 2$ : 1, rt, 16 h, 68\% (two steps). donor degradation was preferred for this glycosylation in order to introduce three Rha residues in one step. Indeed, it was previously shown that multiple hydroxyl groups can be simultaneously glycosylated using SIP. ${ }^{17,36}$ Therefore, as depicted in Scheme 3 , triol 14 was subjected to glycosylation with 5.0 equiv. of donor 12 under SIP providing the expected tetrarhamnoside in convenient yield $(42 \%)$ with full control of stereoselectivity. The latter was deprotected using the aforementioned conditions. Purification using normal phase silica gel followed by solid phase extraction (SPE) furnished target saponin 6 in pure and homogeneous forms.

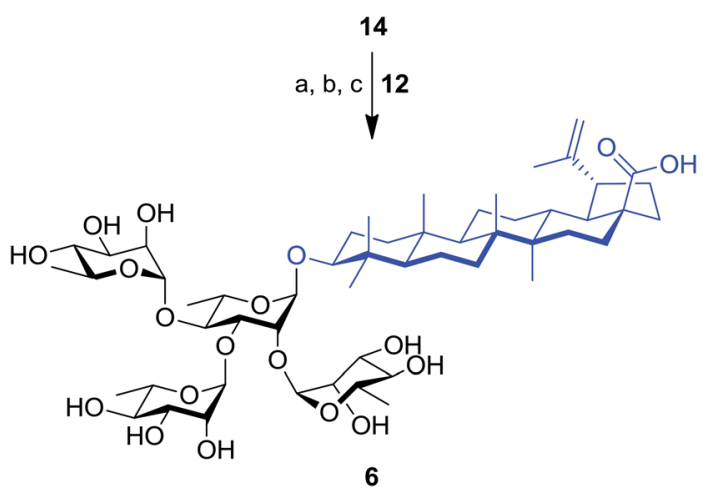

Scheme 3 Synthesis of tetrarhamnoside-containing BA (6). Reagents and conditions: (a) inverse procedure, 12 (5.0 equiv.), TMSOTf (0.1 equiv.), $4 \AA \mathrm{AS}, \mathrm{DCM},-15$ to $0{ }^{\circ} \mathrm{C}, 25 \mathrm{~min}$; (b) $10 \% \mathrm{Pd} / \mathrm{C}, \mathrm{H}_{2}$, EtOAc, $80{ }^{\circ} \mathrm{C}, 3$ h; (c) NaOMe, MeOH/DCM 2 : 1, rt, 16 h, 37\% (three steps). 


\section{Synthesis of UA saponins 7-10}

These results prompted us to apply a similar synthetic approach to prepare rhamnose-containing UA saponins 7-10. Therefore, as shown in Scheme 4, coupling between benzyl ursolate (20) ${ }^{37}$ and TCA donor 12 gave compound 21 with $75 \%$ yield. Removal of benzoyl groups through Zemplén deacylation gave triol 22 . Pd-catalyzed hydrogenolysis afforded UA 3-O- $\alpha$-L-rhamnopyranoside (7) in 74\% yield over two steps. Protection of triol 22 with an isopropylidene group afforded derivative 23 , which was rhamnosylated at the $\mathrm{C}-\mathbf{4}^{\prime}$ position providing dirhamnoside $\mathbf{2 4}$ in $70 \%$ yield. Cleavage of the isopropylidene group generated diol 25 ( $83 \%$ yield), which was subjected to global cleavage of protecting groups giving target dirhamnoside-containing UA saponin 8.

Thereafter, key intermediate 25 was engaged into regioselective glycosylation with TCA donor 12 under TMSOTf promotion (Scheme 5 ) to give trirhamnoside 27 in $62 \%$ yield. The formation of the $\left(1^{\prime \prime \prime} \rightarrow 3^{\prime}\right)$ linkage was proved by a $2 \mathrm{D}$ NMR HMBC experiment, which showed strong cross-peaks from $\mathrm{H}-1^{\prime \prime \prime}$ to $\mathrm{C}-3^{\prime}$. Target trirhamnoside-containing UA saponin 9 was obtained following global deprotection using previously mentioned conditions in 68\% yield over two steps.

At this stage, SIP was used for the simultaneous introduction of three Rha residues. As depicted in Scheme 6, triol 22 was reacted with 5.0 equiv. of TCA donor 12 to provide fully protected tetrarhamnoside 29 in a convenient $47 \%$ yield.
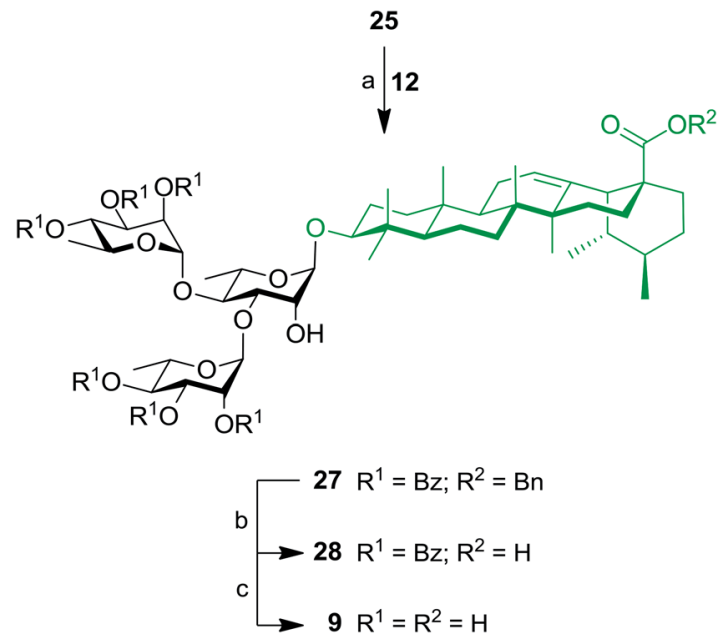

Scheme 5 Synthesis of trirhamnoside-containing UA saponin (9). Reagents and conditions: (a) 12 ( 1.1 equiv.), TMSOTf ( 0.1 equiv.), $4 \AA$ MS, DCM, $0{ }^{\circ} \mathrm{C}, 10 \mathrm{~min}, 62 \%$; (b) $10 \% \mathrm{Pd} / \mathrm{C}, \mathrm{H}_{2}$, EtOAc, $80{ }^{\circ} \mathrm{C}, 4 \mathrm{~h}, 81 \%$; (c) $\mathrm{NaOMe}, \mathrm{MeOH} / \mathrm{DCM} 2$ : 1 , rt, 16 h, $84 \%$.

Deprotection of benzyl and benzoyl groups were performed to give target tetrarhamnoside-containing UA saponin 10 in $90 \%$ over two steps. All of the synthesized BA and UA saponins as well as parent triterpenoids were evaluated for their cytotoxic and anti-inflammatory activities.

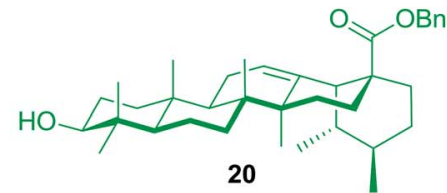

20

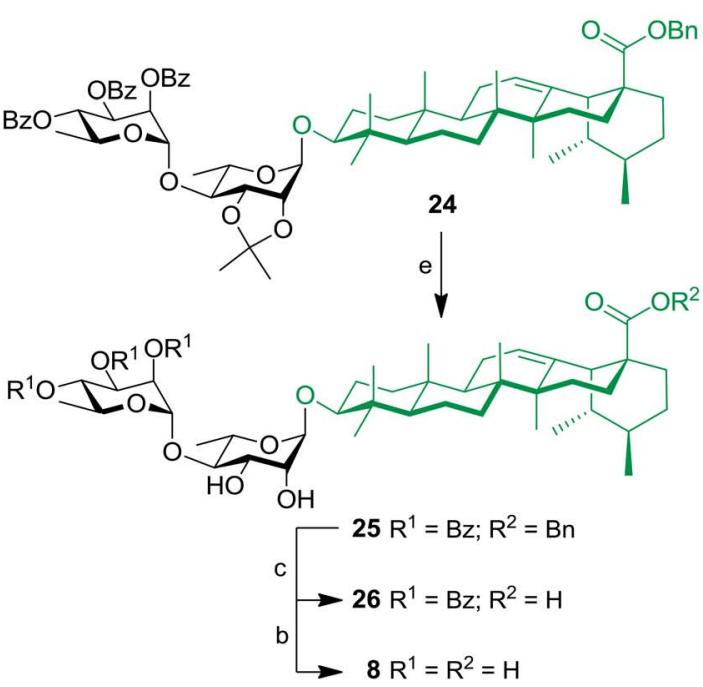

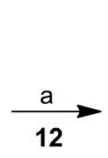

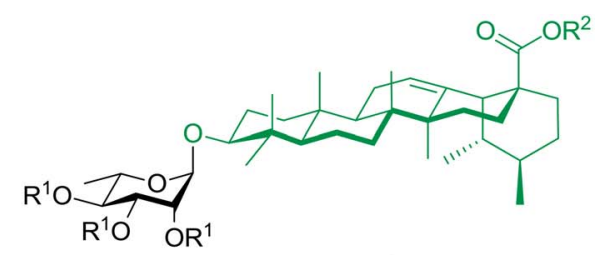

$\mathrm{R}^{1} \mathrm{O} \quad \mathrm{OR}^{1}$ $21 R^{1}=B z ; R^{2}=B n$<smiles>[R][R]#CCCC(C)[Hg]Br</smiles>
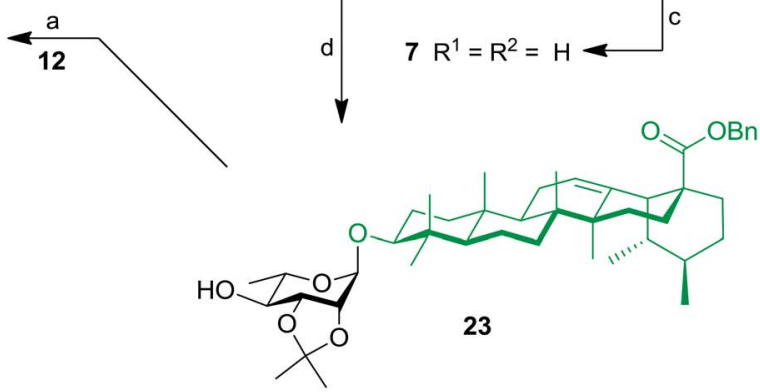

Scheme 4 Synthesis of mono- and dirhamnoside-containing UA saponins (7 and 8). Reagents and conditions: (a) 12 (1.2 equiv.), TMSOTf (0.1 equiv.), $4 \AA \mathrm{MS}, \mathrm{DCM}, 0{ }^{\circ} \mathrm{C}, 30 \mathrm{~min}, 75 \%$ (for 21), 70\% (for 24); (b) $\mathrm{NaOMe}, \mathrm{MeOH} / \mathrm{DCM} 2$ : 1, rt, $16 \mathrm{~h}, 98 \%$ (for 22), 86\% (for 8); (c) 10\% Pd/C, $\mathrm{H}_{2}$, EtOAc, $80{ }^{\circ} \mathrm{C}, 4 \mathrm{~h}, 89 \%$ (for 26), 75\% (for 7, two steps from 21); (d) 2,2-DMP (3 equiv.), PTSA (0.1 equiv.), $\mathrm{CH}_{3} \mathrm{COCH}_{3}, \mathrm{rt}, 2 \mathrm{~h}, 74 \%$; (e) $80 \%$ aq. $\mathrm{HOAc}$, DCM, rt, $16 \mathrm{~h}, 83 \%$. 


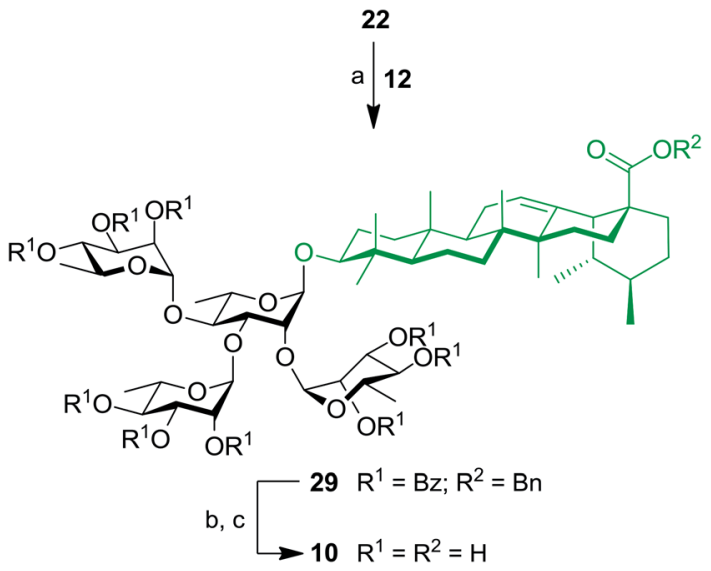

Scheme 6 Synthesis of tetrarhamnoside-containing UA saponin (10). Reagents and conditions: (a) inverse procedure, 12 (5.0 equiv.), TMSOTf (0.1 equiv.), $4 \AA \mathrm{MS}, \mathrm{DCM},-15$ to $0{ }^{\circ} \mathrm{C}, 25 \mathrm{~min}, 47 \%$; (b) $10 \%$ $\mathrm{Pd} / \mathrm{C}, \mathrm{H}_{2}$, EtOAc, $80^{\circ} \mathrm{C}, 3 \mathrm{~h}$; (c) $\mathrm{NaOMe}, \mathrm{MeOH} / \mathrm{DCM} 2$ : $1, \mathrm{rt}, 16 \mathrm{~h}, 90 \%$ (two steps).

\section{Cytotoxic and anti-inflammatory activities of triterpenes and saponins 1-10}

The cytotoxicity of compounds 1-10 was evaluated against human colorectal adenocarcinoma (DLD-1) and healthy human skin fibroblasts (WS1), using Hoechst assay as described in the experimental procedure. The results presented in Table 1 are expressed as the concentration inhibiting $50 \%$ of cell growth $\left(\mathrm{IC}_{50}\right)$. Rha-2-Bet, i.e., $28-O-\alpha$-L-rhamnopyranosylbetulin $3 \beta-O-\alpha-$ L-rhamnopyranoside, was used as positive control with $\mathrm{IC}_{50}$ values of $2.08 \mu \mathrm{M}$ against DLD-1 and $2.5 \mu \mathrm{M}$ against WS-1. ${ }^{14} \mathrm{BA}$ (1) and UA (2) were found cytotoxic against cancer cells with $\mathrm{IC}_{50}$ respectively of 20 and $13 \mu \mathrm{M}$ as well as healthy cells with $\mathrm{IC}_{50}$ respectively of 36 and $14 \mu \mathrm{M}$. As previously reported, the addition of a single rhamnose moiety to BA (3) at the C-3 position selectively improved cytotoxic activity toward cancer cells with IC $_{50}$ of $4 \mu \mathrm{M}$ in comparison with $33 \mu \mathrm{M}$ for healthy cells. ${ }^{15}$
Interestingly, saponin 4 containing a dirhamnose grafted to BA at the same position inhibited cancer cell growth, DLD-1 $\left(\mathrm{IC}_{50}=\right.$ $5 \mu \mathrm{M})$, without affecting healthy cells, WS1 $\left(\mathrm{IC}_{50}>100 \mu \mathrm{M}\right)$. In contrast, saponins 5 and $\mathbf{6}$ containing, respectively, a tri- or a tetra-rhamnose were inactive with $\mathrm{IC}_{50}>100 \mu \mathrm{M}$. In the other hand, the addition of a single rhamnose (7) or a dirhamnose (8) at the C-3 position of UA did not improve the selectivity or the cytotoxic activity. As observed with BA, the presence of tri- (9) or tetrarhamnose (10) residues inhibited the cytotoxicity of UA.

Anti-inflammatory activity of compounds 1-10 was also evaluated using LPS-stimulated RAW 264.7 macrophages, which induces NO overproduction. L-NAME was used as positive control with NO inhibition of $54 \%$ at a concentration of $250 \mu \mathrm{M}$. Compounds 1, 2, and 7 inhibited NO overproduction induced by LPS with $\mathrm{EC}_{50}$ ranging from 9 to $14 \mu \mathrm{M}$ but macrophage cytotoxicity appeared at $20 \mu \mathrm{M}$. Moreover, compounds 3-6 were found inactive with $\mathrm{EC}_{50}>50 \mu \mathrm{M}$. In contrast, all of the UA rhamnosidic derivatives (7-10) inhibited NO overproduction with $\mathrm{EC}_{50}$ ranging from 9.8 to $16 \mu \mathrm{M}$. Interestingly, the presence of mono- (7), di- (8), tri- (9) or tetrarhamnoses (10) at the C-3 position of UA decreased gradually the cytotoxicity against healthy cells with $\mathrm{IC}_{50}$ respectively of $23 \mu \mathrm{M}, 70 \mu \mathrm{M}$ and $>100 \mu \mathrm{M}$ but retained the anti-inflammatory activity.

\section{Conclusions}

In summary, we accomplished the straightforward synthesis of a series of rhamnose-containing saponins (3-10) using the bioactive, naturally-occurring BA (1) and UA (2) as aglycones. Monorhamnosides, $(1 \rightarrow 4)$-linked dirhamnosides as well as branched trirhamnosides and tetrarhamnosides were synthesized in high yields relying on both Schmidt's normal and inverse glycosylation procedures. Outstandingly, 3-O- $\alpha$-L-rhamnopyranosyl-( $1 \rightarrow 4)-\alpha$-L-rhamnopyranosyl-betulinic acid (4) was found to exhibit potent cytotoxic activity against human colorectal adenocarcinoma cells without damaging the healthy cells (selectivity ratio $>20$ ) whereas UA saponins containing more than

Table 1 Cytotoxic and anti-inflammatory activities of compounds 1-10

\begin{tabular}{|c|c|c|c|}
\hline Cpd & \multicolumn{2}{|c|}{ Cytotoxicity, $\mathrm{C}_{50}{ }^{a c}(\mu \mathrm{M})$} & Anti-inflammatory activity, $\mathrm{EC}_{50}{ }^{b c}(\mu \mathrm{M})$ \\
\hline 2 & $13 \pm 2$ & $14 \pm 2$ & $9 \pm 1$ \\
\hline 3 & $4.0 \pm 0.5$ & $33 \pm 6$ & $\mathrm{NA}^{d}$ \\
\hline 4 & $5 \pm 1$ & $>100$ & $\mathrm{NA}^{d}$ \\
\hline 7 & $15 \pm 1$ & $23 \pm 1$ & $10.5 \pm 0.3$ \\
\hline 8 & $>100$ & $70 \pm 4$ & $16 \pm 3$ \\
\hline 9 & $>100$ & $>100$ & $9.8 \pm 0.3$ \\
\hline 10 & $>100$ & $>100$ & $11 \pm 2$ \\
\hline Rha-2-Bet & $2.08 \pm 0.03$ & $2.5 \pm 0.3$ & $14 \pm 1$ \\
\hline
\end{tabular}

${ }^{a} \mathrm{IC}_{50}$ : concentration inhibiting $50 \%$ of cell growth. $28-O-\alpha$-L-Rhamnopyranosylbetulin $3 \beta-O-\alpha$-L-rhamnopyranoside (Rha-2-Bet) was used as positive control. ${ }^{b} \mathrm{EC}_{50}$ : efficacy concentration inhibiting $50 \%$ of NO overproduction induced by LPS. L-NAME was used as positive control inhibits $54 \%$ of NO overproduction at $250 \mu \mathrm{M} .{ }^{c}$ The results are the mean \pm standard deviation of three determination and are representative of three different experiments. ${ }^{d}$ NA: not active; compound was considered inactive when $\mathrm{EC}_{50}$ is $\geq 50 \mu \mathrm{M}$. 
one sugar unit were inactive against cancer cells. Moreover, we found that rhamnose-containing UA saponins 7-10 potently inhibited NO overproduction induced by LPS-stimulated macrophages. Collectively, our results suggest that the cytotoxic and anti-inflammatory activities of rhamnose-containing saponins are strongly modulated by both the nature of the triterpenes and the number and attachment of sugar units.

\section{Experimental section}

\section{General methods}

Air and water sensitive reactions (glycosylation especially) were performed under nitrogen or Ar atmosphere. Moisture sensitive reagents were introduced in reaction media via a dry syringe. AcroSeal ${ }^{\circledR}$ extra dry solvents over molecular sieves (dichloromethane, ethyl acetate, tetrahydrofuran and methanol) were purchased from Acros Organics. All commercial reagents were used without further purification. Purification of reaction products were carried out using 60-230 mesh silica gel obtained from Silicycle (Canada). Compounds were eluted with reagent grade solvent purchased from Fisher Scientific. Analytical thinlayer chromatography was performed with silica gel $60 \mathrm{~F}_{254}$, $0.25 \mathrm{~mm}$ pre-coated TLC plates, supplied by Silicycle (Canada), and visualized using $\mathrm{UV}$ light $(254 \mathrm{~nm})$ and cerium molybdate ( $2 \mathrm{~g} \mathrm{Ce}\left(\mathrm{SO}_{4}\right)_{4}\left(\mathrm{NH}_{4}\right)_{4}, 5 \mathrm{~g} \mathrm{MoO}_{4}\left(\mathrm{NH}_{4}\right)_{2}, 200 \mathrm{~mL} \mathrm{H}{ }_{2} \mathrm{O}$, and $20 \mathrm{~mL}$ $\mathrm{H}_{2} \mathrm{SO}_{4}$ ) with charring. All reaction yields are not optimized values. Optical rotations were measured on a Rudolph Research Analytical AUTOPOL IV digital polarimeter. Absorption UV spectra were recorded with an Agilent 8453 diode-array spectrophotometer. The $1 \mathrm{D}$ and $2 \mathrm{D}$ NMR spectra $\left({ }^{1} \mathrm{H}-{ }^{1} \mathrm{H} \mathrm{COSY}\right.$, HSQC, HMBC and NOESY) were performed using an Avance 400 Bruker spectrometer $\left(400.13 \mathrm{MHz}\right.$ for ${ }^{1} \mathrm{H}, 100.61 \mathrm{MHz}$ for ${ }^{13} \mathrm{C}$ spectra) equipped with a $5 \mathrm{~mm}$ QNP-probe. All spectra were acquired in $\mathrm{CDCl}_{3}, \mathrm{CD}_{3} \mathrm{OD}$, DMSO, or in a mixture of $\mathrm{CDCl}_{3}-$ $\mathrm{CD}_{3} \mathrm{OD} 1: 1$. Chemical shifts are reported in $\mathrm{ppm}(\delta)$ relative to TMS (0 ppm). The modulus of coupling constants $(J)$, extracted from the ${ }^{1} \mathrm{H}$ NMR spectrum, are reported in Hz. HPLC-APCI MS (negative mode) were obtained from an Agilent 1100 series system consisting of a degasser, a quaternary pump, an automatic injector, a temperature-controlled column compartment, a diode array detector and a mass selective detector Agilent G1946 VL model equipped with an APCI source. Analytical

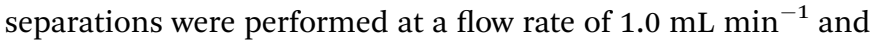
a column temperature of $25{ }^{\circ} \mathrm{C}$. Preparative HPLC separation (Agilent 1100) were carried out on a $20.0 \times 250 \mathrm{~mm} \mathrm{C}_{18}$ column using a multiple wavelength detector and an automatic fraction collector. Chromatographic conditions were the following: gradient elution with $\mathrm{H}_{2} \mathrm{O}: \mathrm{CH}_{3} \mathrm{CN}(10 \rightarrow 100 \%)$ at flow rate of $20.0 \mathrm{~mL} \mathrm{~min}^{-1}$. Mass spectral data (HRMS) were obtained at NanoQAM University of Québec at Montréal (UQAM) and department of chemistry at University of Montréal (UdeM), Québec, Canada.

\section{General procedure for normal Schmidt glycosylation}

Appropriate triterpene acceptor (1 equiv.) and trichloroacetimidate donor (1.5 equiv.) were premixed with $4 \AA$ molecular sieves in dry DCM (5 mL) under Ar atmosphere. After 30 min, TMSOTf (0.1 equiv.) was added dropwise under Ar while keeping rigorous anhydrous conditions. The reaction was generally stirred during $30 \mathrm{~min}$, after which $\mathrm{Et}_{3} \mathrm{~N}$ (0.2 equiv.) was added to quench the reaction. The suspension was filtered, and the solvents were evaporated under reduced pressure. The resulting residue was purified by flash chromatography on silica gel.

\section{General procedure for inverse Schmidt glycosylation}

To a stirred suspension of an appropriate triterpene acceptor and 4 A molecular sieves in dry DCM $(5 \mathrm{~mL})$ was added TMSOTf (0.1 equiv.). The mixture was kept at $-15{ }^{\circ} \mathrm{C}$ under rigorous anhydrous conditions. After $30 \mathrm{~min}$, a solution of trichloroacetimidate donor ( 5 equiv.) in dry DCM was added to the mixture over $5 \mathrm{~min}$. The mixture was stirred at $-15{ }^{\circ} \mathrm{C}$ for $25 \mathrm{~min}$, after which the reaction was quenched with $\mathrm{Et}_{3} \mathrm{~N}(0.2$ equiv.) and filtered. The filtrate was concentrated under reduced pressure to give a residue, which was purified by flash column chromatography.

\section{General procedure for removal of benzoyl groups}

A freshly prepared solution of NaOMe in $\mathrm{MeOH}$ (0.5 M) was added to an appropriate benzoylated compound suspended in dry $\mathrm{MeOH}$ or a mixture of $\mathrm{MeOH}-\mathrm{DCM}(2: 1 \mathrm{v} / \mathrm{v})$. The mixture was stirred overnight at rt. When TLC indicated the completion, the reaction was neutralized to $\mathrm{pH} 7$ with Dowex $\mathrm{G} 26\left(\mathrm{H}^{+}\right.$form $)$ resin and filtered. The filtrate was concentrated to dryness and purified by silica gel flash chromatography.

3-O-(2,3,4-Tri-O-benzoyl- $\alpha$-L-rhamnopyranosyl)-28-benzyl

betulinate (13). Based on the general procedure for direct Schmidt glycosylation, benzyl betulinate 11 (ref. 31) (200 mg, $375 \mu \mathrm{mol}$ ) and 2,3,4-tri-O-benzoyl- $\alpha$-L-rhamnopyranosyl trichloroacetimidate $12(279 \mathrm{mg}, 450 \mu \mathrm{moL})$ was coupled in DCM (8 mL) with TMSOTf $(7 \mu \mathrm{L}, 37,5 \mu \mathrm{mol})$ as Lewis acid for $30 \mathrm{~min}$. The reaction was then quenched with $\mathrm{Et}_{3} \mathrm{~N}(22 \mu \mathrm{L})$ and filtered. Purification by chromatography gave the expected compound 13 (371 mg, 76\%) as colorless oil, $R_{\mathrm{f}}=0.62$ (7:3, hexanesEtOAc), $[\alpha]_{\mathrm{D}}^{20}-15.9$ ( c 1, $\mathrm{CHCl}_{3}$ ). ${ }^{1} \mathrm{H}$ NMR (400 MHz, $\mathrm{CDCl}_{3}$ ) $\delta 8.11$ (br d, $J=7.3 \mathrm{~Hz}, 2 \mathrm{H}, \mathrm{CH}-\mathrm{Bz}$ ), 7.99 (br d, $J=7.3 \mathrm{~Hz}, 2 \mathrm{H}$, $\mathrm{C} H-\mathrm{Bz}$ ), 7.83 (br d, $J=7.3 \mathrm{~Hz}, 2 \mathrm{H}, \mathrm{CH}-\mathrm{Bz}$ ), 7.60 (br t, $J=7.4 \mathrm{~Hz}$, 1H, CH-Bz), 7.51 (br t, $J=7.5 \mathrm{~Hz}, 1 \mathrm{H}, \mathrm{CH}-\mathrm{Bz}$ ), 7.49 (br t, $J=$ $7.5 \mathrm{~Hz}, 2 \mathrm{H}, \mathrm{CH}-\mathrm{Bz}$ ), 7.45-7.30 (m, 7H, CH-Bz, CH-Bn), 7.26 (br t, $J$ $=7.7 \mathrm{~Hz}, 3 \mathrm{H}, \mathrm{CH}-\mathrm{Bz}), 5.82\left(\mathrm{dd}, J=10.1,3.2 \mathrm{~Hz}, 1 \mathrm{H}, \mathrm{H}-3^{\prime}\right), 5.68(\mathrm{t}$, $\left.J=10.1 \mathrm{~Hz}, 1 \mathrm{H}, \mathrm{H}-4^{\prime}\right), 5.64\left(\mathrm{dd}, J=3.1,1.5 \mathrm{~Hz}, 1 \mathrm{H}, \mathrm{H}-2^{\prime}\right), 5.16$ (d, $\left.J=12.3 \mathrm{~Hz}, 1 \mathrm{H}, \mathrm{CH}_{2}-\mathrm{Bn}\right), 5.09$ (d, $\left.J=12.3 \mathrm{~Hz}, 1 \mathrm{H}, \mathrm{CH}_{2}-\mathrm{Bn}\right), 5.07$ (br s, 1H, H-1'), 4.73 (br s, 1H, H-29a), 4.59 (br s, 1H, H-29b), 4.31 $\left(\mathrm{dq}, J=10.1,6.1 \mathrm{~Hz}, 1 \mathrm{H}, \mathrm{H}-5^{\prime}\right), 3.19$ (t, $\left.J=8.2 \mathrm{~Hz}, 1 \mathrm{H}, \mathrm{H}-3\right), 3.03$ (td, $J=10.8,4.5 \mathrm{~Hz}, 1 \mathrm{H}, \mathrm{H}-19), 2.29$ (br d, $J=12.4 \mathrm{~Hz}, 1 \mathrm{H}, \mathrm{H}-$ 16a), 2.19 (td, $J=12.6,3.1 \mathrm{~Hz}, 1 \mathrm{H}, \mathrm{H}-13), 1.68$ (s, 3H, H-30), 1.33 (d, $J=6.2 \mathrm{~Hz}, \mathrm{H}-6^{\prime}$ ), 1.04 (s, 3H, H-23), 0.95 (s, 3H, H-27), 0.92 (s, 3H, H-24), 0.86 (s, 3H, H-25), 0.77 (s, 3H, H-26), 0.71 (br d, $J=8.6 \mathrm{~Hz}, 1 \mathrm{H}, \mathrm{H}-5) .{ }^{13} \mathrm{C} \mathrm{NMR}\left(101 \mathrm{MHz}, \mathrm{CDCl}_{3}\right) \delta 175.8$ (C-28), [165.9, 165.7, 165.6 (CO-Bz)], 150.6 (C-20), 136.5 (C-Bn), [133.4, 133.3, $133.1(\mathrm{CH}-\mathrm{Bz})],[129.9(2 \times), 129.8(2 \times), 129.7$ $(2 \times)(C \mathrm{H}-\mathrm{Bz})],[129.6,129.4,129.3(C-\mathrm{Bz})],[128.6(2 \times), 128.5$ 
$(2 \times), 128.4(2 \times), 128.3(4 \times), 128.1(\mathrm{CH}-\mathrm{Bz}, \mathrm{CH}-\mathrm{Bn})], 109.6(\mathrm{C}-29)$, 99.7 (C-1'), 90.1(C-3), $72.0\left(\mathrm{C}-4^{\prime}\right), 71.2\left(\mathrm{C}-2^{\prime}\right), 70.2\left(\mathrm{C}-3^{\prime}\right), 66.8(\mathrm{C}-$ $\left.5^{\prime}\right), 65.7\left(\mathrm{CH}_{2}\right.$-Bn), 56.6 (C-17), 55.5 (C-5), 50.5 (C-9), 49.4 (C-18), 46.9 (C-19), 42.4 (C-14), 40.7 (C-8), 39.1 (C-4), 38.7 (C-1), 38.2 (C13), 36.9 (2×, C-22, C-10), 34.3 (C-7), 32.1 (C-16), 30.6 (C-21), 29.6 (C-15), 28.3 (C-23), 25.7 (C-2), 25.5 (C-12), 20.9 (C-11), 19.4 (C30), 18.3 (C-6), 17.6 (C-6'), 16.4 (C-24), 16.2 (C-25), 15.8 (C-26), 14.7 (C-27). HRMS calcd for $\mathrm{C}_{64} \mathrm{H}_{77} \mathrm{O}_{10}[\mathrm{M}+\mathrm{H}]^{+}$1005.5511, found 1005.5507; calcd for $\mathrm{C}_{64} \mathrm{H}_{76} \mathrm{O}_{10} \mathrm{Na}[\mathrm{M}+\mathrm{Na}]^{+}$1022.5777, found 1022.5767 .

3-O- $\alpha$-L-Rhamnopyranosyl-28-benzyl betulinate (14). Based on the general procedure for benzoyl groups removal, compound 13 (230 mg, $232 \mu \mathrm{mol}$ ) was dissolved in $\mathrm{MeOH}-\mathrm{DCM}$ (2 : 1, $3 \mathrm{~mL})$ with NaOMe in $\mathrm{MeOH}(0.5 \mathrm{M}, 3 \mathrm{~mL})$ overnight. The reaction was then neutralized to $\mathrm{pH} 7$ with Dowex G26 $\left(\mathrm{H}^{+}\right.$ form), filtered and purified by flash chromatography $(9: 1$, DCM-MeOH) to give compound $14(153 \mathrm{mg}, 97 \%)$ as colorless oil, $R_{\mathrm{f}}=0.5\left(\mathrm{CHCl}_{3}: \mathrm{MeOH}, 7: 1\right),[\alpha]_{\mathrm{D}}^{20}-18.9\left(c 3, \mathrm{CHCl}_{3}\right) \cdot{ }^{1} \mathrm{H}$ NMR (400 MHz, $\left.\mathrm{CDCl}_{3}\right) \delta 7.39-7.28(\mathrm{~m}, 5 \mathrm{H}, \mathrm{H}-\mathrm{Ar}), 5.14(\mathrm{~d}, J=$ $12.4 \mathrm{~Hz}, 1 \mathrm{H}, \mathrm{CH}_{2}-\mathrm{Bn}$ ), 5.10 (d, $\left.J=12.4 \mathrm{~Hz}, 1 \mathrm{H}, \mathrm{CH}_{2}-\mathrm{Bn}\right), 4.77$ (s, $1 \mathrm{H}, \mathrm{H}-1^{\prime}$ ), 4.73 (s, 1H, H-29a), 4.60 (s, 1H, H-29b), 3.90 (s, 1H, H$2^{\prime}$ ), 3.81-3.68 (m, 2H, H-3', H-5'), 3.44 (d, $\left.J=9.9 \mathrm{~Hz}, 1 \mathrm{H}, \mathrm{H}-4^{\prime}\right)$, 3.08-2.97 (m, 2H, H-3, H-19), 2.28 (d, $J=10.4 \mathrm{~Hz}, 1 \mathrm{H}, \mathrm{H}-16 \mathrm{a})$, $2.18(\mathrm{t}, J=11.1 \mathrm{~Hz}, 1 \mathrm{H}, \mathrm{H}-13), 1.68$ (s, 3H, H-30), 1.25 (d, $J=$ $6.6 \mathrm{~Hz}, 3 \mathrm{H}, \mathrm{H}-6^{\prime}$ ), 0.94 (s, 3H, H-27), 0.86 (s, 3H, H-23), 0.78 (s, $3 \mathrm{H}, \mathrm{H}-25), 0.75$ (s, 3H, H-26), 0.71 (s, 3H, H-24), 0.63 (br d, $J=$ $7.3 \mathrm{~Hz}, 1 \mathrm{H}, \mathrm{H}-5) .{ }^{13} \mathrm{C} \mathrm{NMR}\left(101 \mathrm{MHz}, \mathrm{CDCl}_{3}\right) \delta 175.8(\mathrm{C}-28)$, 150.5 (C-20), 136.4 (C-Bn), [128.4 (2×), $128.2(2 \times), 128.0(\mathrm{CH}-$ $\mathrm{Bn}$ )], 109.6 (C-29), 102.3 (C-1'), 89.3 (C-3), 72.8 (C-4'), 71.8 (C3'), 71.3 (C-2'), $68.0\left(\mathrm{C}-5^{\prime}\right), 65.7\left(\mathrm{CH}_{2}-\mathrm{Bn}\right), 56.5$ (C-17), 55.4 (C-5), 50.5 (C-9), 49.4 (C-18), 46.9 (C-19), 42.3 (C-14), 40.6 (C-8), 39.0 (C4), 38.6 (C-1), 38.1 (C-13), 36.9 (C-22), 36.8 (C-10), 34.2 (C-7), 32.1 (C-16), 30.5 (C-21), 29.5 (C-15), 28.1 (C-23), 25.5 (C-12), 25.4 (C2), 20.8 (C-11), 19.3 (C-30), 18.2 (C-6), 17.4 (C-6'), 16.2 (C-24), 16.1 (C-25), 15.8 (C-26), 14.6 (C-27). HRMS calcd for $\mathrm{C}_{43} \mathrm{H}_{65} \mathrm{O}_{7}$ $[\mathrm{M}+\mathrm{H}]^{+}$693.4725, found 693.4698.

3-O- $\alpha$-L-Rhamnopyranosyl betulinic acid (3). In parallel, BA 3- $O-\alpha$-L-rhamnopyranoside 3 was synthesized in two steps starting from 13. A solution of $\mathbf{1 3}(50 \mathrm{mg}, 50 \mu \mathrm{mol})$ and $10 \% \mathrm{Pd} /$ C (1 mg) in dry EtOAc $(3 \mathrm{~mL})$ was refluxed and purged with $\mathrm{H}_{2}$ for $2 \mathrm{~h}$. When TLC indicated the disappearance of the starting material, the residue was filtered over Celite ${ }^{\circledR}$ and concentrated before the removal of benzoyl groups. This was accomplished according to the general procedure using MeOH-DCM $2: 1$ as solvent. The reaction was neutralized to $\mathrm{pH} 7$ with Dowex G26 $\left(\mathrm{H}^{+}\right.$form $)$, filtered and purified by flash chromatography $(7: 1$, DCM-MeOH) to give compound 3 (25 mg, 82\%, two steps) as colorless oil, $R_{\mathrm{f}}=0.3$ (DCM : MeOH, $\left.7: 1\right)$. The NMR data are in adequation with those described in the literature. ${ }^{15,32}$

3-O-(2,3-Di-O-isopropylidene- $\alpha$-L-rhamnopyranosyl)-28-benzyl betulinate (15). Compound $14(140 \mathrm{mg}, 206 \mu \mathrm{mol})$ was dissolved in acetone $(5 \mathrm{~mL})$ to which was added 2,2-dimethoxypropane $(76 \mu \mathrm{L}, 618 \mu \mathrm{mol})$ and PTSA $(3.55 \mathrm{mg}, 20 \mu \mathrm{mol})$ as catalyst. After $2 \mathrm{~h}$, reaction was evaporated to dryness and purified by flash chromatography (7:3, hexanes-EtOAc) to give compound 15 (92 mg, 62\%) as colorless oil, $R_{\mathrm{f}}=0.7$ (hexanes-EtOAc, $7: 3$ ), $[\alpha]_{\mathrm{D}}^{20}-5.8\left(c 2.3, \mathrm{CHCl}_{3}\right) .{ }^{1} \mathrm{H} \mathrm{NMR}\left(400 \mathrm{MHz}, \mathrm{CDCl}_{3}\right) \delta 7.42-7.22$ (m, 5H, H-Ar), 5.15 (d, $\left.J=12.3 \mathrm{~Hz}, 1 \mathrm{H}, \mathrm{CH}_{2}-\mathrm{Bn}\right), 5.09$ (d, $J=$ $12.3 \mathrm{~Hz}, 1 \mathrm{H}, \mathrm{CH}_{2}-\mathrm{Bn}$ ), 4.97 (s, 1H, H-1'), 4.72 (br s, 1H, H-29a), 4.59 (br s, 1H, H-29b), 4.18-4.09 (m, 2H, H-2', H-3'), 3.83 (dq, $\left.J=8.8,6.3 \mathrm{~Hz}, 1 \mathrm{H}, \mathrm{H}-5^{\prime}\right), 3.42\left(\mathrm{dd}, J=8.4,6.3 \mathrm{~Hz}, 1 \mathrm{H}, \mathrm{H}-4^{\prime}\right), 3.11$ (dd, $J=11.4,4.5 \mathrm{~Hz}, 1 \mathrm{H}, \mathrm{H}-3), 3.02$ (td, $J=10.6,4.2 \mathrm{~Hz}, 1 \mathrm{H}, \mathrm{H}-$ 19), 2.27 (br d, $J=12.2 \mathrm{~Hz}, 1 \mathrm{H}, \mathrm{H}-16 \mathrm{a}$ ), 2.17 (td, $J=12.7,3.1 \mathrm{~Hz}$, 1H, H-13), 1.68 (s, 3H, H-30), 1.52 (s, 3H, CH H $_{3}$ iso), 1.37 (s, 3H, $\mathrm{CH}_{3}$-iso), 1.27 (d, J=6.4 Hz, 3H, H-6'), 0.93 (s, 3H, H-27), 0.91 (s, $3 \mathrm{H}, \mathrm{H}-23$ ), 0.80 (s, 3H, H-25), 0.75 (s, 6H, H-24, H-26), 0.67 (br d, $J=9.6 \mathrm{~Hz}, 1 \mathrm{H}, \mathrm{H}-5) .{ }^{13} \mathrm{C} \mathrm{NMR}\left(101 \mathrm{MHz}, \mathrm{CDCl}_{3}\right) \delta 175.8(\mathrm{C}-28)$, 150.6 (C-20), 136.5 (C-Bn), [128.5 (2×), $128.2(2 \times), 128.1(\mathrm{CH}-$ $\mathrm{Bn})$, 109.6 (C-29), 109.4 (C-iso), 99.8 (C-1'), 89.1 (C-3), 78.1 (C$\left.3^{\prime}\right), 75.8\left(\mathrm{C}-2^{\prime}\right), 74.0\left(\mathrm{C}-4^{\prime}\right), 66.5\left(\mathrm{C}-5^{\prime}\right), 65.7\left(\mathrm{CH}_{2}-\mathrm{Bn}\right), 56.5(\mathrm{C}-17)$, 55.5 (C-5), 50.5 (C-9), 49.4 (C-18), 46.9 (C-19), 42.4 (C-14), 40.6 (C8), 39.1 (C-4), 38.7 (C-1), 38.2 (C-13), 36.9 (C-22), 36.9 (C-10), 34.2 (C-7), 32.1 (C-16), 30.6 (C-21), 29.5 (C-15), 28.2 (C-23), $27.9\left(\mathrm{CH}_{3}\right.$ iso), 26.1 ( $\mathrm{CH}_{3}$-iso), 25.6 (C-12), 25.5 (C-2), 20.9 (C-11), 19.4 (C30), 18.2 (C-6), 17.7 (C-6'), 16.3 (C-24), 16.2 (C-25), 15.8 (C-26), 14.7 (C-27). HRMS calcd for $\mathrm{C}_{46} \mathrm{H}_{69} \mathrm{O}_{7}[\mathrm{M}+\mathrm{H}]^{+}$733.5038, found 733.5010 .

3-O-(2,3,4-Tri-O-benzoyl- $\alpha$-L-rhamnopyranosyl- $(1 \rightarrow 4)-2,3-d i-$ $O$-isopropylidene- $\alpha$-L-rhamnopyranosyl)-28-benzyl betulinate (16). Based on the general procedure for normal Schmidt glycosylation, compound 15 (62 mg, $86 \mu \mathrm{mol})$ and 2,3,4-tri-Obenzoyl- $\alpha$-L-rhamnopyranosyl trichloroacetimidate $12(63 \mathrm{mg}$, $103 \mu \mathrm{moL})$ was coupled in DCM (4 mL) with TMSOTf $(1.5 \mu \mathrm{L}, 9$ $\mu \mathrm{mol})$ as Lewis acid for $30 \mathrm{~min}$. When TLC indicated completion, reaction was then quenched with $\mathrm{Et}_{3} \mathrm{~N}(5 \mu \mathrm{L})$ filtered and evaporated before purification by flash chromatography $(8: 2$, hexanes-EtOAc) to give compound $16(73 \mathrm{mg}, 72 \%)$ as colorless oil, $R_{\mathrm{f}}=0.6$ (hexanes-EtOAc, $8: 2$ ), $[\alpha]_{\mathrm{D}}^{20}+35$ (c 2, $\left.\mathrm{CHCl}_{3}\right) \cdot{ }^{1} \mathrm{H}$ $\mathrm{NMR}\left(400 \mathrm{MHz}, \mathrm{CDCl}_{3}\right.$ ) $\delta 8.11$ (br d, $J=7.7 \mathrm{~Hz}, 2 \mathrm{H}, \mathrm{CH}-\mathrm{Bz}$ ), 7.96 (br d, $J=7.9 \mathrm{~Hz}, 2 \mathrm{H}, \mathrm{CH}-\mathrm{Bz}$ ), 7.80 (br d, $J=8.0 \mathrm{~Hz}, 2 \mathrm{H}, \mathrm{CH}-\mathrm{Bz}$ ), 7.61 (br t, $J=7.6 \mathrm{~Hz}, 1 \mathrm{H}, \mathrm{CH}-\mathrm{Bz}) 7.55-7.22(\mathrm{~m}, 13 \mathrm{H}, \mathrm{CH}-\mathrm{Bz}, \mathrm{CH}-$ $\mathrm{Bn}), 5.77\left(\mathrm{dd}, J=10.0,3.3 \mathrm{~Hz}, 1 \mathrm{H}, \mathrm{H}-4^{\prime \prime}\right), 5.73(\mathrm{dd}, J=3.2$, $\left.1.7 \mathrm{~Hz}, 1 \mathrm{H}, \mathrm{H}-2^{\prime \prime}\right), 5.67$ (t, $\left.J=9.8 \mathrm{~Hz}, 1 \mathrm{H}, \mathrm{H}-4^{\prime \prime}\right), 5.58(\mathrm{~d}, J=$ $\left.1.4 \mathrm{~Hz}, 1 \mathrm{H}, \mathrm{H}-1^{\prime \prime}\right), 5.16$ (d, $\left.J=12.3 \mathrm{~Hz}, 1 \mathrm{H}, \mathrm{CH}_{2}-\mathrm{Bn}\right), 5.10$ (d, $J=$ $\left.12.3 \mathrm{~Hz}, 1 \mathrm{H}, \mathrm{CH}_{2}-\mathrm{Bn}\right), 5.03$ (s, $\left.1 \mathrm{H}, \mathrm{H}-1^{\prime}\right), 4.74$ (d, $J=2.4 \mathrm{~Hz}, 1 \mathrm{H}$, H-29a), 4.61 (s, 1H, H-29b), 4.31 (dd, $J=7.2,5.4 \mathrm{~Hz}, 1 \mathrm{H}, \mathrm{H}-3^{\prime}$ ), $4.19\left(\mathrm{dq}, J=9.5,6.2 \mathrm{~Hz}, 1 \mathrm{H}, \mathrm{H}-5^{\prime \prime}\right), 4.13$ (d, $J=5.5 \mathrm{~Hz}, 1 \mathrm{H}, \mathrm{H}-2^{\prime}$ ), $3.97\left(\mathrm{dq}, J=10.0,6.2 \mathrm{~Hz}, 1 \mathrm{H}, \mathrm{H}-5^{\prime}\right), 3.61(\mathrm{dd}, J=9.9,7.3 \mathrm{~Hz}, 1 \mathrm{H}$, $\mathrm{H}-4^{\prime}$ ), 3.14 (dd, $\left.J=9.9,6.1 \mathrm{~Hz}, 1 \mathrm{H}, \mathrm{H}-3\right), 3.03(\mathrm{td}, J=10.7,4.3 \mathrm{~Hz}$, 1H, H-19), 2.29 (br d, $J=12.3 \mathrm{~Hz}, 1 \mathrm{H}, \mathrm{H}-16 \mathrm{a}), 2.19$ (td, $J=12.4$, $3.3 \mathrm{~Hz}, 1 \mathrm{H}, \mathrm{H}-13$ ), 1.69 (s, 3H, H-29), 1.55 (s, 3H, $\mathrm{CH}_{3}$-iso), 1.38 (d, $\left.J=5.8 \mathrm{~Hz}, 3 \mathrm{H}, \mathrm{H}-6^{\prime}\right), 1.37$ (d, $\left.J=6.0 \mathrm{~Hz}, 3 \mathrm{H}, \mathrm{H}-6^{\prime \prime}\right), 1.35$ (s, $3 \mathrm{H}, \mathrm{CH}_{3}$-iso), 0.95 (s, 3H, H-27), 0.93 (s, 3H, H-23), 0.84 (s, 3H, H25), 0.80 (s, 3H, H-24), 0.77 (s, 3H, H-26), 0.70 (br d, $J=8.5 \mathrm{~Hz}$, $1 \mathrm{H}, \mathrm{H}-5) .{ }^{13} \mathrm{C}$ NMR (101 MHz, $\left.\mathrm{CDCl}_{3}\right) \delta 175.8$ (C-28), [165.8, 165.6, 165.4 (CO-Bz)], 150.6 (C-20), 136.5 (C-Bz), [133.4, 133.3, 133.1, $130.0(2 \times), 129.7(2 \times), 129.7(2 \times)(\mathrm{CH}-\mathrm{Bz})],[129.5,129.3$, $129.2(\mathrm{C}-\mathrm{Bz})], 128.5_{3}(2 \times), 1_{128.4_{9}}(2 \times), 128.4_{1}(2 \times), 128.3(4 \times)$, 128.1 (CH-Bz, CH-Bn), 109.6 (C-29), 109.5 (C-iso), 99.5 (C-1'), $96.0\left(\mathrm{C}-1^{\prime \prime}\right), 89.0(\mathrm{C}-3)$, $78.2\left(\mathrm{C}-3^{\prime}\right), 78.0\left(\mathrm{C}-4^{\prime}\right), 76.3\left(\mathrm{C}-2^{\prime}\right), 71.7$ (C$\left.4^{\prime \prime}\right), 70.8\left(\mathrm{C}-2^{\prime \prime}\right), 70.0\left(\mathrm{C}-3^{\prime \prime}\right), 67.3\left(\mathrm{C}-5^{\prime \prime}\right), 65.7\left(\mathrm{CH}_{2}\right.$-Bn), $63.7(\mathrm{C}-$ 5'), 56.6 (C-17), 55.5 (C-5), 50.6 (C-9), 49.5 (C-18), 46.9 (C-19), 42.4 (C-14), 40.7 (C-8), 39.2 (C-4), 38.8 (C-1), 38.2 (C-13), 36.9 (C-22), 36.9 (C-10), 34.3 (C-7), 32.1 (C-16), 30.6 (C-21), 29.6 (C- 
15), 28.3 (C-23), 28.0 ( $\mathrm{CH}_{3}$-iso), 26.5 ( $\mathrm{CH}_{3}$-iso), 25.6 (C-12), 25.5 (C-2), 20.9 (C-11), 19.4 (C-30), 18.3 (C-6), 18.1 (C-6"), 17.7 (C-6'), 16.3 (C-24), 16.2 (C-25), 15.8 (C-26), 14.7 (C-27). HRMS calcd for $\mathrm{C}_{73} \mathrm{H}_{94} \mathrm{O}_{14} \mathrm{~N}\left[\mathrm{M}+\mathrm{NH}_{4}\right]^{+}$1208.6669, found 1208.6703.

3-O-(2,3,4-Tri-O-benzoyl- $\alpha$-L-rhamnopyranosyl-(1 $\rightarrow 4)-\alpha-\mathrm{L}^{-}$ rhamnopyranosyl)-28-benzyl betulinate (17). To a solution of compound 16 (197 mg, $167 \mu \mathrm{mol})$ in DCM $(5 \mathrm{~mL})$ was added HOAc $80 \%$ aq. $(15 \mathrm{~mL})$. After $3 \mathrm{~h}$ stirring at $80{ }^{\circ} \mathrm{C}$, reaction was evaporated to dryness and the crude was purified by flash chromatography $(8: 2$, hexanes-EtOAc) to give compound 17 $(120 \mathrm{mg}, 63 \%)$ as colorless oil, $R_{f}=0.5$ (hexanes-EtOAc, $8: 2$ ), $[\alpha]_{\mathrm{D}}^{20}+36.4\left(c 2, \mathrm{CHCl}_{3}\right) .{ }^{1} \mathrm{H}$ NMR $\left(400 \mathrm{MHz}, \mathrm{CDCl}_{3}\right) \delta 8.07(\mathrm{~d}, J=$ $7.3 \mathrm{~Hz}, 2 \mathrm{H}, \mathrm{CH}-\mathrm{Bz}), 7.97$ (d, $J=7.3 \mathrm{~Hz}, 2 \mathrm{H}, \mathrm{CH}-\mathrm{Bz}), 7.83$ (d, $J=$ $7.3 \mathrm{~Hz}, 2 \mathrm{H}, \mathrm{CH}-\mathrm{Bz}), 7.59(\mathrm{t}, J=7.4 \mathrm{~Hz}, 1 \mathrm{H}, \mathrm{CH}-\mathrm{Bz}), 7.52(\mathrm{t}, J=$ $7.4 \mathrm{~Hz}, 1 \mathrm{H}, \mathrm{CH}-\mathrm{Bz}), 7.49-7.22(\mathrm{~m}, 12 \mathrm{H}, \mathrm{CH}-\mathrm{Bz}), 5.81$ (dd, $J=$ 10.1, 3.4 Hz, 1H, H-3"), 5.77 (dd, $J=3.2,1.8 \mathrm{~Hz}, 1 \mathrm{H}, \mathrm{H}-2^{\prime \prime}$ ), 5.68 ( $\left.\mathrm{t}, J=9.9 \mathrm{~Hz}, 1 \mathrm{H}, \mathrm{H}-4^{\prime \prime}\right), 5.48\left(\mathrm{br} \mathrm{s}, 1 \mathrm{H}, \mathrm{H}-1^{\prime \prime}\right), 5.16$ (d, $J=12.3 \mathrm{~Hz}$, $\left.1 \mathrm{H}, \mathrm{CH}_{2}-\mathrm{Bn}\right), 5.10$ (d, $\left.J=12.3 \mathrm{~Hz}, 1 \mathrm{H}, \mathrm{CH}_{2}-\mathrm{Bn}\right), 4.85$ (s, $1 \mathrm{H}, \mathrm{H}-1^{\prime}$ ), 4.73 (d, $J=2.4 \mathrm{~Hz}, 1 \mathrm{H}, \mathrm{H}-29 \mathrm{a}$ ), 4.60 (br s, 1H, H-29b), 4.29 (dq, $J$ = 9.6, 6.2 Hz, $\left.1 \mathrm{H}, \mathrm{H}-5^{\prime \prime}\right), 4.07$ (dd, $\left.J=9.1,3.3 \mathrm{~Hz}, 1 \mathrm{H}, \mathrm{H}-3^{\prime}\right), 4.01-$ $3.90\left(\mathrm{~m}, 2 \mathrm{H}, \mathrm{H}-2^{\prime}, \mathrm{H}-5^{\prime}\right), 3.63$ (t, $\left.J=9.3 \mathrm{~Hz}, 1 \mathrm{H}, \mathrm{H}-4^{\prime}\right), 3.08$ (dd, $J$ $=10.8,5.3 \mathrm{~Hz}, 1 \mathrm{H}, \mathrm{H}-3), 3.03$ (dd, $J=10.8,4.4 \mathrm{~Hz}, 2 \mathrm{H}, \mathrm{H}-19$ ), 2.29 (br d, $J=12.3 \mathrm{~Hz}, 1 \mathrm{H}, \mathrm{H}-16 \mathrm{a}$ ), 2.19 (td, $J=12.8,3.4 \mathrm{~Hz}$, 1H, H-13), 1.69 (s, 3H, H-30), 1.37 (d, $J=6.8 \mathrm{~Hz}, 3 \mathrm{H}, \mathrm{H}-6^{\prime}$ ), 1.36 $\left(\mathrm{d}, J=6.6 \mathrm{~Hz}, 3 \mathrm{H}, \mathrm{H}-6^{\prime \prime}\right), 0.95$ (s, 3H, H-27), 0.89 (s, 3H, H-23), 0.84 (s, 3H, H-25), 0.79 (s, 3H, H-24), 0.76 (s, 3H, H-26), 0.66 (br d, $J=9.1 \mathrm{~Hz}, 1 \mathrm{H}, \mathrm{H}-5) .{ }^{13} \mathrm{C}$ NMR $\left(101 \mathrm{MHz}, \mathrm{CDCl}_{3}\right) \delta 175.8$ (C-28), [165.9, 165.8, 165.8 (CO-Bz)], 150.6 (C-20), 136.5 (C-Bn), [133.5, 133.3, $133.2(\mathrm{CH}-\mathrm{Bz})],[129.9(2 \times), 129.7(4 \times)(\mathrm{CH}-\mathrm{Bz})]$, [129.3, 129.3, 129.1 (C-Bz)], $128.6(2 \times), 128.5(2 \times), 128.4(2 \times)$, 128.3 $\left.1_{1}(2 \times), 128.2_{5}(2 \times), 128.1(\mathrm{CH}-\mathrm{Bz}, \mathrm{CH}-\mathrm{Bn})\right], 109.6(\mathrm{C}-29)$, 101.9 (C-1'), 98.9 (C-1"), 89.6 (C-3), $81.6\left(\mathrm{C}-4^{\prime}\right), 71.9\left(\mathrm{C}-2^{\prime}\right), 71.9$ $\left(\mathrm{C}-3^{\prime}\right), 71.6\left(\mathrm{C}-4^{\prime \prime}\right), 71.2\left(\mathrm{C}-2^{\prime \prime}\right), 70.1\left(\mathrm{C}-3^{\prime \prime}\right), 67.5\left(\mathrm{C}-5^{\prime \prime}\right), 66.2\left(\mathrm{C}-5^{\prime}\right)$, $65.7\left(\mathrm{CH}_{2}\right.$-Bn), 56.5 (C-17), 55.5 (C-5), 50.5 (C-9), 49.4 (C-18), 46.9 (C-19), 42.4 (C-14), 40.6 (C-8), 39.1 (C-4), 38.7 (C-1), 38.2 (C-13), 36.9 (C-22), 36.9 (C-10), 34.3 (C-7), 32.1 (C-16), 30.6 (C-21), 29.6 (C-15), 28.2 (C-23), 25.6 (C-12), 25.5 (C-2), 20.9 (C-11), 19.4 (C30), 18.3 (C-6), 17.9 (C-6'), $17.6\left(\mathrm{C}-6^{\prime \prime}\right), 16.3$ (C-24), 16.1 (C-25), 15.8 (C-26), 14.7 (C-27). HRMS calcd for $\mathrm{C}_{70} \mathrm{H}_{90} \mathrm{O}_{14} \mathrm{~N}[\mathrm{M}+$ $\left.\mathrm{NH}_{4}\right]^{+}$1168.63558, found 1168.63697 .

3-O-(2,3,4-Tri-O-benzoyl- $\alpha$-L-rhamnopyranosyl-(1 $\rightarrow 4)-\alpha-\mathrm{L}^{-}$ rhamnopyranosyl) betulinic acid (18). A solution of compound $17(116 \mathrm{mg}, 102 \mu \mathrm{mol})$ and $10 \% \mathrm{Pd} / \mathrm{C}(2 \mathrm{mg})$ in dry EtOAc $(5 \mathrm{~mL})$ was refluxed and purged with $\mathrm{H}_{2}$. When TLC indicated the disappearance of the starting material, the mixture was filtered over Celite ${ }^{\circledR}$ and concentrated under reduced pressure. The residue was purified by flash chromatography $(7: 3$, hexanesEtOAc) to give compound 18 (92 $\mathrm{mg}, 86 \%)$ as colorless oil, $R_{\mathrm{f}}=$ 0.2 (hexanes-EtOAc, $7: 3$ ), $[\alpha]_{\mathrm{D}}^{20}+28.3$ (c 2.2, $\mathrm{CHCl}_{3}$ ). ${ }^{1} \mathrm{H}$ NMR $\left(400 \mathrm{MHz}, \mathrm{CDCl}_{3}\right) \delta 8.07(\mathrm{~d}, J=8.2 \mathrm{~Hz}, 2 \mathrm{H}, \mathrm{CH}-\mathrm{Bz}), 7.97$ (d, $J=$ $8.3 \mathrm{~Hz}, 2 \mathrm{H}, \mathrm{CH}-\mathrm{Bz}), 7.82(\mathrm{~d}, J=8.2 \mathrm{~Hz}, 2 \mathrm{H}, \mathrm{CH}-\mathrm{Bz}), 7.62-7.20(\mathrm{~m}$, 12H, CH-Bz), 5.81 (dd, $\left.J=10.2,3.2 \mathrm{~Hz}, 1 \mathrm{H}, \mathrm{H}-3^{\prime \prime}\right), 5.77-5.73(\mathrm{~m}$, $\left.1 \mathrm{H}, \mathrm{H}-2^{\prime \prime}\right), 5.68\left(\mathrm{t}, J=9.9 \mathrm{~Hz}, 1 \mathrm{H}, \mathrm{H}-4^{\prime \prime}\right), 5.48\left(\mathrm{~s}, 1 \mathrm{H}, \mathrm{H}-1^{\prime \prime}\right), 4.86$ (s, 1H, H-1'), 4.75 (br s, 1H, H-29a), 4.62 (br s, 1H, H-29b), 4.29 (dq, $J=9.3,6.1 \mathrm{~Hz}, 1 \mathrm{H}, \mathrm{H}-5^{\prime \prime}$ ), 4.10-4.05 (m, 1H, H-3'), 4.01-3.92 $\left(\mathrm{m}, 2 \mathrm{H}, \mathrm{H}-2^{\prime}, \mathrm{H}-5^{\prime}\right), 3.64\left(\mathrm{t}, J=9.2 \mathrm{~Hz}, 1 \mathrm{H}, \mathrm{H}-4^{\prime}\right), 3.10(\mathrm{dd}, J=$ 10.4, 5.2 Hz, 1H, H-3), 3.06-2.96 (m, 1H, H-19), 2.32-2.14 (m,
2H, H-16a, H-13), 1.70 (s, 3H, H-30), 1.38 (d, J=6.6 Hz, 3H, H$\left.6^{\prime}\right), 1.36\left(\mathrm{~d}, J=6.6 \mathrm{~Hz}, 3 \mathrm{H}, \mathrm{H}-6^{\prime \prime}\right), 0.98$ (s, 3H, H-27), $0.94(\mathrm{~s}, 3 \mathrm{H}$, $\mathrm{H}-26), 0.91$ (s, 3H, H-23), 0.87 (s, 3H, H-25), 0.81 (s, 3H, H-24), $0.70(\mathrm{~d}, J=8.5 \mathrm{~Hz}, 1 \mathrm{H}, \mathrm{H}-5) .{ }^{13} \mathrm{C} \mathrm{NMR}\left(101 \mathrm{MHz}, \mathrm{CDCl}_{3}\right.$ ) $\delta 181.3$ (C-28), [165.9 (2×), 165.8 (CO-Bz)], 150.4 (C-20), [133.5, 133.4, 133.2 , 130.0, $129.7(2 \times)(\mathrm{CH}-\mathrm{Bz})],\left[129.2_{9}, 129.2_{7}, 129.1(\mathrm{C}-\right.$ $\mathrm{Bz})$ ], [128.6, 128.4, 128.3 (CH-Bz)], 109.7 (C-29), 101.9 (C-1'), 98.9 $\left(\mathrm{C}-1^{\prime \prime}\right), 89.6(\mathrm{C}-3), 81.4\left(\mathrm{C}-4^{\prime}\right), 71.9\left(2 \times, \mathrm{C}-3^{\prime}, \mathrm{C}-2^{\prime}\right), 71.6\left(\mathrm{C}-4^{\prime \prime}\right)$, $71.2\left(\mathrm{C}-2^{\prime \prime}\right), 70.0\left(\mathrm{C}-3^{\prime \prime}\right), 67.6\left(\mathrm{C}-5^{\prime \prime}\right), 66.2\left(\mathrm{C}-5^{\prime}\right), 56.4$ (C-17), 55.5 (C-5), 50.5 (C-9), 49.3 (C-18), 46.9 (C-19), 42.4 (C-14), 40.7 (C-8), 39.1 (C-4), 38.7 (C-1), 38.4 (C-13), 37.1 (C-22), 36.9 (C-10), 34.3 (C7), 32.2 (C-16), 30.6 (C-21), 29.7 (C-15), 28.2 (C-23), 25.6 (C-12), 25.5 (C-2), 20.9 (C-11), 19.4 (C-30), 18.3 (C-6), 17.9 (C-6'), 17.6 (C-6"), 16.4 (C-24), 16.2 (C-25), 16.0 (C-26), 14.7 (C-27). HRMS calcd for $\mathrm{C}_{63} \mathrm{H}_{84} \mathrm{O}_{14} \mathrm{~N}\left[\mathrm{M}+\mathrm{NH}_{4}\right]^{+}$1078.5856, found 1078.5901.

3-O-( $\alpha$-L-Rhamnopyranosyl- $(1 \rightarrow 4)$ - $\alpha$-L-rhamnopyranosyl) betulinic acid (4). Based on the general procedure for benzoyl groups removal, compound $18(70 \mathrm{mg}, 67 \mu \mathrm{mol})$ was dissolved in $\mathrm{MeOH}-\mathrm{DCM}(2: 1,3 \mathrm{~mL})$ with NaOMe in $\mathrm{MeOH}(0.5 \mathrm{M}, 3 \mathrm{~mL})$ overnight. The reaction was then neutralized to $\mathrm{pH} 7$ with Dowex $\mathrm{G} 26\left(\mathrm{H}^{+}\right.$form), filtered and purified by flash chromatography (7:1, DCM-MeOH) to give compound 4 (42 mg, 85\%) as colorless oil, $R_{\mathrm{f}}=0.4\left(\mathrm{CHCl}_{3}: \mathrm{MeOH}, 7: 1\right),[\alpha]_{\mathrm{D}}^{20}-18.9(c 3$, $\mathrm{CHCl}_{3}$ ). ${ }^{1} \mathrm{H}$ NMR (400 MHz, DMSO- $d_{6}$ ) $\delta 12.11$ (br s, $1 \mathrm{H}, \mathrm{COOH}$ ), 5.06 (s, 1H, H-1"), 4.95 (s, 1H, OH), 4.76 (br s, 2H, OH), 4.69 (s, 1H, H-29a), 4.65 (br s, 1H, OH), 4.60-4.54 (m, 2H, H-1', H-29b), 3.69 (s, $1 \mathrm{H}, \mathrm{H}-2^{\prime \prime}$ ), 3.60 (s, $1 \mathrm{H}, \mathrm{H}-2^{\prime}$ ), 3.58-3.51 (m, 2H, H-5', H$3^{\prime}$ ), 3.51-3.44 (m, 1H, H-5"), 3.43-3.30 (m, 2H, H-4', H-3"), 3.233.14 (m, 1H, H-4"), 3.04-2.89 (m, 2H, H-3, H-19), 2.23 (br t, $J=$ $10.6 \mathrm{~Hz}, 1 \mathrm{H}, \mathrm{H}-13$ ), 2.11 (br d, $J=7.9 \mathrm{~Hz}, 1 \mathrm{H}, \mathrm{H}-16 \mathrm{a}), 1.64$ (s, 3H, $\mathrm{H}-30), 1.12\left(\mathrm{~d}, J=6.0 \mathrm{~Hz}, \mathrm{H}-6^{\prime}\right), 1.11$ (d, $\left.J=6.0 \mathrm{~Hz}, \mathrm{H}-6^{\prime \prime}\right), 0.93$ (s, $3 \mathrm{H}, \mathrm{H}-27), 0.86$ (s, 6H, H-23, H-26), 0.78 (s, 3H, H-25), 0.70 (s, $3 \mathrm{H}, \mathrm{H}-24) .{ }^{13} \mathrm{C}$ NMR (101 MHz, DMSO- $\left.d_{6}\right) \delta 177.2$ (C-28), 150.2 (C-20), 109.5 (C-29), 102.5 (C-1'), 101.0 (C-1), 87.6 (C-3), 77.9 (C$\left.4^{\prime}\right), 71.8\left(\mathrm{C}-4^{\prime \prime}\right), 71.5\left(\mathrm{C}-3^{\prime}\right), 71.1\left(\mathrm{C}-2^{\prime}\right), 70.6\left(\mathrm{C}-3^{\prime \prime}\right), 70.5\left(\mathrm{C}-2^{\prime \prime}\right)$, $68.8\left({\mathrm{C}-5^{\prime \prime}}^{\prime \prime}, 66.6\left(\mathrm{C}-5^{\prime}\right), 55.3(\mathrm{C}-17), 54.6(\mathrm{C}-5), 49.7\right.$ (C-9), $48.4(\mathrm{C}-$ 18), 46.5 (C-19), 41.9 (C-14), 40.1 (C-8), 38.5 (C-4), 38.0 (C-1), 37.4 (C-13), 36.4 (C-10), 36.2 (C-22), 33.7 (C-7), 31.6 (C-16), 30.0 (C21), 29.1 (C-15), 27.7 (C-23), 25.0 (2×, C-2, C-12), 20.3 (C-11), 18.8 (C-30), 18.0 (C-6'), 17.7 3 (C-6), 17.6 (C-6 $\left.^{\prime \prime}\right), 16.1$ (C-24), 15.8 (C-25), 15.6 (C-26), 14.3 (C-27). HRMS calcd for $\mathrm{C}_{42} \mathrm{H}_{72} \mathrm{O}_{11} \mathrm{~N}\left[\mathrm{M}+\mathrm{NH}_{4}\right]^{+}$766.51, found 766.5128.

3-O-(2,3,4-Tri-O-benzoyl- $\alpha$-L-rhamnopyranosyl- $(1 \rightarrow 2)-[2,3,4-$ tri- $O$-benzoyl- $\alpha$-L-rhamnopyranosyl- $(1 \rightarrow 4)]$ - $\alpha$-L-rhamnopyranosyl)-28-benzyl betulinate (19). Based on the general procedure for normal Schmidt glycosylation, compound 17 (120 mg, 106 $\mu \mathrm{mol}$ ) and 2,3,4-tri-O-benzoyl- $\alpha$-L-rhamnopyranosyl trichloroa cetimidate 12 (66 mg, $106 \mu \mathrm{moL})$ was coupled in DCM $(6 \mathrm{~mL})$ with TMSOTf $(2 \mu \mathrm{L}, 11 \mu \mathrm{mol})$ as Lewis acid for $30 \mathrm{~min}$. When TLC indicated completion, reaction was then quenched with $\mathrm{Et}_{3} \mathrm{~N}(5 \mu \mathrm{L})$ filtered and evaporated before purification by flash chromatography ( $7: 3$, hexanes-EtOAc) to give compound 19 (107 mg, 63\%) as colorless oil, $R_{\mathrm{f}}=0.5$ (hexanes-EtOAc, $7: 3$ ), $[\alpha]_{\mathrm{D}}^{20}+44.5\left(c 1.9, \mathrm{CHCl}_{3}\right) .{ }^{1} \mathrm{H} \mathrm{NMR}\left(400 \mathrm{MHz}, \mathrm{CDCl}_{3}\right) \delta 8.02-7.74$ (m, 12H, CH-Bz), 7.55-7.06 (m, 17H, CH-Bz, CH-Bn), 6.04 (dd, $J$ $\left.=3.4,1.7 \mathrm{~Hz}, 1 \mathrm{H}, \mathrm{H}-2^{\prime \prime \prime}\right), 5.99\left(\mathrm{dd}, J=10.1,3.2 \mathrm{~Hz}, 1 \mathrm{H}, \mathrm{H}-3^{\prime \prime \prime}\right)$, $5.95\left(\mathrm{dd}, J=10.2,3.1 \mathrm{~Hz}, 1 \mathrm{H}, \mathrm{H}-3^{\prime \prime}\right), 5.83(\mathrm{dd}, J=3.5,1.8 \mathrm{~Hz}, 1 \mathrm{H}$, 
$\left.\mathrm{H}-2^{\prime \prime}\right), 5.75\left(\mathrm{t}, J=10.0 \mathrm{~Hz}, 1 \mathrm{H}, \mathrm{H}-4^{\prime \prime}\right), 5.67(\mathrm{t}, J=9.9 \mathrm{~Hz}, 1 \mathrm{H}, \mathrm{H}-$ $\left.4^{\prime \prime \prime}\right), 5.54\left(\mathrm{~d}, J=1.9 \mathrm{~Hz}, 1 \mathrm{H}, \mathrm{H}-1^{\prime \prime}\right), 5.37$ (br s, $\left.1 \mathrm{H}, \mathrm{H}-1^{\prime \prime \prime}\right), 5.16$ (d, $J$ $\left.=12.3 \mathrm{~Hz}, 1 \mathrm{H}, \mathrm{CH}_{2}-\mathrm{Bn}\right), 5.09\left(\mathrm{~d}, J=12.3 \mathrm{~Hz}, 1 \mathrm{H}, \mathrm{CH}_{2}-\mathrm{Bn}\right), 4.86$ (s, 1H, H-1'), 4.73 (d, J=2.5 Hz, 1H, H-29a), 4.60 (br s, 1H, H29b), 4.46 (dq, $\left.J=9.7,6.2 \mathrm{~Hz}, 1 \mathrm{H}, \mathrm{H}-5^{\prime \prime \prime}\right), 4.32$ (dq, $J=9.6$, $\left.6.3 \mathrm{~Hz}, 1 \mathrm{H}, \mathrm{H}-5^{\prime \prime}\right), 4.22-4.14\left(\mathrm{~m}, 2 \mathrm{H}, \mathrm{H}-2^{\prime}, \mathrm{H}-3^{\prime}\right), 4.03(\mathrm{dq}, J=9.3$, $\left.6.3 \mathrm{~Hz}, 1 \mathrm{H}, \mathrm{H}-5^{\prime}\right), 3.84\left(\mathrm{t}, J=9.2 \mathrm{~Hz}, 1 \mathrm{H}, \mathrm{H}-4^{\prime}\right), 3.15-3.07(\mathrm{~m}, 1 \mathrm{H}$, $\mathrm{H}-3), 3.03(\mathrm{td}, J=10.9,4.5 \mathrm{~Hz}, 1 \mathrm{H}, \mathrm{H}-19), 2.29$ (br d, $J=12.2 \mathrm{~Hz}$, $1 \mathrm{H}), 2.18(\mathrm{td}, J=12.4,3.2 \mathrm{~Hz}, 1 \mathrm{H}), 1.68(\mathrm{~s}, 3 \mathrm{H}, \mathrm{H}-30), 1.43(\mathrm{~d}, J=$ $\left.6.2 \mathrm{~Hz}, 3 \mathrm{H}, \mathrm{H}-6^{\prime}\right), 1.36$ (d, $\left.J=6.3 \mathrm{~Hz}, 3 \mathrm{H}, \mathrm{H}-6^{\prime \prime}\right), 1.35$ (d, $J=$ $6.2 \mathrm{~Hz}, 3 \mathrm{H}, \mathrm{H}-6^{\prime \prime \prime}$ ), 0.94 (s, 3H, H-27), 0.91 (s, 3H, H-23), 0.86 (s, $3 \mathrm{H}, \mathrm{H}-25), 0.83$ (s, 3H, H-24), 0.76 (s, 3H, H-26), 0.68 (br d, $J=$ $\left.8.2 \mathrm{~Hz},{ }^{1} \mathrm{H}, \mathrm{H}-5\right) .{ }^{13} \mathrm{C}$ NMR (101 MHz, $\left.\mathrm{CDCl}_{3}\right) \delta 175.8(\mathrm{C}-28)$, [165.9, 165.8, 165.6, 165.5, 165.1, 164.9 (CO-Bz)], 150.6 (C-20), 136.5 (C-Bn), [133.2 $, 133.2_{3}, 133.1,132.8,132.7,132.6,129.9$, $129.8_{2}, 129.7_{7}, 129.6_{3}, 129.5_{9}, 129.5_{1}, 129.4,129.3,128.5,128.4$, $128.3_{5}, 128.3_{3}, 128.2_{7}, 128.2_{1}, 128.1_{0}, 128.0_{8}, 128.0(\mathrm{CH}-\mathrm{Bz}, \mathrm{CH}-$ $\mathrm{Bn})], 109.6$ (C-29), $101.8\left(\mathrm{C}-1^{\prime}\right), 99.7\left(\mathrm{C}-1^{\prime \prime}\right), 99.5\left(\mathrm{C}-1^{\prime \prime \prime}\right), 89.9(\mathrm{C}-$ 3), $81.7\left(\mathrm{C}-3^{\prime}\right), 81.0\left(\mathrm{C}-4^{\prime}\right), 72.0\left(\mathrm{C}-4^{\prime \prime \prime}\right), 72.0\left(\mathrm{C}-4^{\prime \prime}\right), 71.9\left(\mathrm{C}-2^{\prime \prime}\right)$, $71.3\left(\mathrm{C}-2^{\prime \prime \prime}\right), 71.1\left(\mathrm{C}-2^{\prime}\right), 69.4\left(\mathrm{C}-3^{\prime \prime \prime}\right), 69.4\left(\mathrm{C}-3^{\prime \prime}\right), 67.7\left(\mathrm{C}-5^{\prime \prime \prime}\right), 67.6$ $\left(\mathrm{C}-5^{\prime \prime}\right), 67.1$ (C-5'), 65.7 (C-7), 56.6 (C-17), 55.5 (C-5), 50.5 (C-9), 49.5 (C-18), 47.0 (C-19), 42.4 (C-14), 40.7 (C-8), 39.1 (C-4), 38.7 (C-1), 38.2 (C-13), 36.9 (C-22), 36.9 (C-10), 34.3 (C-7), 32.1 (C-16), 30.6 (C-21), 29.7 (C-15), 29.6 (C-15), 28.3 (C-23), 25.7 (C-12), 25.5 (C-2), 20.9 (C-11), 19.4 (C-30), 18.3 (C-6'), 18.3 (C-6), 17.7 (C-6"), 17.6 (C-6"' $), 16.5$ (C-24), 16.2 (C-25), 15.8 (C-26), 14.7 (C-27). HRMS calcd for $\mathrm{C}_{97} \mathrm{H}_{112} \mathrm{O}_{21} \mathrm{~N}\left[\mathrm{M}+\mathrm{NH}_{4}\right]^{+}$1626.7721, found 1626.7762.

3-O- $\alpha$-L-Rhamnopyranosyl-( $1 \rightarrow 2)$ - [ $\alpha$-L-rhamnopyranosyl- $(1 \rightarrow 4)]$ - $\alpha$-L-rhamnopyranosyl betulinic acid (5). A solution of compound 19 (43 mg, $27 \mu \mathrm{mol})$ and 10\% Pd/C (1 mg) in dry EtOAc $(3 \mathrm{~mL})$ was refluxed and purged with $\mathrm{H}_{2}$. When TLC indicated the disappearance of the starting material, the mixture was filtered over Celite ${ }^{\circledR}$ and concentrated under reduced pressure. The residue was dissolved in $\mathrm{MeOH}-\mathrm{DCM}(2: 1,1.5 \mathrm{~mL})$ with $\mathrm{NaOMe}$ in $\mathrm{MeOH}(0.5 \mathrm{M}, 1.5 \mathrm{~mL})$ overnight. The reaction was then neutralized to $\mathrm{pH} 7$ with Dowex $\mathrm{G} 26\left(\mathrm{H}^{+}\right.$form), filtered and purified by flash chromatography $\left(7: 1, \mathrm{CHCl}_{3}-\mathrm{MeOH}\right.$ to $\left.50: 10: 1, \mathrm{CHCl}_{3}-\mathrm{MeOH}-\mathrm{H}_{2} \mathrm{O}\right)$ to give compound $5(19.5 \mathrm{mg}$, $84 \%)$ as amorphous powder, $R_{\mathrm{f}}=0.3\left(26: 14: 3 \mathrm{CHCl}_{3}-\mathrm{MeOH}-\right.$ $\left.\mathrm{H}_{2} \mathrm{O}\right),[\alpha]_{\mathrm{D}}^{20}-6.42\left(c, 1.09,1: 1, \mathrm{CHCl}_{3}-\mathrm{MeOH}\right) .{ }^{1} \mathrm{H}$ NMR $[400$ MHz, DMSO- $d_{6}+1$ drop $\left.\mathrm{H}_{2} \mathrm{O}\right] \delta 4.82\left(\mathrm{~s}, 1 \mathrm{H}, \mathrm{H}-1^{\prime \prime}\right), 4.68(\mathrm{~m}, 1 \mathrm{H}$, $\mathrm{H}-29), 4.60$ (s, 1H, H-1'" ) 4.58-4.53 (s, 1H, H-1', H-29b), 3.753.55 (m, 6H, H-2', H-2 ${ }^{\prime \prime \prime}, \mathrm{H}-5^{\prime \prime \prime}, \mathrm{H}-3^{\prime}, \mathrm{H}-5^{\prime}, \mathrm{H}-2^{\prime}$ ), 3.54-3.30 (m, $\left.4 \mathrm{H}, \mathrm{H}-4^{\prime}, \mathrm{H}-3^{\prime \prime \prime}, \mathrm{H}-5^{\prime \prime}, \mathrm{H}-3^{\prime \prime}\right), 3.22-3.14$ (m, 2H, H-4"', $\left.\mathrm{H}-4^{\prime \prime}\right), 3.04-$ 2.90 (m, 2H, H-3, H-19), 2.28-2.16 (m, 1H, H-13), 2.14-2.06 (m, 1H, H-16a), 1.63 (s, 3H, H-30), 1.13 (d, $J=6.3 \mathrm{~Hz}, 3 \mathrm{H}, \mathrm{H}-6^{\prime}$ ), 1.11 $\left(\mathrm{d}, J=6.3 \mathrm{~Hz}, 3 \mathrm{H}, \mathrm{H}-6^{\prime \prime}\right), 1.07$ (d, $\left.J=6.2 \mathrm{~Hz}, 3 \mathrm{H}, \mathrm{H}-6^{\prime \prime \prime}\right), 0.92$ (s, $3 \mathrm{H}, \mathrm{H}-27), 0.85$ (s, 3H, H-23), 0.85 (s, 3H, H-26), 0.77 (s, 4H, H$25, \mathrm{H}-5) .{ }^{13} \mathrm{C}$ NMR $\left[400 \mathrm{MHz},\left(\mathrm{CD}_{3}\right)_{2} \mathrm{SO}+1\right.$ drop $\left.\mathrm{H}_{2} \mathrm{O}\right] \delta 185.5(\mathrm{C}-$ 28), 150.4 (C-20), 109.7 (C-29), 102.9 (C-1"'), 102.6 (C-1'), 101.8 $\left(\mathrm{C}-1^{\prime \prime}\right), 88.0(\mathrm{C}-3), 79.6\left(\mathrm{C}-3^{\prime}\right), 77.4\left(\mathrm{C}-4^{\prime}\right), 71.9\left(\mathrm{C}-4^{\prime \prime \prime}\right), 71.7\left(\mathrm{C}-4^{\prime \prime}\right)$, 70.7 (C-2"), $70.7\left(\mathrm{C}-3^{\prime \prime}\right), 70.5\left(\mathrm{C}-3^{\prime \prime \prime}\right), 70.4\left(\mathrm{C}-2^{\prime}\right), 70.4\left(\mathrm{C}-2^{\prime \prime \prime}\right), 69.3$ $\left(\mathrm{C}-5^{\prime \prime}\right), 68.6\left({\mathrm{C}-5^{\prime \prime \prime}}^{\prime \prime}\right), 67.4\left(\mathrm{C}-5^{\prime}\right), 55.5$ (C-17), 54.7 (C-5), 49.9 (C-9), 48.6 (C-18), 46.7 (C-19), 42.1 (C-14), 40.3 (C-8), 38.4 (C-4), 38.0 (C1), 37.6 (C-13), 36.6 (C-10), 36.5 (C-22), 33.9 (C-7), 31.8 (C-16), 30.2 (C-21), 29.3 (C-15), 27.8 (C-23), 25.2 (C-2), 25.2 (C-12),
20.5 (C-11), 19.0 (C-30), 18.1 (C-6'), 17.9 (C-6), 17.7 (C-6"), 17.7 (C-6"'), 16.2 (C-24), 15.9 (C-25), 15.8 (C-26), 14.4 (C-27). HRMS calcd for $\mathrm{C}_{48} \mathrm{H}_{78} \mathrm{O}_{15}[\mathrm{M}+\mathrm{Na}]^{+}$917.5232, found 917.5229.

3-O- $\alpha$-L-Rhamnopyranosyl- $(1 \rightarrow 2)$-[ $\alpha$-L-rhamnopyranosyl$(1 \rightarrow 3)]$-[ $\alpha$-L-rhamnopyranosyl- $(1 \rightarrow 4)]-\alpha$-L-rhamnopyranosyl betulinic acid (6). Based on the general procedure for inverse Schmidt glycosylation, compound $14(70 \mathrm{mg}, 103 \mu \mathrm{mol})$ and TMSOTf $(2 \mu \mathrm{L}, 10 \mu \mathrm{mol})$ were dissolved in dry DCM $(4 \mathrm{~mL})$ with $4 \AA$ A molecular sieves $(50 \mathrm{mg})$ at $-78{ }^{\circ} \mathrm{C}$. After stirring the solution during $30 \mathrm{~min}$, a solution of 2,3,4-tri- $O$-benzoyl- $\alpha$-L-rhamnopyranosyl trichloroacetimidate $12(320 \mathrm{mg}, 515 \mu \mathrm{moL})$ in dry DCM $(2 \mathrm{~mL})$ was added. The reaction mixture was stirred at $-15{ }^{\circ} \mathrm{C}$ for $25 \mathrm{~min}$, then the reaction was quenched with $\mathrm{Et}_{3} \mathrm{~N}$ (0.2 equiv.) and filtered. The filtrate was concentrated under reduced pressure, and the residue was mixed with $10 \% \mathrm{Pd} / \mathrm{C}(2$ $\mathrm{mg}$ ) in dry EtOAc $(5 \mathrm{~mL})$. The reaction was refluxed under $\mathrm{H}_{2}$ atmosphere. When TLC indicated the disappearance of the starting material, the mixture was filtered over Celite ${ }^{\circledR}$ and concentrated under reduced pressure. The residue was suspended in dry $\mathrm{MeOH}-\mathrm{DCM}(2: 1,3 \mathrm{~mL})$ to which a freshly prepared solution of NaOMe $(0.5 \mathrm{M}, 3 \mathrm{~mL})$ was added. After overnight stirring, reaction was neutralized to $\mathrm{pH} 7$ with Dowex G-26 $\left(\mathrm{H}^{+}\right.$form $)$and filtered. The filtrate was concentrated to dryness and purified by normal phase flash chromatography (26:14:3 $\mathrm{CHCl}_{3}-\mathrm{MeOH}-\mathrm{H}_{2} \mathrm{O}$ ) and by preparative reversedphase HPLC (Phenomenex Kinetex $\mathrm{XB}_{18}$ column, gradient elution with $\mathrm{H}_{2} \mathrm{O}: \mathrm{CH}_{3} \mathrm{CN} 10 \rightarrow 100 \%$ at a flow rate of 20 $\mathrm{mL} \min ^{-1}$ for $30 \mathrm{~min}$, retention time: $18.944 \mathrm{~min}$ ) to give 6 (40 mg, 37\%, three steps) $R_{\mathrm{f}}=0.19$ (26:14:3, $\mathrm{CHCl}_{3}-\mathrm{MeOH}-$ $\mathrm{H}_{2} \mathrm{O}$ ); $[\alpha]_{\mathrm{D}}^{20}-37.7$ (c 0.1, $\left.\mathrm{CHCl}_{3}-\mathrm{MeOH} 1: 1\right) .{ }^{1} \mathrm{H}$ NMR $(400 \mathrm{MHz}$, $\mathrm{CD}_{3} \mathrm{OD} / \mathrm{CDCl}_{3} 1:$ 1) $\delta 4.97\left(\mathrm{~s}, 1 \mathrm{H}, \mathrm{H}-1^{\prime \prime}\right), 4.93\left(\mathrm{~s}, 1 \mathrm{H}, \mathrm{H}-1^{\prime \prime \prime \prime}\right), 4.86$ (s, 1H, H-1'"), 4.82 (s, 1H, H-1'), 4.73 (br s, 1H, H-29), 4.60 (m, 1H, H-29), 3.98 (dd, J = 9.7, $2.8 \mathrm{~Hz}, 1 \mathrm{H}, \mathrm{H}-3^{\prime}$ ), 3.93 (br s, 1H, H$2^{\prime \prime \prime \prime}$ ), 3.90 (br s, $1 \mathrm{H}, \mathrm{H}-2^{\prime \prime \prime}$ ), 3.88 (br s, $1 \mathrm{H}, \mathrm{H}-2^{\prime}$ ), 3.82 (br s, $1 \mathrm{H}, \mathrm{H}-$ $2^{\prime \prime}$ ), 3.80-3.55 (m, 8H, H-5', H-5" $\mathrm{H}-3^{\prime \prime \prime \prime}, \mathrm{H}-5^{\prime \prime \prime \prime}, \mathrm{H}-5^{\prime \prime \prime}, \mathrm{H}-3^{\prime \prime}, \mathrm{H}-$ $3^{\prime \prime \prime}, \mathrm{H}-4^{\prime}$ ), 3.47-3.37 (m, 3H, H-4"', H-4", $\mathrm{H}-4^{\prime \prime \prime \prime}$ ), 3.10-2.98 (m, 2H, H-3, H-19), 2.32-2.19 (m, 2H, H-13, H-16a), 2.02-1.88 (m, 2H, H-21a, H-22a), 1.69 (s, 3H, H-30), 1.33-1.23 (m, 12H, H-6"', H-6", H-6"' ${ }^{\prime \prime \prime}, \mathrm{H}-6^{\prime}$ ), 0.99 (s, 3H, H-27), 0.95 (s, 3H, H-26), 0.92 (s, $3 \mathrm{H}, \mathrm{H}-23), 0.85$ (s, 3H, H-25), 0.77 (s, 3H, H-24), 0.72 (br d, $J=$ $9.7 \mathrm{~Hz}, 1 \mathrm{H}, \mathrm{H}-5) .{ }^{13} \mathrm{C} \mathrm{NMR}\left(101 \mathrm{MHz}, \mathrm{CD}_{3} \mathrm{OD} / \mathrm{CDCl}_{3} 1: 1\right)$ $\delta 179.7$ (C-28), 151.1 (C-20), 109.7 (C-29), $103.2\left(\mathrm{C}-1^{\prime \prime \prime}\right), 102.7$ (C$\left.1^{\prime \prime}\right), 102.6\left(\mathrm{C}-1^{\prime \prime \prime \prime}\right), 101.7\left(\mathrm{C}-1^{\prime}\right), 89.8(\mathrm{C}-3), 80.1\left(\mathrm{C}-4^{\prime}\right), 79.8\left(\mathrm{C}-3^{\prime}\right)$, $78.8\left(\mathrm{C}-2^{\prime}\right), 73.0\left({\mathrm{C}-4^{\prime \prime \prime \prime}}^{\prime \prime}\right), 72.9\left(\mathrm{C}-4^{\prime \prime \prime}\right), 72.6\left(\mathrm{C}-4^{\prime \prime}\right), 71.6\left(\mathrm{C}-3^{\prime \prime}\right), 71.5$ $\left(\mathrm{C}-3^{\prime \prime \prime}\right), 71.4\left(\mathrm{C}-3^{\prime \prime \prime \prime}\right), 71.3\left(\mathrm{C}-2^{\prime \prime}\right), 71.0\left(2 \times, \mathrm{C}-2^{\prime \prime \prime \prime}, \mathrm{C}-2^{\prime \prime \prime}\right), 69.7(\mathrm{C}-$ $\left.5^{\prime \prime}\right), 69.6\left(\mathrm{C}-5^{\prime \prime \prime}\right), 69.3\left(\mathrm{C}-5^{\prime \prime \prime \prime}\right), 68.1\left(\mathrm{C}-5^{\prime}\right), 56.6(\mathrm{C}-17), 55.8$ (C-5), 50.9 (C-9), 49.6 (C-18), 47.4 (C-19), 42.8 (C-14), 41.1 (C-8), 39.5 (C4), 39.0 (C-1), 38.7 (C-13), 37.5 (C-22), 37.3 (C-10), 34.7 (C-7), 32.7 (C-16), 31.0 (C-21), 30.0 (C-15), 28.4 (C-23), 26.0 (C-2), 25.9 (C12), 21.3 (C-11), 19.5 (C-30), 18.6 (C-6), 18.2 (C-6'), 17.6 (C$\left.6^{\prime \prime \prime \prime}\right), 17.6\left(\mathrm{C}-6^{\prime \prime \prime}\right), 17.3\left(\mathrm{C}-6^{\prime \prime}\right), 16.5(\mathrm{C}-24), 16.4(\mathrm{C}-25), 16.2(\mathrm{C}-26)$, 14.9 (C-27). HRMS calcd for $\mathrm{C}_{54} \mathrm{H}_{92} \mathrm{O}_{19} \mathrm{~N}\left[\mathrm{M}+\mathrm{NH}_{4}\right]^{+}$1058.62581, found 1058.62553.

3-O-(2,3,4-Tri-O-benzoyl- $\alpha$-L-rhamnopyranosyl)-28-benzyl ursolate (21). Based on the general procedure for normal Schmidt glycosylation, a solution of benzyl ursolate 20 (ref. 37) $(270 \mathrm{mg}, 507 \mu \mathrm{mol})$ and $12(377 \mathrm{mg}, 608 \mu \mathrm{mol})$ in DCM $(8 \mathrm{~mL})$ 
were added TMSOTf $(9.2 \mu \mathrm{L}, 51 \mu \mathrm{mol})$ and stirred for $30 \mathrm{~min}$. After filtration and concentration to dryness, the residue was purified by flash chromatography $(8: 2$, hexanes-EtOAc) to yield 21 as a white powder $(342 \mathrm{mg}, 68 \%): R_{\mathrm{f}}=0.52(8: 2$, hexanesEtOAc); $[\alpha]_{\mathrm{D}}^{20}+82.6$ (c 1, $\left.\mathrm{CHCl}_{3}\right) .{ }^{1} \mathrm{H} \mathrm{NMR}\left(400 \mathrm{MHz}, \mathrm{CDCl}_{3}\right.$ ) $\delta 8.11(\mathrm{~d}, J=7.2 \mathrm{~Hz}, 2 \mathrm{H}, \mathrm{CH}-\mathrm{Bz}), 7.99(\mathrm{~d}, J=7.2 \mathrm{~Hz}, 2 \mathrm{H}, \mathrm{CH}-\mathrm{Bz})$, $7.84(\mathrm{~d}, J=7.2 \mathrm{~Hz}, 2 \mathrm{H}, \mathrm{CH}-\mathrm{Bz}), 7.60$ (t, $J=7.4 \mathrm{~Hz}, 2 \mathrm{H}, \mathrm{CH}-\mathrm{Bz})$, 7.55-7.22 (m, 13H, CH-Bz, CH-Bn), $5.84(\mathrm{dd}, J=10.2,3.3 \mathrm{~Hz}, 1 \mathrm{H}$, $\left.\mathrm{H}-3^{\prime}\right), 5.69\left(\mathrm{t}, J=10.0 \mathrm{~Hz}, 1 \mathrm{H}, \mathrm{H}-4^{\prime}\right), 5.65$ (dd, $J=3.2,1.7 \mathrm{~Hz}, 1 \mathrm{H}$, $\left.\mathrm{H}-2^{\prime}\right), 5.25$ (t, $\left.J=3.1 \mathrm{~Hz}, 1 \mathrm{H}, \mathrm{H}-12\right), 5.12\left(\mathrm{~d}, J=12.5 \mathrm{~Hz}, 1 \mathrm{H}, \mathrm{CH}_{2^{-}}\right.$ $\mathrm{Bn}), 5.09$ (br s, $1 \mathrm{H}, \mathrm{H}^{-1}{ }^{\prime}$ ), 4.99 (d, $\left.J=12.5 \mathrm{~Hz}, 1 \mathrm{H}, \mathrm{CH}_{2}-\mathrm{Bn}\right), 4.32$ (dq, $\left.J=9.7,6.1 \mathrm{~Hz}, 1 \mathrm{H}, \mathrm{H}-5^{\prime}\right), 3.24(\mathrm{~m}, 1 \mathrm{H}, \mathrm{H}-3), 2.27$ (d, $J=$ $11.3 \mathrm{~Hz}, 1 \mathrm{H}, \mathrm{H}-18) 1.34$ (d, $J=6.3 \mathrm{~Hz}, 3 \mathrm{H}, \mathrm{H}-6^{\prime}$ ), 1.08 (s, 3H, H27), 1.07 (s, 3H, H-23), 0.97 (s, 3H, H-25), 0.96 (s, 3H, H-24), 0.93 (d, $J=6.1 \mathrm{~Hz}, 3 \mathrm{H}, \mathrm{H}-30), 0.86$ (d, $J=6.4 \mathrm{~Hz}, 3 \mathrm{H}, \mathrm{H}-29), 0.76$ (d, $J$ $=11.2 \mathrm{~Hz}, 1 \mathrm{H}, \mathrm{H}-5), 0.66$ (s, 3H, H-26). ${ }^{13} \mathrm{C}$ NMR $(101 \mathrm{MHz}$, $\mathrm{CDCl}_{3}$ ) $\delta 177.3$ (C-28), [165.8, 165.7, 165.6 (CO-Bz)], 138.1 (C-13), 136.4 (C-Bn), [133.4, 133.3, 133.1, 129.9, 129.7 3 , 129.6 $\left.{ }_{6}(\mathrm{CH}-\mathrm{Bz})\right]$, [129.5, 129.3, $\left.129.2_{5}(\mathrm{C}-\mathrm{Bz})\right],[128.6,128.4(2 \times), 128.3,128.1$, 127.9 (CH-Bz, $C \mathrm{H}-\mathrm{Bn})$ ], 125.6 (C-12), 99.7 (C-1'), 90.0 (C-3), 72.0 $\left(\mathrm{C}-4^{\prime}\right), 71.2\left(\mathrm{C}-2^{\prime}\right), 70.2\left(\mathrm{C}-3^{\prime}\right), 66.7\left(\mathrm{C}^{\prime} 5^{\prime}\right), 66.0\left(\mathrm{CH}_{2}-\mathrm{Bn}\right), 55.4(\mathrm{C}-$ 5), 52.9 (C-18), 48.1 (C-17), 47.5 (C-9), 42.0 (C-14), 39.5 (C-8), 39.1 (C-19), 39.0 (C-4), 38.8 (C-20), 38.6 (C-1), 36.7 (C-10), 36.6 (C-16), 33.0 (C-7), 30.6 (C-21), 28.4 (C-23), 27.9 (C-15), 25.5 (C-2), 24.2 (C22), 23.5 (C-27), 23.3 (C-11), 21.2 (C-30), 18.3 (C-6), 17.6 (C-6'), 17.0 1 (C-26), 17.9 (C-29), 16.6 (C-24), 15.5 (C-25). HRMS calcd for $\mathrm{C}_{64} \mathrm{H}_{76} \mathrm{O}_{10} \mathrm{Na}[\mathrm{M}+\mathrm{Na}]^{+} 1027.53307$, found 1027.53329.

3-O- $\alpha$-L-Rhamnopyranosyl-28-benzyl ursolate (22). Based on the general procedure for benzoyl groups removal, compound 21 (300 mg, $303 \mu \mathrm{mol}$ ) was dissolved in MeOH-DCM (2: 1, 5 $\mathrm{mL})$ with $\mathrm{NaOMe}$ in $\mathrm{MeOH}(0.5 \mathrm{M}, 5 \mathrm{~mL})$ overnight. The reaction was then neutralized to $\mathrm{pH} 7$ with Dowex G26 ( $\mathrm{H}^{+}$form), filtered and purified by flash chromatography (9:1, DCM$\mathrm{MeOH})$ to give compound 22 (202 $\mathrm{mg}, 98 \%$ ) as amorphous solid, $R_{\mathrm{f}}=0.21\left(7: 1, \mathrm{CHCl}_{3}: \mathrm{MeOH}\right),[\alpha]_{\mathrm{D}}^{20}+1.3\left(c 7, \mathrm{CHCl}_{3}\right) \cdot{ }^{1} \mathrm{H}$ NMR (400 MHz, $\left.\mathrm{CDCl}_{3}\right) \delta 7.36-7.31(\mathrm{~m}, 5 \mathrm{H}, \mathrm{CH}-\mathrm{Bn}), 5.23(\mathrm{t}, J=$ $3.1 \mathrm{~Hz}, 1 \mathrm{H}, \mathrm{H}-12$ ), 5.11 (d, $\left.J=12.5 \mathrm{~Hz}, 1 \mathrm{H}, \mathrm{CH}_{2}-\mathrm{Bn}\right), 4.97$ (d, $J=$ $12.5 \mathrm{~Hz}, 1 \mathrm{H}, \mathrm{CH}_{2}-\mathrm{Bn}$ ), 4.80 (br s, $1 \mathrm{H}, \mathrm{H}-1^{\prime}$ ), 3.93 (br s, $1 \mathrm{H}, \mathrm{H}-2^{\prime}$ ), 3.79-3.74 (m, 2H, H-3', H-5'), 3.47 (m, 1H, H-4'), 3.07 (dd, $J=$ 10.5, 4.4 Hz, 1H, H-3), 2.26 (d, $J=11.1 \mathrm{~Hz}, 1 \mathrm{H}, \mathrm{H}-18), 1.27$ (d, $J=$ $6.0 \mathrm{~Hz}, 1 \mathrm{H}, \mathrm{H}-6^{\prime}$ ), 1.06 (s, 3H, H-27), 0.93 (s, 3H, H-30), 0.90 (s, $3 \mathrm{H}, \mathrm{H}-23$ ), 0.89 (s, 3H, H-25) 0.85 (d, $J=6.2 \mathrm{~Hz}, 3 \mathrm{H}, \mathrm{H}-29), 0.75$ (s, 3H, H-24), 0.69 (d, $J=11.1 \mathrm{~Hz}, 1 \mathrm{H}, \mathrm{H}-5), 0.63$ (s, 3H, H-26). ${ }^{13} \mathrm{C}$ NMR (101 MHz, $\mathrm{CDCl}_{3}$ ) $\delta 177.3$ (C-28), 138.1 (C-13), 136.4 (C-Bn), [128.4 $(2 \times), 128.1(2 \times), 127.9(\mathrm{CH}-\mathrm{Bn})], 125.7(\mathrm{C}-12)$, $102.2\left(\mathrm{C}-1^{\prime}\right), 89.6$ (C-3), $73.8\left(\mathrm{C}-4^{\prime}\right), 72.0\left(\mathrm{C}-3^{\prime}\right), 71.3\left(\mathrm{C}-2^{\prime}\right), 67.7$ $\left(\mathrm{C}-5^{\prime}\right), 66.0\left(\mathrm{CH}_{2}-\mathrm{Bn}\right), 55.4$ (C-5), 52.9 (C-18), 48.1 (C-17), 47.5 (C9), 42.0 (C-14), 39.5 (C-8), 39.1 (C-19), 39.0 (C-4), 38.8 (C-20), 38.6 (C-1), 36.6 (C-22), 36.6 (C-10), 33.0 (C-7), 30.6 (C-21), 28.3 (C-23), 27.9 (C-15), 25.3 (C-2), 24.2 (C-16), 23.6 (C-27), 23.3 (C-11), 21.2 (C-30), 18.2 (C-6), 17.4 (C-6'), 17.0 4 (C-29), 16.9 8 (C-26), 16.5 (C24), 15.5 (C-25). HRMS calcd for $\mathrm{C}_{43} \mathrm{H}_{64} \mathrm{O}_{7} \mathrm{Na}[\mathrm{M}+\mathrm{Na}]^{+}$ 715.45443 , found 715.45649 .

3-O- $\alpha$-L-Rhamnopyranosyl ursolic acid (7). In parallel, UA 3$O$ - $\alpha$-L-rhamnopyranoside 7 was synthesized in two steps starting from 21. Therefore, a solution of compound 21 (54 mg, $54 \mu \mathrm{mol})$ and $10 \% \mathrm{Pd} / \mathrm{C}(1 \mathrm{mg})$ in dry EtOAc $(3 \mathrm{~mL})$ was refluxed and purged with $\mathrm{H}_{2}$ for $2 \mathrm{~h}$. When TLC indicated the disappearance of the starting material, the residue was filtered over Celite ${ }^{\circledR}$ and concentrated before engaged on the benzoyl groups removal as described on general procedure 5.1.3 with NaOMe in $\mathrm{MeOH}(0.5 \mathrm{M}, 2 \mathrm{~mL})$ in a mixture of $\mathrm{MeOH}-\mathrm{DCM}(2: 1,2 \mathrm{~mL})$ overnight. The reaction was then neutralized to $\mathrm{pH} 7$ with Dowex $\mathrm{G} 26\left(\mathrm{H}^{+}\right.$form), filtered and purified by flash chromatography (7 : 1, DCM-MeOH) to give compound 7 (24 mg, 74\%, two steps) as colorless oil, $R_{\mathrm{f}}=0.3$ (DCM: $\mathrm{MeOH}, 7: 1$ ), $[\alpha]_{\mathrm{D}}^{20}+5.7\left(c\right.$ 0.74, $\left.\mathrm{CHCl}_{3}-\mathrm{MeOH} 1: 1\right) .{ }^{1} \mathrm{H}$ NMR $(400 \mathrm{MHz}$, $\mathrm{CD}_{3} \mathrm{OD} / \mathrm{CDCl}_{3} 1:$ 1) $\delta 5.24$ (br s, $1 \mathrm{H}, \mathrm{H}-12$ ), 4.77 (br s, $1 \mathrm{H}, \mathrm{H}-1^{\prime}$ ), $3.89\left(\mathrm{dd}, J=3.4,1.7 \mathrm{~Hz}, 1 \mathrm{H}, \mathrm{H}-2^{\prime}\right), 3.76(\mathrm{dq}, J=9.5,6.2 \mathrm{~Hz}, 1 \mathrm{H}$, $\left.\mathrm{H}-5^{\prime}\right), 3.70\left(\mathrm{dd}, J=9.5,3.3 \mathrm{~Hz}, 1 \mathrm{H}, \mathrm{H}-3^{\prime}\right), 3.39(\mathrm{t}, J=9.5 \mathrm{~Hz}, 1 \mathrm{H}$, $\mathrm{H}-4^{\prime}$ ), 3.10 (dd, $\left.J=11.2,4.7 \mathrm{~Hz}, 1 \mathrm{H}, \mathrm{H}-3\right), 2.20$ (d, $J=11.3 \mathrm{~Hz}$, 1H, H-18), 1.27 (d, J = 6.1 Hz, 3H, H-6'), 1.10 (s, 3H, H-27), 0.96 (m, 3H, H-30), 0.95 (s, 3H, H-23), 0.95 (s, 3H, H-25), 0.88 (d, $J=$ $6.4 \mathrm{~Hz}, 3 \mathrm{H}, \mathrm{H}-29), 0.83$ (s, 3H, H-26), 0.78 (s, 3H, H-24). ${ }^{13} \mathrm{C}$ NMR (101 MHz, $\left.\mathrm{CD}_{3} \mathrm{OD} / \mathrm{CDCl}_{3} 1: 1\right) \delta 181.1$ (C-28), 138.7 (C-13), 125.9 (C-12), $103.2\left(\mathrm{C}-1^{\prime}\right), 89.7$ (C-3), $73.4\left({\left.\mathrm{C}-4^{\prime}\right),}^{\prime}\right) 1.9\left(\mathrm{C}-3^{\prime}\right), 71.5\left(\mathrm{C}-2^{\prime}\right)$, 68.7 (C-5'), 55.8 (C-5), 53.3 (C-18), 48.2 (C-17), 48.0 (C-9), 42.5 (C14), 39.9 (C-8), 39.6 (C-19), 39.4 (C-20), 39.3 (C-4), 39.0 (C-1), 37.3 (C-22), 37.1 (C-10), 33.5 (C-7), 31.1 (C-21), 30.0 (C-), 28.5 (C-23), 28.5 (C-15), 25.8 (C-2), 24.6 (C-16), 23.8 (C-27), 23.7 (C-11), 21.4 (C-30), 18.7 (C-6), 17.5 (C-6'), 17.3 (C-29), 17.2 (C-26), 16.7 (C-24), 15.7 (C-25). HRMS calcd for $\mathrm{C}_{36} \mathrm{H}_{58} \mathrm{O}_{7}[\mathrm{M}+\mathrm{H}]^{+}$603.4255, found 603.4273.

3-O-(2,3-Di-O-isopropylidene- $\alpha$-L-rhamnopyranosyl)-28benzyl ursolate (23). Compound $22(500 \mathrm{mg}, 736 \mu \mathrm{mol})$ was dissolved in acetone $(10 \mathrm{~mL})$ to which was added 2,2-dimethoxypropane $(272 \mu \mathrm{L}, 2209 \mu \mathrm{mol})$ and PTSA $(12.7 \mathrm{mg}, 74 \mu \mathrm{mol})$ as catalyst. After $2 \mathrm{~h}$, reaction was evaporated to dryness and purified by flash chromatography ( $7: 3$, hexanes-EtOAc) to give compound 23 (392 mg, 74\%) as colorless oil, $R_{\mathrm{f}}=0.7$ (hexanesEtOAc, $7: 3),[\alpha]_{\mathrm{D}}^{20}+6.7\left(c 10, \mathrm{CHCl}_{3}\right) \cdot{ }^{1} \mathrm{H} \mathrm{NMR}\left(400 \mathrm{MHz}, \mathrm{CDCl}_{3}\right)$ $\delta 7.38-7.28(\mathrm{~m}, 5 \mathrm{H}, \mathrm{CH}-\mathrm{Bn}), 5.23(\mathrm{t}, J=3.1 \mathrm{~Hz}, 1 \mathrm{H}, \mathrm{H}-12), 5.10$ $\left(\mathrm{d}, J=12.5 \mathrm{~Hz}, 1 \mathrm{H}, \mathrm{CH}_{2}-\mathrm{Bn}\right), 4.99\left(\mathrm{~s}, 1 \mathrm{H}, \mathrm{H}-1^{\prime}\right), 4.97(\mathrm{~d}, J=$ $\left.12.2 \mathrm{~Hz}, 1 \mathrm{H}, \mathrm{CH}_{2}-\mathrm{Bn}\right), 3.16-4.10$ (m, $\left.2 \mathrm{H}, \mathrm{H}-2^{\prime}, \mathrm{H}-3^{\prime}\right), 3.82$ (dq, $J=$ 12.6, $\left.6.2 \mathrm{~Hz}, 1 \mathrm{H}, \mathrm{H}-5^{\prime}\right), 3.42\left(\mathrm{t}, 1 \mathrm{H}, J=8.5 \mathrm{~Hz}, \mathrm{H}-4^{\prime}\right), 3.15$ (dd, $J=$ $10.8,4.3 \mathrm{~Hz}, 1 \mathrm{H}, \mathrm{H}-3$ ), 2.26 (d, $J=11.1 \mathrm{~Hz}, 1 \mathrm{H}, \mathrm{H}-18$ ), 1.99 (dd, $J$ $=12.8,4.1 \mathrm{~Hz}, 1 \mathrm{H}$ ), 1.53 (s, 3H, $\mathrm{CH}_{3}$-iso), 1.37 (s, 3H, $\mathrm{CH}_{3}$-iso), $1.26\left(\mathrm{~d}, J=6.6 \mathrm{~Hz}, 3 \mathrm{H}, \mathrm{H}-6^{\prime}\right), 1.07$ (s, 3H, H-27), 0.94 (s, 6H, H-23, H-30), 0.90 (s, 3H, H-25), 0.85 (d, $J=6.3 \mathrm{~Hz}, 3 \mathrm{H}, \mathrm{H}-29), 0.77$ (s, $3 \mathrm{H}, \mathrm{H}-24), 0.72$ (d, 1H, $J=11.3 \mathrm{~Hz} \mathrm{H}-5), 0.63$ (s, 3H, H-26). ${ }^{13} \mathrm{C}$ NMR (101 MHz, $\mathrm{CDCl}_{3}$ ) $\delta 177.3$ (C-28), 138.0 (C-13), 136.3 (CBn), [128.4 (2×), $128.1(2 \times), 127.9(\mathrm{CH}-\mathrm{Bn})], 125.7$ (C-12), 109.3 (C-iso), 99.7 (C-1'), $88.9(\mathrm{C}-3), 78.3\left(\mathrm{C}-3^{\prime}\right), 75.8\left(\mathrm{C}-2^{\prime}\right), 74.1\left(\mathrm{C}-4^{\prime}\right)$, $66.2\left(\mathrm{C}-5^{\prime}\right), 66.0\left(\mathrm{CH}_{2}-\mathrm{Bn}\right), 55.3$ (C-5), 52.8 (C-18), 48.1 (C-17), 47.5 (C-9), 42.0 (C-14), 39.5 (C-8), 39.1 (C-19), 39.0 (C-4), 38.8 (C-20), 38.6 (C-1), 36.6 (C-10), 36.6 (C-22), 32.9 (C-7), 30.6 (C-21), 28.4 (C-23), 27.9 ( $\mathrm{CH}_{3}$-iso), 27.9 (C-15), $26.2\left(\mathrm{CH}_{3}\right.$-iso), 25.4 (C-2), 24.2 (C-16), 23.5 (C-27), 23.2 (C-11), 21.2 (C-30), 18.2 (C-6), 17.5 (C-6'), 17.0 (C-29), 17.0 (C-26), 16.5 (C-24), 15.5 (C-25). HRMS calcd for $\mathrm{C}_{46} \mathrm{H}_{68} \mathrm{O}_{7} \mathrm{Na}[\mathrm{M}+\mathrm{Na}]^{+}$755.48573, found 755.48487.

3-O-(2,3,4-Tri-O-benzoyl- $\alpha$-L-rhamnopyranosyl-(1 $\rightarrow$ 4)-2,3-di$O$-isopropylidene- $\alpha$-L-rhamnopyranosyl)-28-benzyl ursolate (24). Based on the general procedure for normal Schmidt glycosylation, compound 23 (191 mg, $266 \mu \mathrm{mol})$ and 2,3,4-tri-O-benzoyl- 
$\alpha$-L-rhamnopyranosyl trichloroacetimidate 12 (198 mg, 319 $\mu \mathrm{moL})$ was coupled in DCM $(8 \mathrm{~mL})$ with TMSOTf $(4.8 \mu \mathrm{L}, 26$ $\mu \mathrm{mol})$ as Lewis acid for $25 \mathrm{~min}$. When TLC indicated completion, reaction was then quenched with $\mathrm{Et}_{3} \mathrm{~N}(12 \mu \mathrm{L})$ filtered and evaporated before purification by flash chromatography $(8: 2$, hexanes-EtOAc) to give compound $24(219 \mathrm{mg}, 70 \%)$ as colorless oil, $R_{\mathrm{f}}=0.6$ (hexanes-EtOAc, $8: 2$ ), $[\alpha]_{\mathrm{D}}^{20}+36.1\left(c 2, \mathrm{CHCl}_{3}\right.$ ). ${ }^{1} \mathrm{H}$ NMR $\left(400 \mathrm{MHz}, \mathrm{CDCl}_{3}\right) \delta 8.12(\mathrm{~d}, J=7.2 \mathrm{~Hz}, 2 \mathrm{H}, \mathrm{CH}-\mathrm{Bz}), 7.96$ $(\mathrm{d}, J=7.3 \mathrm{~Hz}, 2 \mathrm{H}, \mathrm{CH}-\mathrm{Bz}), 7.81(\mathrm{~d}, J=7.3 \mathrm{~Hz}, 2 \mathrm{H}, \mathrm{CH}-\mathrm{Bz}), 7.61(\mathrm{t}$, $J=7.5 \mathrm{~Hz}, 1 \mathrm{H}, \mathrm{CH}-\mathrm{Bz}), 7.54-7.46$ (m, 3H, CH-Bz), 7.44-7.30 (m, $7 \mathrm{H}, \mathrm{CH}-\mathrm{Bz}, \mathrm{CH}-\mathrm{Bn}$ ), 7.28-7.22 (m, 3H, CH-Bz), 5.77 (dd, $J=10.1$, $\left.3.3 \mathrm{~Hz}, 1 \mathrm{H}, \mathrm{H}-3^{\prime \prime}\right), 5.74\left(\mathrm{dd}, J=3.1,1.8 \mathrm{~Hz}, 1 \mathrm{H}, \mathrm{H}-2^{\prime \prime}\right), 5.67(\mathrm{t}, J=$ $\left.9.8 \mathrm{~Hz}, 1 \mathrm{H}, \mathrm{H}-4^{\prime \prime}\right), 5.59$ (d, J=1.7 Hz, 1H, H-1"), 5.26 (br s, $1 \mathrm{H}, \mathrm{H}-$ 12), 5.12 (d, $\left.J=12.5 \mathrm{~Hz}, 1 \mathrm{H}, \mathrm{CH}_{2}-\mathrm{Bn}\right), 5.04$ (br s, $\left.1 \mathrm{H}, \mathrm{H}-1^{\prime}\right), 4.99$ $\left(\mathrm{d}, J=12.5 \mathrm{~Hz}, 1 \mathrm{H}, \mathrm{CH}_{2}-\mathrm{Bn}\right), 4.31\left(\mathrm{dd}, J=7.2,5.5 \mathrm{~Hz}, 1 \mathrm{H}, \mathrm{H}-3^{\prime}\right)$, $4.20\left(\mathrm{dq}, J=9.6,6.4 \mathrm{~Hz}, 1 \mathrm{H}, \mathrm{H}-5^{\prime \prime}\right), 4.14\left(\mathrm{~d}, J=5.5 \mathrm{~Hz}, 1 \mathrm{H}, \mathrm{H}-2^{\prime}\right)$, $3.98\left(\mathrm{dq}, J=10.0,6.1 \mathrm{~Hz}, 1 \mathrm{H}, \mathrm{H}-5^{\prime}\right), 3.62(\mathrm{dd}, J=9.9,7.3 \mathrm{~Hz} 1 \mathrm{H}$, $\mathrm{H}-4^{\prime}$ ), 3.17 (dd, $\left.J=9.2,6.9 \mathrm{~Hz}, 1 \mathrm{H}, \mathrm{H}-3\right), 2.28$ (d, $J=11.3 \mathrm{~Hz}, 1 \mathrm{H}$, $\mathrm{H}-18$ ), 2.02 (td, $J=12.7,3.9 \mathrm{~Hz}, 1 \mathrm{H}, \mathrm{H}-16), 1.55$ (s, 3H, $\mathrm{CH}_{3}$-iso), 1.38 (m, 6H, H-6' $\mathrm{H}^{\prime \prime}$ ') $^{\prime \prime} 1.35$ (s, 3H, $\mathrm{CH}_{3}$-iso), 1.08 (s, 3H, H-27), 0.96 (s, 3H, H-23), 0.94 (m, 6H, H-30, H-25), 0.86 (d, $J=6.2 \mathrm{~Hz}$, H-29), 0.83 (s, 3H, H-24), 0.75 (br d, $J=11.5 \mathrm{~Hz}, 1 \mathrm{H}, \mathrm{H}-5), 0.66$ (s, $3 \mathrm{H}, \mathrm{H}-26) .{ }^{13} \mathrm{C}$ NMR (101 MHz, $\left.\mathrm{CDCl}_{3}\right) \delta 177.3$ (C-28), [165.7, 165.6, 165.4 (CO-Bz)], 138.1 (C-13), 136.4 (C-Bn), [133.4, 133.3, 133.1, $\left.130.0(2 \times), 129.7_{1}(2 \times), 129.6_{8}(2 \times)(\mathrm{CH}-\mathrm{Bz})\right],[129.5$, 129.3, $129.2(\mathrm{C}-\mathrm{Bz})$ ], [128.5 $(2 \times), 128.4(4 \times), 128.2_{5}(2 \times), 128.1_{6}$ $(2 \times), 127.9$ ( $C \mathrm{H}-\mathrm{Bz}, C \mathrm{H}-\mathrm{Bn})], 125.7$ (C-12), 109.5 ( $C$-iso), 99.5 (C$\left.1^{\prime}\right), 96.0\left(\mathrm{C}-1^{\prime \prime}\right), 89.0(\mathrm{C}-3), 78.2\left(\mathrm{C}-3^{\prime}\right), 77.9\left(\mathrm{C}-4^{\prime}\right), 76.3\left(\mathrm{C}-2^{\prime}\right), 71.7$ $\left(\mathrm{C}-4^{\prime \prime}\right), 70.8\left(\mathrm{C}-2^{\prime \prime}\right), 70.0\left(\mathrm{C}-3^{\prime \prime}\right), 67.3\left(\mathrm{C}-5^{\prime \prime}\right), 66.0(\mathrm{C}-7), 63.7\left(\mathrm{C}-5^{\prime}\right)$, 55.4 (C-5), 52.9 (C-18), 48.1 (C-17), 47.6 (C-9), 42.0 (C-14), 39.5 (C8), 39.09 (C-19), 39.0 8 (C-4), 38.8 (C-20), 38.7 (C-1), 36.7 (2×, C22, C-10), 33.0 (C-7), 30.7 (C-21), 28.4 (C-23), $28.0\left(\mathrm{CH}_{3}\right.$-iso), 27.9 (C-15), 26.5 ( $\mathrm{CH}_{3}$-iso), 25.5 (C-2), 24.2 (C-16), 23.6 (C-27), 23.3 (C-11), 21.2 (C-30), 18.3 (C-6), 18.1 (C-6'), 17.7 (C-6"), 17.0 (C-29), 17.0 (C-26), 16.6 (C-24), 15.5 (C-25). HRMS calcd for $\mathrm{C}_{73} \mathrm{H}_{90} \mathrm{O}_{18} \mathrm{~N}\left[\mathrm{M}+\mathrm{NH}_{4}\right]^{+}$1208.6668, found 1208.6647.

3-O-(2,3,4-Tri-O-benzoyl- $\alpha$-L-rhamnopyranosyl-(1 $\rightarrow 4)-\alpha$-Lrhamnopyranosyl)-28-benzyl ursolate (25). To a solution of compound 24 (161 mg, $137 \mu \mathrm{mol})$ in DCM $(5 \mathrm{~mL})$ was added HOAc $80 \%$ aq. $(15 \mathrm{~mL})$. After $3 \mathrm{~h}$ stirring at $80{ }^{\circ} \mathrm{C}$, the reaction was evaporated to dryness and the crude was purified by flash chromatography ( $8: 2$, hexanes-EtOAc) to give compound 25 $(129.1 \mathrm{mg}, 83 \%)$ as a colorless oil, $R_{\mathrm{f}}=0.5$ (hexanes-EtOAc, $8: 2),[\alpha]_{\mathrm{D}}^{20}+37.7\left(c 4.1, \mathrm{CHCl}_{3}\right) .{ }^{1} \mathrm{H}$ NMR (400 $\mathrm{MHz}, \mathrm{CDCl}_{3}$ ) $\delta 8.07$ (d, $J=7.3 \mathrm{~Hz}, 2 \mathrm{H}, \mathrm{CH}-\mathrm{Bz}), 7.97$ (d, $J=7.3 \mathrm{~Hz}, 2 \mathrm{H}, \mathrm{CH}-\mathrm{Bz})$, 7.82 (d, $J=7.3 \mathrm{~Hz}, 2 \mathrm{H}, \mathrm{CH}-\mathrm{Bz}), 7.58$ (t, $J=7.4 \mathrm{~Hz}, 1 \mathrm{H}, \mathrm{CH}-\mathrm{Bz})$, $7.51(\mathrm{t}, J=7.4 \mathrm{~Hz}, 1 \mathrm{H}, \mathrm{CH}-\mathrm{Bz}), 7.48-7.30$ (m, $10 \mathrm{H}, \mathrm{CH}-\mathrm{Bz}), 7.28-$ $7.22(\mathrm{~m}, 2 \mathrm{H}, \mathrm{CH}-\mathrm{Bz}), 5.82\left(\mathrm{dd}, J=10.1,3.2 \mathrm{~Hz}, 1 \mathrm{H}, \mathrm{H}-3^{\prime \prime}\right) 5.79(\mathrm{~m}$, $\left.1 \mathrm{H}, \mathrm{H}-2^{\prime \prime}\right), 5.68\left(\mathrm{t}, J=9.9 \mathrm{~Hz}, 1 \mathrm{H}, \mathrm{H}-4^{\prime \prime}\right), 5.49\left(\mathrm{br} \mathrm{s}, 1 \mathrm{H}, \mathrm{H}-1^{\prime \prime}\right), 5.25$ (br s, 1H, H-12), 5.11 (d, $J=12.5 \mathrm{~Hz}, 1 \mathrm{H}, \mathrm{CH}_{2}-\mathrm{Bn}$ ), 4.99 (d, $J=$ $12.5 \mathrm{~Hz}, 1 \mathrm{H}, \mathrm{CH}_{2}-\mathrm{Bn}$ ), 4.86 (br s, $1 \mathrm{H}, \mathrm{H}-1^{\prime}$ ), 4.30 (dq, $J=9.6$, $6.2 \mathrm{~Hz}, 1 \mathrm{H}, \mathrm{H}-5^{\prime \prime}$ ), 4.07 (dd, $J=9.0,2.8 \mathrm{~Hz}, 1 \mathrm{H}, \mathrm{H}-3^{\prime}$ ), 4.01-3.92

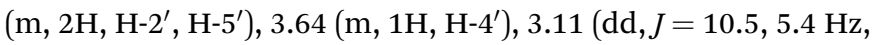

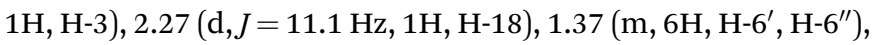
1.08 (s, 3H, H-27), 0.94 (m, 3H, H-30), 0.93 (s, 3H, H-25), 0.91 (s, $3 \mathrm{H}, \mathrm{H}-23$ ), 0.86 (d, $J=6.4 \mathrm{~Hz}, 3 \mathrm{H}, \mathrm{H}-29), 0.81$ (s, 3H, H-24), 0.71 (br d, $J=11.4 \mathrm{~Hz}, 1 \mathrm{H}, \mathrm{H}-5), 0.65$ (s, 3H, H-26). ${ }^{13} \mathrm{C}$ NMR (101
$\left.\mathrm{MHz}, \mathrm{CDCl}_{3}\right) \delta 177.4$ (C-28), [165.9, 165.8, 165.7 (CO-Bz)], 138.1 (C-13), 136.3 (C-Bn), [133.5, 133.3, 133.2, $129.9(2 \times), 129.7(4 \times)$ (CH-Bz)], [129.3, 129.2, $129.1(C-\mathrm{Bz})],[128.5(2 \times), 128.4(4 \times)$, $128.3(2 \times), 128.1(2 \times), 127.9$ (CH-Bz, $C H-B n)], 125.7$ (C-12), $102.0\left(\mathrm{C}-1^{\prime}\right), 99.0\left(\mathrm{C}-1^{\prime \prime}\right), 89.5$ (C-3), $81.6\left(\mathrm{C}-4^{\prime}\right), 71.9\left(\mathrm{C}-2^{\prime}\right), 71.9$ $\left(\mathrm{C}-3^{\prime}\right), 71.6\left(\mathrm{C}-4^{\prime \prime}\right), 71.2\left(\mathrm{C}-2^{\prime \prime}\right), 70.1\left(\mathrm{C}-3^{\prime \prime}\right), 67.5\left(\mathrm{C}-5^{\prime \prime}\right), 66.3\left(\mathrm{C}-5^{\prime}\right)$, $66.0\left(\mathrm{CH}_{2}-\mathrm{Bn}\right), 55.3$ (C-5), 52.9 (C-18), 48.1 (C-17), 47.5 (C-9), 42.0 (C-14), 39.5 (C-8), 39.1 (C-19), 38.9 (C-4), 38.8 (C-20), 38.6 (C-1), 36.6 (C-22), 36.6 (C-10), 33.0 (C-7), 30.6 (C-21), 28.3 (C-23), 27.9 (C-15), 25.4 (C-2), 24.2 (C-16), 23.6 (C-27), 23.3 (C-11), 21.2 (C30), 18.2 (C-6), 17.9 (C-6'), 17.6 (C-6"), 17.0 (C-29), 17.0 (C-26), 16.6 (C-24), 15.4 (C-25). HRMS calcd for $\mathrm{C}_{70} \mathrm{H}_{90} \mathrm{O}_{14} \mathrm{~N}[\mathrm{M}+$ $\left.\mathrm{NH}_{4}\right]^{+}$1168.6355, found 1168.6351 .

3-O-(2,3,4-Tri-O-benzoyl- $\alpha$-L-rhamnopyranosyl- $(1 \rightarrow 4)-\alpha-L^{-}$ rhamnopyranosyl)ursolic acid (26). A solution of compound 25 (40 mg, $35 \mu \mathrm{mol})$ and 10\% Pd/C $(2 \mathrm{mg})$ in dry EtOAc $(3 \mathrm{~mL})$ was refluxed and purged with $\mathrm{H}_{2}$. When TLC indicated the disappearance of the starting material, the mixture was filtered over Celite ${ }^{\circledR}$ and concentrated under reduced pressure. The residue was purified by flash chromatography $(7: 3$, hexanesEtOAc) to give compound $26(33 \mathrm{mg}, 89 \%)$ as a colorless oil, $R_{\mathrm{f}}=$ 0.6 (hexanes-EtOAc, $7: 3),[\alpha]_{\mathrm{D}}^{20}+31.3\left(c 3, \mathrm{CHCl}_{3}\right) .{ }^{1} \mathrm{H}$ NMR $(400$ $\left.\mathrm{MHz} \mathrm{CDCl}_{3}\right) \delta 8.05(\mathrm{~d}, J=7.7 \mathrm{~Hz}, 2 \mathrm{H}, \mathrm{CH}-\mathrm{Bz}), 7.97(\mathrm{~d}, J=7.8 \mathrm{~Hz}$, $2 \mathrm{H}, \mathrm{CH}-\mathrm{Bz}), 7.82(\mathrm{~d}, J=7.8 \mathrm{~Hz}, 2 \mathrm{H}, \mathrm{CH}-\mathrm{Bz}), 7.58(\mathrm{t}, J=7.4 \mathrm{~Hz}$, $1 \mathrm{H}, \mathrm{CH}-\mathrm{Bz}), 7.52$ (t, $J=7.4 \mathrm{~Hz}, 1 \mathrm{H}, \mathrm{CH}-\mathrm{Bz}), 7.45(\mathrm{t}, J=7.6 \mathrm{~Hz}$, 2H, CH-Bz), 7.43-7.36 (m, 3H, CH-Bz), 7.28-7.23 (m, 2H, CH-Bz), $5.81\left(\mathrm{dd}, J=10.2,3.4 \mathrm{~Hz}, 1 \mathrm{H}, \mathrm{H}-3^{\prime \prime}\right), 5.75\left(\mathrm{br} \mathrm{s}, 1 \mathrm{H}, \mathrm{H}-2^{\prime \prime}\right), 5.68(\mathrm{t}$, $\left.J=9.9 \mathrm{~Hz}, 1 \mathrm{H}, \mathrm{H}-4^{\prime \prime}\right), 5.50$ (s, 1H, H-1") 5.26 (br s, 1H, H-12), $4.86\left(\mathrm{~s}, 1 \mathrm{H}, \mathrm{H}-1^{\prime}\right), 4.29\left(\mathrm{dq}, J=9.6,6.5 \mathrm{~Hz}, 1 \mathrm{H}, \mathrm{H}-5^{\prime \prime}\right), 4.10$ (dd, $J=9.1,3.3 \mathrm{~Hz}, 1 \mathrm{H}, \mathrm{H}-3^{\prime}$ ), 4.01-3.93 (m, 2H, H-2', $\left.\mathrm{H}-5^{\prime}\right), 3.64$ (t, $J=9.2 \mathrm{~Hz}, 1 \mathrm{H}, \mathrm{H}-4^{\prime}$ ), 3.13 (dd, $\left.J=9.5,6.0 \mathrm{~Hz}, 1 \mathrm{H}, \mathrm{H}-3\right), 2.19$ (br d, $J=11.1 \mathrm{~Hz}, 1 \mathrm{H}, \mathrm{H}-18$ ), 1.38 (d, $J=6.0 \mathrm{~Hz}, 3 \mathrm{H}, \mathrm{H}-6^{\prime}$ ), 1.36 (d, $\left.J=6.5 \mathrm{~Hz}, 3 \mathrm{H}, \mathrm{H}-6^{\prime \prime}\right) 1.08$ (s, 3H, H-27), 0.98 (s, 3H, H-25), 0.95 (s, 3H, H-23), 0.95 (m, 3H, H-30), 0.87 (d, $J=6.3 \mathrm{~Hz}, 3 \mathrm{H}$, H-29), 0.84 (s, 3H, H-24), 0.79 (s, 3H, H-26), 0.75 (m, 1H, H-5). ${ }^{13} \mathrm{C}$ NMR (101 MHz, $\left.\mathrm{CDCl}_{3}\right) \delta 182.9$ (C-28), [165.9 (2×), 165.8 (CO-Bz)], 137.9 (C-13), [133.5, 133.4, 133.2, $130.0(2 \times), 129.7$ $(4 \times)(C \mathrm{H}-\mathrm{Bz})],[129.3(2 \times), 129.1(C-\mathrm{Bz})],[128.6(2 \times), 128.4(2 \times)$, $128.3(2 \times)(\mathrm{CH}-\mathrm{Bz})], 125.9(\mathrm{C}-12), 101.9\left(\mathrm{C}-1^{\prime}\right), 98.8\left(\mathrm{C}-1^{\prime \prime}\right), 89.6$ (C-3), $81.2\left(\mathrm{C}-4^{\prime}\right), 72.0\left(\mathrm{C}-2^{\prime}\right), 71.9\left(\mathrm{C}-3^{\prime}\right), 71.6\left(\mathrm{C}-4^{\prime \prime}\right), 71.2\left(\mathrm{C}-2^{\prime \prime}\right)$, $70.0\left(\mathrm{C}-3^{\prime \prime}\right), 67.5\left(\mathrm{C}-5^{\prime \prime}\right), 66.2\left(\mathrm{C}-5^{\prime}\right), 55.4$ (C-5), 52.6 (C-18), 47.9 (C-17), 47.5 (C-9), 41.9 (C-14), 39.5 (C-8), 39.1 (C-19), 39.0 (C-4), 38.8 (C-20), 38.6 (C-1), 36.7 (2×, C-22, C-10), 32.9 (C-7), 30.6 (C21), 28.4 (C-23), 28.0 (C-15), 25.5 (C-2), 24.1 (C-16), 23.6 (C-27), 23.3 (C-11), 21.2 (C-30), 18.3 (C-6), $18.0\left(\mathrm{C}-6^{\prime}\right), 17.6$ (C-6"), 17.1 (C-26), 17.0 (C-29), 16.6 (C-24), 15.5 (C-25). HRMS calcd for $\mathrm{C}_{63} \mathrm{H}_{80} \mathrm{O}_{14} \mathrm{Na}[\mathrm{M}+\mathrm{Na}]^{+}$1083.54403, found 1083.54598 .

3-O- $\alpha$-L-Rhamnopyranosyl- $(1 \rightarrow 4)$ - $\alpha$-L-rhamnopyranosyl ursolic acid (8). Based on the general procedure for benzoyl groups removal, compound 26 (33 mg, $32 \mu \mathrm{mol})$ was dissolved in MeOH-DCM (2:1, $3 \mathrm{~mL})$ with $\mathrm{NaOMe}$ in $\mathrm{MeOH}$ (0.5 M, $3 \mathrm{~mL}$ ) overnight. The reaction was then neutralized to pH 7 with Dowex $\mathrm{G} 26$ ( $\mathrm{H}^{+}$form), filtered and purified by flash chromatography (9:1 DCM-MeOH $\rightarrow$ 26:14:3 DCM$\left.\mathrm{MeOH}-\mathrm{H}_{2} \mathrm{O}\right)$ to give compound $8(20 \mathrm{mg}, 86 \%)$ as a colorless oil, $R_{\mathrm{f}}=0.2$ (DCM: MeOH, $9: 1$ ), $[\alpha]_{\mathrm{D}}^{20}-40.0$ (c 0.5, $1: 1$, $\left.\mathrm{CHCl}_{3}-\mathrm{MeOH}\right) .{ }^{1} \mathrm{H} \mathrm{NMR}\left(400 \mathrm{MHz}, \mathrm{CDCl}_{3} / \mathrm{CD}_{3} \mathrm{OD} 1: 1\right) \delta 5.24$ 
(m, 1H, H-12), 5.20 (d, $\left.J=1.3 \mathrm{~Hz}, 1 \mathrm{H}, \mathrm{H}-1^{\prime \prime}\right), 4.75(\mathrm{~m}, 1 \mathrm{H}, \mathrm{H}-$ $\left.1^{\prime}\right), 3.98\left(\mathrm{dd}, J=3.2,1.8 \mathrm{~Hz}, 1 \mathrm{H}, \mathrm{H}-2^{\prime \prime}\right), 3.82(\mathrm{dd}, J=3.1$, $1.7 \mathrm{~Hz}, 1 \mathrm{H}, \mathrm{H}-2^{\prime}$ ), 3.79 (dd, $J=9.2,3.3 \mathrm{~Hz}, 1 \mathrm{H}, \mathrm{H}-3^{\prime}$ ), 3.76-3.70 $\left(\mathrm{m}, 2 \mathrm{H}, \mathrm{H}-5^{\prime}, \mathrm{H}-5^{\prime \prime}\right), 3.68\left(\mathrm{dd}, J=9.5,3.3 \mathrm{~Hz}, 1 \mathrm{H}, \mathrm{H}-3^{\prime \prime}\right), 3.52(\mathrm{t}$, $\left.J=9.3 \mathrm{~Hz}, 1 \mathrm{H}, \mathrm{H}-4^{\prime}\right), 3.41\left(\mathrm{t}, J=9.5 \mathrm{~Hz}, 1 \mathrm{H}, \mathrm{H}-4^{\prime \prime}\right), 3.11(\mathrm{dd}, J$ $=10.7,4.7 \mathrm{~Hz}, 1 \mathrm{H}, \mathrm{H}-3), 2.20(\mathrm{br} \mathrm{d}, J=11.4 \mathrm{~Hz}, 1 \mathrm{H}, \mathrm{H}-18)$, $2.02(\mathrm{td}, J=13.3,3.6 \mathrm{~Hz}, 1 \mathrm{H}, \mathrm{H}-16 \mathrm{a}), 1.28(\mathrm{~d}, J=6.1 \mathrm{~Hz}$, $6 \mathrm{H}, \mathrm{H}-6^{\prime}, \mathrm{H}-6^{\prime \prime}$ ), 1.11 (s, 3H, H-27), 0.96 (m, 9H, H-25, H-30, H23), 0.88 (d, $J=6.4 \mathrm{~Hz}, 3 \mathrm{H}, \mathrm{H}-29), 0.84$ (s, 3H, H-26), 0.80 (s, $3 \mathrm{H}, \mathrm{H}-24) .{ }^{13} \mathrm{C}$ NMR (101 MHz, $\left.\mathrm{CDCl}_{3} / \mathrm{CD}_{3} \mathrm{OD} 1: 1\right) \delta 180.3$ (C-28), 138.9 (C-13), 126.1 (C-12), $103.3\left(\mathrm{C}-1^{\prime}\right), 102.3\left(\mathrm{C}-1^{\prime \prime}\right)$,

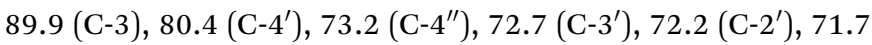
$\left(\mathrm{C}-3^{\prime \prime}\right), 71.5\left(\mathrm{C}-2^{\prime \prime}\right), 69.6\left(\mathrm{C}-5^{\prime \prime}\right), 67.5\left(\mathrm{C}-5^{\prime}\right), 56.0(\mathrm{C}-5), 53.5(\mathrm{C}-$ 18), 48.2 (C-9), 48.0 (C-17), 42.6 (C-14), 40.1 (C-8), 39.7 (C-19), 39.6 (C-20), 39.5 (C-4), 39.2 (C-22), 37.5 (C-1), 37.2 (C-10), 33.6 (C-7), 31.2 (C-21), 28.6 (C-15), 28.5 (C-23), 26.0 (C-2), 24.8 (C16), 23.9 (C-27), 23.8 (C-11), 21.4 (C-30), 18.8 (C-6), $18.2\left(\mathrm{C}-6^{\prime}\right)$, 17.6 (C-6"), 17.4 (C-26), 17.3 (C-29), 16.8 (C-24), 15.8 (C-25). HRMS calcd for $\mathrm{C}_{42} \mathrm{H}_{68} \mathrm{O}_{11} \mathrm{Na}[\mathrm{M}+\mathrm{Na}]^{+} 771.4653$, found 771.4657.

3-O-(2,3,4-Tri-O-benzoyl- $\alpha$-L-rhamnopyranosyl- $(1 \rightarrow 2)-[2,3,4$ tri- $O$-benzoyl- $\alpha$-L-rhamnopyranosyl- $(1 \rightarrow 4)]$ - $\alpha$-L-rhamnopyrano syl)-28-benzyl ursolate (27). Based on the general procedure for normal Schmidt glycosylation, compound 25 (94 mg, $83 \mu \mathrm{mol}$ ) and 2,3,4-tri-O-benzoyl- $\alpha$-L-rhamnopyranosyl trichloroace timidate 12 (56 mg, $91 \mu \mathrm{moL})$ was coupled in DCM $(5 \mathrm{~mL})$ with TMSOTf $(1.5 \mu \mathrm{L}, 8.3 \mu \mathrm{mol})$ as Lewis acid for $10 \mathrm{~min}$. When TLC indicated completion, reaction was then quenched with $\mathrm{Et}_{3} \mathrm{~N}$ (5 $\mu \mathrm{L}$ ) filtered and evaporated before purification by flash chromatography (7:3, hexanes-EtOAc) to give compound 27 (83 mg, 62\%) as colorless oil, $R_{\mathrm{f}}=0.6$ (hexanes-EtOAc, $8: 2$ ), $[\alpha]_{\mathrm{D}}^{20}-1.0\left(c 4.4, \mathrm{CHCl}_{3}\right) \cdot{ }^{1} \mathrm{H} \mathrm{NMR}\left(400 \mathrm{MHz}, \mathrm{CDCl}_{3}\right) \delta 8.02-7.92$ (m, 8H, CH-Bz), 7.89 (d, $J=8.0 \mathrm{~Hz}, 2 \mathrm{H}, \mathrm{CH}-\mathrm{Bz}), 7.77$ (d, $J=$ $8.0 \mathrm{~Hz}, 2 \mathrm{H}, \mathrm{CH}-\mathrm{Bz}), 7.56-7.23(\mathrm{~m}, 19 \mathrm{H}, \mathrm{CH}-\mathrm{Bz}), 7.17(\mathrm{t}, J=$ $7.8 \mathrm{~Hz}, 2 \mathrm{H}, \mathrm{CH}-\mathrm{Bz}), 7.10(\mathrm{t}, J=7.8 \mathrm{~Hz}, 2 \mathrm{H}, \mathrm{CH}-\mathrm{Bz}), 6.04$ (dd, $J=$ $\left.3.5,1.8 \mathrm{~Hz}, 1 \mathrm{H}, \mathrm{H}-2^{\prime \prime \prime}\right), 5.98\left(\mathrm{dd}, J=10.1,3.3 \mathrm{~Hz}, 1 \mathrm{H}, \mathrm{H}-3^{\prime \prime \prime}\right), 5.95$ (dd, $J=10.2,3.1 \mathrm{~Hz}, 1 \mathrm{H}, \mathrm{H}-3^{\prime \prime}$ ), 5.83 (dd, $J=3.4,1.9 \mathrm{~Hz}, 1 \mathrm{H}, \mathrm{H}-$ $\left.2^{\prime \prime}\right), 5.75\left(\mathrm{t}, J=10.0 \mathrm{~Hz}, 1 \mathrm{H}, \mathrm{H}-4^{\prime \prime}\right), 5.67\left(\mathrm{t}, J=9.9 \mathrm{~Hz}, 1 \mathrm{H}, \mathrm{H}-4^{\prime \prime \prime}\right)$, 5.54 (br s, $1 \mathrm{H}, \mathrm{H}^{-1}{ }^{\prime \prime}$ ), 5.37 (br s, $1 \mathrm{H}, \mathrm{H}-1^{\prime \prime \prime}$ ), 5.25 (br s, $1 \mathrm{H}, \mathrm{H}-12$ ), 5.10 (d, $\left.J=12.5 \mathrm{~Hz}, 1 \mathrm{H}, \mathrm{CH}_{2}-\mathrm{Bn}\right), 4.99$ (d, $J=12.5 \mathrm{~Hz}, 1 \mathrm{H}, \mathrm{CH}_{2^{-}}$ $\mathrm{Bn}), 4.87$ (br s, $1 \mathrm{H}, \mathrm{H}-1^{\prime}$ ), 4.47 (dq, $\left.J=9.8,6.3 \mathrm{~Hz}, 1 \mathrm{H}, \mathrm{H}-5^{\prime \prime \prime}\right)$, $4.32\left(\mathrm{dq}, J=9.8,5.9 \mathrm{~Hz}, 1 \mathrm{H}, \mathrm{H}-5^{\prime \prime}\right), 4.22-4.16$ (m, $\left.2 \mathrm{H}, \mathrm{H}-2^{\prime}, \mathrm{H}-3^{\prime}\right)$, $4.04\left(\mathrm{dq}, J=9.7,6.3 \mathrm{~Hz}, 1 \mathrm{H}, \mathrm{H}-5^{\prime}\right), 3.85$ (t, $\left.J=9.3 \mathrm{~Hz}, 1 \mathrm{H}, \mathrm{H}-4^{\prime}\right)$, 3.14 (t, $J=7.9 \mathrm{~Hz}, 1 \mathrm{H}, \mathrm{H}-3), 2.27$ (d, $J=11.1 \mathrm{~Hz}, 1 \mathrm{H}, \mathrm{H}-18), 1.43$ $\left(\mathrm{d}, J=6.1 \mathrm{~Hz}, 3 \mathrm{H}, \mathrm{H}-6^{\prime}\right), 1.36\left(\mathrm{~d}, J=6.8 \mathrm{~Hz}, 3 \mathrm{H}, \mathrm{H}-6^{\prime \prime}\right), 1.35$ (d, $J$ $\left.=7.1 \mathrm{~Hz}, 3 \mathrm{H}, \mathrm{H}-6^{\prime \prime \prime}\right), 1.07$ (s, 3H, H-27), 0.96 (s, 3H, H-25), 0.93 (m, 6H, H-23, H-30), 0.85 (m, 6H, H-24, H-29), 0.73 (br d, $J=$ $12.0 \mathrm{~Hz}, 1 \mathrm{H}, \mathrm{H}-5), 0.65$ (s, 3H, H-26). ${ }^{13} \mathrm{C} \mathrm{NMR}\left(101 \mathrm{MHz}, \mathrm{CDCl}_{3}\right.$ ) $\delta 177.3$ (C-28), [165.87, 165.8 $, 165.6,165.5,165.1,164.9$ (CO$\mathrm{Bz})$ ], 138.1 (C-13), 136.4 (C-Bn), [133.2 ${ }_{5}, 133.2_{2}, 133.1,132.8_{4}$, $\left.132.7_{6}, 132.6,129.9(4 \times), 129.8_{1}(2 \times), 129.7_{7}(4 \times)(C \mathrm{H}-\mathrm{Bz})\right]$, $\left[129.7_{1}, 129.6_{3}, 129.5_{8}, 129.5_{1}, 129.4,129.3(\mathrm{C}-\mathrm{Bz})\right],\left[128.4_{1}\right.$ $(2 \times), 128.3_{9}(2 \times), 128.3_{5}(2 \times), 128.3_{3}(2 \times), 128.2_{6}, 128.2_{2}(2 \times)$, $128.1_{7}(2 \times), 128.1(2 \times), 127.9_{7}(2 \times), 127.9_{6}(2 \times)(C H-B z, C H-B n]$, 125.7 (C-12), 101.9 (C-1'), 99.7 (C-1"), $99.5\left(\mathrm{C}-1^{\prime \prime \prime}\right), 89.9(\mathrm{C}-3), 81.7$ $\left(\mathrm{C}-3^{\prime}\right), 81.0\left(\mathrm{C}-4^{\prime}\right), 72.0\left(\mathrm{C}-4^{\prime \prime}\right), 72.0\left(\mathrm{C}-4^{\prime \prime \prime}\right), 72.0\left(\mathrm{C}-2^{\prime \prime}\right), 71.3(\mathrm{C}-$ $\left.2^{\prime \prime \prime}\right), 71.1\left(\mathrm{C}-2^{\prime}\right), 69.5\left(\mathrm{C}-3^{\prime \prime \prime}\right), 69.5\left(\mathrm{C}-3^{\prime \prime}\right), 67.7\left(\mathrm{C}-5^{\prime \prime \prime}\right), 67.6\left(\mathrm{C}-5^{\prime \prime}\right)$,
$67.1\left(\mathrm{C}-5^{\prime}\right), 66.0$ (C-7), 55.4 (C-5), 52.9 (C-18), 48.1 (C-17), 47.6 (C9), 42.1 (C-14), 39.6 (C-8), 39.1 (C-19), 39.0 (C-4), 38.8 (C-20), 38.7 (C-1), 36.7 (C-10), 36.7 (C-22), 33.0 (C-7), 30.7 (C-21), 28.4 (C-23), 28.0 (C-15), 25.7 (C-2), 24.3 (C-16), 23.6 (C-27), 23.3 (C-11), 21.2 (C-30), 18.3 (C-6'), 18.3 (C-6), $17.7\left(\mathrm{C}-6^{\prime \prime}\right), 17.6\left(\mathrm{C}-6^{\prime \prime \prime}\right), 17.0(\mathrm{C}-29)$, 17.0 (C-26), 16.7 (C-24), 15.5 (C-25). HRMS calcd for $\mathrm{C}_{97} \mathrm{H}_{112} \mathrm{O}_{11} \mathrm{~N}\left[\mathrm{M}+\mathrm{NH}_{4}\right]^{+}$1626.7721, found 1626.7724.

3-O-(2,3,4-Tri-O-benzoyl- $\alpha$-L-rhamnopyranosyl-(1 $\rightarrow 2)-[2,3,4-$ tri- $O$-benzoyl- $\alpha$-L-rhamnopyranosyl- $(1 \rightarrow 4)]$ - $\alpha$-L-rhamnopyrano syl)ursolic acid (28). A solution of compound 27 (44 mg, 27 $\mu \mathrm{mol})$ and $10 \% \mathrm{Pd} / \mathrm{C}(2 \mathrm{mg})$ in dry EtOAc $(3 \mathrm{~mL})$ was refluxed and purged with $\mathrm{H}_{2}$. When TLC indicated the disappearance of the starting material, the mixture was filtered over Celite ${ }^{\circledR}$ and concentrated under reduced pressure. The residue was purified by flash chromatography $(8: 2$, hexanes-EtOAc) to give compound $28(33.2 \mathrm{mg}, 81 \%)$ as a colorless oil, $R_{\mathrm{f}}=0.3$ (hexanes-EtOAc, $8: 2$ ), $[\alpha]_{\mathrm{D}}^{20}+60.6\left(c 3.4, \mathrm{CHCl}_{3}\right) .{ }^{1} \mathrm{H}$ NMR $(400$ $\left.\mathrm{MHz} \mathrm{CDCl}_{3}\right) \delta 8.01-7.92(\mathrm{~m}, 8 \mathrm{H}, \mathrm{CH}-\mathrm{Bz}), 7.88(\mathrm{~d}, J=7.5 \mathrm{~Hz}, 2 \mathrm{H}$, $\mathrm{CH}-\mathrm{Bz}), 7.77$ (d, $J=7.6 \mathrm{~Hz}, 2 \mathrm{H}, \mathrm{CH}-\mathrm{Bz}), 7.54-7.25(\mathrm{~m}, 9 \mathrm{H}, \mathrm{CH}-$ $\mathrm{Bz}), 7.16(\mathrm{t}, J=7.7 \mathrm{~Hz}, 2 \mathrm{H}, \mathrm{CH}-\mathrm{Bz}), 7.10(\mathrm{t}, J=7.8 \mathrm{~Hz}, 2 \mathrm{H}, \mathrm{CH}-$ $\mathrm{Bz}$ ), 6.04 (br s, $1 \mathrm{H}, \mathrm{H}-2^{\prime \prime \prime}$ ), 6.00 (dd, $J=10.0,3.0 \mathrm{~Hz}, 1 \mathrm{H}, \mathrm{H}-3^{\prime \prime \prime}$ ), $5.95\left(\mathrm{dd}, J=10.0,3.0 \mathrm{~Hz}, 1 \mathrm{H}, \mathrm{H}-3^{\prime \prime}\right), 5.83\left(\mathrm{br} \mathrm{s}, 1 \mathrm{H}, \mathrm{H}-2^{\prime \prime}\right), 5.76(\mathrm{t}$, $\left.J=9.9 \mathrm{~Hz}, 1 \mathrm{H}, \mathrm{H}-4^{\prime \prime}\right), 5.67\left(\mathrm{t}, J=10.0 \mathrm{~Hz}, 1 \mathrm{H}, \mathrm{H}-4^{\prime \prime \prime}\right), 5.54(\mathrm{~s}, 1 \mathrm{H}$, $\mathrm{H}-1^{\prime \prime}$ ), 5.38 (s, 1H, H-1'"'), 5.26 (br s, $1 \mathrm{H}, \mathrm{H}-12$ ), 4.88 (s, 1H, H-1'), $4.47\left(\mathrm{dq}, J=10.0,6.4 \mathrm{~Hz}, 1 \mathrm{H}, \mathrm{H}-5^{\prime \prime \prime}\right), 4.32(\mathrm{dq}, J=9.7,6.4 \mathrm{~Hz}, 1 \mathrm{H}$, $\left.\mathrm{H}-5^{\prime \prime}\right), 4.22-4.15\left(\mathrm{~m}, 2 \mathrm{H}, \mathrm{H}-2^{\prime}, \mathrm{H}-3^{\prime}\right), 4.04\left(\mathrm{~m}, \mathrm{H}-5^{\prime}\right), 3.85(\mathrm{t}, J=$ $\left.8.7 \mathrm{~Hz}, 1 \mathrm{H}, \mathrm{H}-4^{\prime}\right), 3.15$ (t, $\left.J=8.0 \mathrm{~Hz}, 1 \mathrm{H}, \mathrm{H}-3\right), 2.19$ (br d, $J=$ $10.9 \mathrm{~Hz}, 1 \mathrm{H}, \mathrm{H}-18), 1.43$ (d, $\left.J=6.1 \mathrm{~Hz}, 3 \mathrm{H}, \mathrm{H}-6^{\prime}\right), 1.37$ (d, $J=$ $\left.6.1 \mathrm{~Hz}, 3 \mathrm{H}, \mathrm{H}-6^{\prime \prime}\right), 1.35$ (d, $\left.J=6.0 \mathrm{~Hz}, 3 \mathrm{H}, \mathrm{H}-6^{\prime \prime \prime}\right), 1.09$ (s, 3H, H27), 0.99 (s, 3H, H-25), 0.96 (m, 6H, H-30, H-23), 0.86 (m, 6H, H29, H-24), 0.80 (s, 3H, H-26), 0.75 (br d, $J=11.7 \mathrm{~Hz}, 1 \mathrm{H}, \mathrm{H}-5) .{ }^{13} \mathrm{C}$ NMR (101 MHz, $\left.\mathrm{CDCl}_{3}\right) \delta 182.5$ (C-28), [165.8 $, 165.8_{5}, 165.6$, 165.5, 165.1, 164.9 (CO-Bz)], 137.9 (C-13), [133.2 $, 133.2_{2}, 133.1$, $132.8,132.7,132.6,129.9_{5}(2 \times), 129.9_{2}(2 \times), 129.8_{1}(4 \times), 129.7_{6}$ $(4 \times), 129.6_{3}, 129.5_{7}, 129.5_{1}, 129.4,129.3(2 \times), 128.3_{9}(2 \times)$, $128.3_{5}(2 \times), 128.3_{3}(2 \times), 128.2(2 \times), 128.1(2 \times), 128.0(2 \times), C H-$

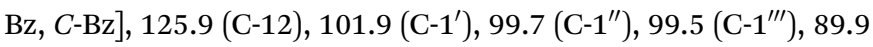
(C-3), $81.7\left(\mathrm{C}-3^{\prime}\right), 81.0\left(\mathrm{C}-4^{\prime}\right), 72.0\left(\mathrm{C}-4^{\prime \prime \prime}\right), 72.0\left(\mathrm{C}-4^{\prime \prime}\right), 71.9\left(\mathrm{C}-2^{\prime \prime}\right)$, $71.3\left(\mathrm{C}-2^{\prime \prime \prime}\right), 71.1\left(\mathrm{C}-2^{\prime}\right), 69.4\left(\mathrm{C}-3^{\prime \prime \prime}\right), 69.4\left(\mathrm{C}-3^{\prime \prime}\right), 67.7\left(\mathrm{C}-5^{\prime \prime \prime}\right), 67.6$ $\left(\mathrm{C}-5^{\prime \prime}\right), 67.1$ (C-5'), 55.4 (C-5), 52.6 (C-18), 47.9 (C-17), 47.6 (C-9), 42.0 (C-14), 39.5 (C-8), 39.1 (C-19), 39.0 (C-4), 38.8 (C-20), 38.7 (C1), 36.7 (C-10), 36.6 (C-22), 32.9 (C-7), 30.5 (C-21), 28.4 (C-23), 28.0 (C-15), 25.5 (C-2), 24.2 (C-16), 23.6 (C-27), 23.4 (C-11), 21.2 (C-30), 18.8 (C-6), 18.3 (C-6'), 17.7 (C-6"), 17.6 (C-6 $\left.{ }^{\prime \prime \prime}\right), 17.0$ (C-29), 16.9 (C-26), 16.7 (C-24), 15.5 (C-25). HRMS calcd for $\mathrm{C}_{90} \mathrm{H}_{106} \mathrm{O}_{21} \mathrm{~N}\left[\mathrm{M}+\mathrm{NH}_{4}\right]^{+}$1536.7252, found 1536.7236.

3-O- $\alpha$-L-Rhamnopyranosyl- $(1 \rightarrow 2)$ - $\alpha$-L-rhamnopyranosyl-(1 $\rightarrow$ 4)- $\alpha$-L-rhamnopyranosyl ursolic acid (9). Compound 28 (34.4 mg, $23 \mu \mathrm{mol})$ was dissolved in MeOH-DCM $(2: 1,3 \mathrm{~mL}$ ) with $\mathrm{NaOMe}$ in $\mathrm{MeOH}(0.5 \mathrm{M}, 3 \mathrm{~mL})$ overnight. The reaction was then neutralized to $\mathrm{pH} 7$ with Dowex $\mathrm{G} 26\left(\mathrm{H}^{+}\right.$form $)$, filtered and purified by flash chromatography (9:1, DCM-MeOH $\rightarrow$ 26 : $14: 3$ DCM-MeOH- $\mathrm{H}_{2} \mathrm{O}$ ) to give compound 9 (17 $\mathrm{mg}, 84 \%$ ) as a colorless oil, $R_{\mathrm{f}}=0.3\left(26: 14: 3 \mathrm{CHCl}_{3}-\mathrm{MeOH}-\mathrm{H}_{2} \mathrm{O}\right)$, $[\alpha]_{\mathrm{D}}^{20}+12.3$ (c 1.8, $\left.1: 1, \mathrm{CHCl}_{3}-\mathrm{MeOH}\right) .{ }^{1} \mathrm{H}$ NMR $[400 \mathrm{MHz}$, $\left.\mathrm{CD}_{3} \mathrm{OD} / \mathrm{CDCl}_{3} 1: 1\right] \delta 5.23$ (br s, $\mathrm{H}-12$ ), 5.00 (br s, $1 \mathrm{H}, \mathrm{H}-1^{\prime \prime}$ ), 4.88 (br s, 1H, H-1"' ), 4.73 (m, 1H, H-1'), 3.96-3.62 (m, 10H, H-2'"', H- 
$\left.2^{\prime}, \mathrm{H}-3^{\prime}, \mathrm{H}-2^{\prime \prime}, \mathrm{H}-5^{\prime}, \mathrm{H}-5^{\prime \prime \prime}, \mathrm{H}-3^{\prime \prime \prime}, \mathrm{H}-5^{\prime \prime}, \mathrm{H}-4^{\prime}, \mathrm{H}-3^{\prime \prime}\right), 3.46-3.38$ (m, $2 \mathrm{H}, \mathrm{H}-4^{\prime \prime}, \mathrm{H}-4^{\prime \prime \prime}$ ), 3.11 (dd, $J=10.9,4.7 \mathrm{~Hz}, 1 \mathrm{H}, \mathrm{H}-3$ ), 1.32-1.26 (m, 9H, H-6', H-6"' , H-6"), 1.11 (s, 3H, H-27), 0.99-0.94 (m, 9H, $\mathrm{H}-30, \mathrm{H}-25, \mathrm{H}-23$ ), 0.88 (d, $J=6.4 \mathrm{~Hz}, 3 \mathrm{H}, \mathrm{H}-29$ ), 0.85 (s, 3H, H26), 0.81 (s, 3H, H-24). ${ }^{13} \mathrm{C}$ NMR $\left[101 \mathrm{MHz}, \mathrm{CD}_{3} \mathrm{OD} / \mathrm{CDCl}_{3} 1: 1\right]$ $\delta 179.7$ (C-28), 139.2 (C-13), 125.9 (C-12), $103.5\left(\mathrm{C}-1^{\prime \prime \prime}\right), 103.3$ (C$\left.1^{\prime}\right), 102.9\left(\mathrm{C}-1^{\prime \prime}\right), 90.1(\mathrm{C}-3), 80.9\left(\mathrm{C}-3^{\prime}\right), 80.0\left(\mathrm{C}-4^{\prime}\right), 73.2\left(\mathrm{C}-4^{\prime \prime \prime}\right)$, $73.0\left(\mathrm{C}-4^{\prime \prime}\right), 71.8\left(\mathrm{C}-3^{\prime \prime}\right), 71.7\left(\mathrm{C}-2^{\prime \prime}\right), 71.6\left(\mathrm{C}-2^{\prime \prime \prime}\right), 71.6\left(\mathrm{C}-3^{\prime \prime \prime}\right), 71.4$ $\left(\mathrm{C}-2^{\prime}\right), 69.9\left(\mathrm{C}-5^{\prime \prime}\right), 69.6\left(\mathrm{C}-5^{\prime \prime \prime}\right), 68.3\left(\mathrm{C}-5^{\prime}\right), 56.0$ (C-5), 53.7 (C-18), 48.2 (C-9), 42.7 (C-14), 40.1 (C-8), 39.9 (C-19), 39.7 (C-20), 39.5 (C4), 39.2 (C-22), 37.3 (C-1), 37.3 (C-10), 33.7 (C-7), 28.7 (C-15), 28.6 (C-23), 26.0 (C-2), 24.9 (C-16), 23.9 (C-27), 23.9 (C-11), 21.5 (C30), 18.9 (C-6), 18.2 (C-6'), $17.6\left(\mathrm{C}-6^{\prime \prime \prime}\right), 17.5\left(\mathrm{C}-6^{\prime \prime}\right), 17.5$ (C-26), 17.5 (C-29), 16.9 (C-24), 15.9 (C-25). HRMS: calcd for $\mathrm{C}_{48} \mathrm{H}_{82} \mathrm{O}_{15} \mathrm{~N}\left[\mathrm{M}+\mathrm{NH}_{4}\right]^{+}$912.5679, found 912.5678.

3-O-(2,3,4-Tri-O-benzoyl- $\alpha$-L-rhamnopyranosyl- $(1 \rightarrow 2)$-[2,3,4tri-O-benzoyl- $\alpha$-L-rhamnopyranosyl- $(1 \rightarrow 3)]$-[2,3,4-tri-O-benzoyl$\alpha$-L-rhamnopyranosyl-( $1 \rightarrow 4)]$ - $\alpha$-L-rhamnopyranosyl)-28-benzyl

ursolate (29). Based on the general procedure for inverse Schmidt glycosylation, compound $22(89 \mathrm{mg}, 131 \mu \mathrm{mol})$ and TMSOTf $(2.4 \mu \mathrm{L}, 13 \mu \mathrm{mol})$ were dissolved in dry DCM $(4 \mathrm{~mL})$ with $4 \AA$ molecular sieves (50 mg) at $-78^{\circ} \mathrm{C}$. After stirring the solution during $30 \mathrm{~min}$, a solution of 2,3,4-tri-O-benzoyl- $\alpha-\mathrm{L}-$ rhamnopyranosyl trichloroacetimidate 12 (407 mg, $656 \mu \mathrm{moL})$ in dry DCM $(2 \mathrm{~mL})$ was added. The reaction mixture was stirred at $-15{ }^{\circ} \mathrm{C}$ for $25 \mathrm{~min}$ then the reaction was quenched with $\mathrm{Et}_{3} \mathrm{~N}$ ( 0.2 equiv.) and filtered. The filtrate was concentrated under reduced pressure, and the residue was purified by flash chromatography (hexanes-EtOAc, $5 \rightarrow 30 \%$ ) to afford the expected compound $29(127 \mathrm{mg}, 47 \%)$ as a colourless oil. $R_{\mathrm{f}}=0.48(7: 3$, hexanes-EtOAc); $[\alpha]_{\mathrm{D}}^{20}+12.3\left(c 1, \mathrm{CHCl}_{3}\right) .{ }^{1} \mathrm{H}$ NMR $(400 \mathrm{MHz}$, $\left.\mathrm{CDCl}_{3}\right) \delta 8.07-7.73(\mathrm{~m}, 18 \mathrm{H}, \mathrm{CH}-\mathrm{Bz}), 7.55-7.06(\mathrm{~m}, 32 \mathrm{H}, \mathrm{CH}-\mathrm{Bz}$, CH-Bn), 6.11-5.94 (m, 5H, H-3 $\left.3^{\prime \prime \prime}, \mathrm{H}-2^{\prime \prime \prime}, \mathrm{H}-3^{\prime \prime}, \mathrm{H}-3^{\prime \prime \prime \prime}, \mathrm{H}-2^{\prime \prime}\right), 5.88$ (dd, $\left.J=3.4,1.6 \mathrm{~Hz}, 1 \mathrm{H}, \mathrm{H}-2^{\prime \prime \prime \prime}\right), 5.78-5.67$ (m, 3H, H-4 $4^{\prime \prime}, \mathrm{H}-4^{\prime \prime \prime \prime}$, $\mathrm{H}-4^{\prime \prime \prime}$ ), 5.60 (br s, $1 \mathrm{H}, \mathrm{H}-1^{\prime \prime}$ ), 5.39 (br s, $1 \mathrm{H}, \mathrm{H}-1^{\prime \prime \prime}$ ), 5.38 (br s, $1 \mathrm{H}$, ${\left.\mathrm{H}-1^{\prime \prime \prime \prime}\right)}^{\prime \prime 26}(\mathrm{t}, J=3.5 \mathrm{~Hz}, 1 \mathrm{H}, \mathrm{H}-12), 5.11(\mathrm{~d}, J=12.5 \mathrm{~Hz}, 1 \mathrm{H}$, $\mathrm{CH}_{2}-\mathrm{Bn}$ ), 5.07 (br s, $1 \mathrm{H}, \mathrm{H}_{-1}^{\prime}$ ), 4.99 (d, $J=12.5 \mathrm{~Hz}, 1 \mathrm{H}, \mathrm{CH}_{2}-\mathrm{Bn}$ ), 4.50 (dq, $\left.J=9.7,6.5 \mathrm{~Hz}, 1 \mathrm{H}, \mathrm{H}-5^{\prime \prime \prime}\right), 4.44-4.34$ (m, $2 \mathrm{H}, \mathrm{H}-5^{\prime \prime \prime \prime}, \mathrm{H}-$ $5^{\prime \prime}$ ), 4.32 (dd, $\left.J=8.8,2.6 \mathrm{~Hz}, 1 \mathrm{H}, \mathrm{H}_{-} 3^{\prime}\right), 4.23$ (br s, $\left.1 \mathrm{H}, \mathrm{H}-2^{\prime}\right), 4.09-$ 3.98 (m, 2H, H-4' H-5 $^{\prime}$ ), 3.14 (dd, $\left.J=10.5,4.6 \mathrm{~Hz}, 1 \mathrm{H}, \mathrm{H}-3\right), 2.27$ $(\mathrm{d}, J=11.2 \mathrm{~Hz}, 1 \mathrm{H}, \mathrm{H}-18), 1.53$ (d, $\left.J=5.6 \mathrm{~Hz}, 3 \mathrm{H}, \mathrm{H}-6^{\prime}\right), 1.43$ (d, $J$ $\left.=6.2 \mathrm{~Hz}, 3 \mathrm{H}, \mathrm{H}-6^{\prime \prime}\right), 1.36\left(\mathrm{~d}, J=6.5 \mathrm{~Hz}, 3 \mathrm{H}, \mathrm{H}-6^{\prime \prime \prime \prime}\right), 1.35(\mathrm{~d}, J=$ $6.1 \mathrm{~Hz}, 3 \mathrm{H}, \mathrm{H}-6^{\prime \prime \prime}$ ), 1.06 (s, 3H, H-27), 0.97 (s, 3H, H-25), 0.95 (s, $3 \mathrm{H}, \mathrm{H}-23$ ), 0.93 (d, $J=6.1 \mathrm{~Hz}, 3 \mathrm{H}, \mathrm{H}-30), 0.88$ (s, 3H, H-24), 0.86 (d, $J=6.3 \mathrm{~Hz}, 3 \mathrm{H}, \mathrm{H}-29), 0.73$ (br d, $J=11.0 \mathrm{~Hz}, 1 \mathrm{H}, \mathrm{H}-5), 0.65$ (s, 3H, H-26). ${ }^{13} \mathrm{C}$ NMR (101 MHz, $\mathrm{CDCl}_{3}$ ) $\delta 177.3$ (C-28), [166.1, 166, 165.9, 165.5, 165.15, $165.11(2 \times), 165.1,164.6$ (CO-Bz)], 138.1 (C-13), 136.4 (C-Bn), [133.3, 133.18, 133.12, 132.88, $132.81(2 \times), 132.72,132.69,132.4,130.06(2 \times), 130.04(2 \times)$, $129.95(2 \times), 129.87(4 \times), 129.81(4 \times), 129.76(4 \times), 129.68(2 \times)$, 129.63, 129.54, $129.51(2 \times), 129.4,129.3,128.4(4 \times), 128.37$ $(2 \times), 128.33(2 \times), 128.2(2 \times), 128.18(4 \times), 128.13(2 \times), 128.1$ (4×), $128(2 \times), 127.9(2 \times)(C \mathrm{H}-\mathrm{Bz}, C-\mathrm{Bz}, C \mathrm{H}-\mathrm{Bn})], 125.7$ (C-12), $100.7\left(\mathrm{C}-1^{\prime}\right), 100.6\left(\mathrm{C}-1^{\prime \prime \prime}\right), 99.6\left(\mathrm{C}-1^{\prime \prime}\right), 99.2\left(\mathrm{C}-1^{\prime \prime \prime \prime}\right), 90.0(\mathrm{C}-3)$, $80.9\left(\mathrm{C}-4^{\prime}\right), 80.7\left(\mathrm{C}-3^{\prime}\right), 79.5\left(\mathrm{C}-2^{\prime}\right), 72.3\left(\mathrm{C}-4^{\prime \prime}\right), 72.1\left(\mathrm{C}-4^{\prime \prime \prime}\right), 72.0$ $\left(\mathrm{C}-4^{\prime \prime \prime \prime}\right), 71.7\left(\mathrm{C}-2^{\prime \prime}\right), 71.6\left(\mathrm{C}-2^{\prime \prime \prime}\right), 71.2\left(\mathrm{C}-2^{\prime \prime \prime \prime}\right), 69.7\left(\mathrm{C}-3^{\prime \prime \prime \prime}\right), 69.6$ $\left(\mathrm{C}-3^{\prime \prime}\right), 69.5\left(\mathrm{C}-3^{\prime \prime \prime}\right), 67.9\left(\mathrm{C}-5^{\prime}\right), 67.8\left(\mathrm{C}-5^{\prime \prime \prime}\right), 67.6\left(\mathrm{C}-5^{\prime \prime}\right), 67.5(\mathrm{C}-$ $5^{\prime \prime \prime \prime}$ ), 66.0 (C-7), 55.4 (C-5), 52.9 (C-18), 48.1 (C-17), 47.6 (C-9), 42.0 (C-14), 39.6 (C-8), 39.1 (C-19), 39.1 (C-4), 38.8 (C-20), 38.7 (C-1), 36.7 (C-10), 36.7 (C-22), 33.0 (C-7), 30.7 (C-21), 28.5 (C-23), 28.0 (C-15), 25.7 (C-2), 24.3 (C-16), 23.6 (C-27), 23.3 (C-11), 21.2

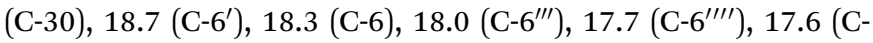
$6^{\prime \prime}$ ), 17.0 (C-29), 17.0 (C-26), 16.8 (C-24), 15.5 (C-25). HRMS calcd for $\mathrm{C}_{124} \mathrm{H}_{134} \mathrm{O}_{28} \mathrm{~N}\left[\mathrm{M}+\mathrm{NH}_{4}\right]^{+}$2084.90869, found 2084.91553 .

3-O- $\alpha$-L-Rhamnopyranosyl- $(1 \rightarrow 2)$-[ $\alpha$-L-rhamnopyranosyl$(1 \rightarrow 3)]$-[ $\alpha$-L-rhamnopyranosyl- $(1 \rightarrow 4)]-\alpha-L-r h a m n o p y r a n o s y l$ ursolic acid (10). A solution of compound 29 (55 mg, $27 \mu \mathrm{mol})$ and $10 \% \mathrm{Pd} / \mathrm{C}(2 \mathrm{mg})$ in dry EtOAc $(3 \mathrm{~mL})$ was refluxed and purged with $\mathrm{H}_{2}$. When TLC indicated the disappearance of the starting material, the mixture was filtered over Celite ${ }^{\circledR}$ and concentrated under reduced pressure. The residue was suspended in dry MeOH-DCM $(2: 1,2 \mathrm{~mL})$, to which a freshly prepared solution of NaOMe $(0.5 \mathrm{M}, 2 \mathrm{~mL})$ was added. After overnight stirring, the reaction was neutralized to $\mathrm{pH} 7$ with Dowex G-26 ( $\mathrm{H}^{+}$form) and filtered. The filtrate was concentrated to dryness and purified by reversed-phase flash chromatography SPE $\left(1 \mathrm{~g}\right.$ cartridge, $\left.\mathrm{H}_{2} \mathrm{O}: \mathrm{MeOH} 50 \rightarrow 85 \%\right)$, to give $10(25 \mathrm{mg}$, 90\% over two steps) $R_{\mathrm{f}}=0.18\left(26: 14: 3 \mathrm{CHCl}_{3}-\mathrm{MeOH}-\mathrm{H}_{2} \mathrm{O}\right)$; $[\alpha]_{\mathrm{D}}^{20}+36.8$ (c 3.9, $\left.1: 1, \mathrm{CHCl}_{3}-\mathrm{MeOH}\right) .{ }^{1} \mathrm{H}$ NMR $(400 \mathrm{MHz}$, $\left.\mathrm{CD}_{3} \mathrm{OD} / \mathrm{CDCl}_{3} 1: 1\right) \delta 5.24$ (br s, $1 \mathrm{H}, \mathrm{H}-12$ ), 4.98 (s, 1H, H-1"), $4.92\left(\mathrm{~s}, 1 \mathrm{H}, \mathrm{H}-\mathrm{H}-1^{\prime \prime \prime \prime}\right), 4.86$ (s, 1H, H-1"' $), 4.85$ (s, 1H, H-1'), 3.98 (dd, $J=9.8,2.8 \mathrm{~Hz}, 1 \mathrm{H}, \mathrm{H}-3^{\prime}$ ), 3.94-3.87 (m, 3H, H-2 ${ }^{\prime \prime \prime \prime}, \mathrm{H}-2^{\prime \prime \prime}, \mathrm{H}-$ $2^{\prime}$ ), 3.85-3.57 (m, 9H, H-2" , H-5', H-5 $5^{\prime \prime}, \mathrm{H}-3^{\prime \prime \prime \prime}, \mathrm{H}-5^{\prime \prime \prime}, \mathrm{H}-5^{\prime \prime \prime \prime}, \mathrm{H}-3^{\prime \prime}$, $\left.\mathrm{H}-3^{\prime \prime \prime}, \mathrm{H}-4^{\prime}\right), 3.47-3.32\left(\mathrm{~m}, 3 \mathrm{H}, \mathrm{H}-4^{\prime \prime \prime}, \mathrm{H}-4^{\prime \prime}, \mathrm{H}-4^{\prime \prime \prime \prime}\right), 3.11(\mathrm{t}, J=$ $8.4 \mathrm{~Hz}, 1 \mathrm{H}, \mathrm{H}-3), 2.20$ (br d, $J=11.2 \mathrm{~Hz}, 1 \mathrm{H}, \mathrm{H}-18), 1.28(\mathrm{~m}, 12 \mathrm{H}$, H-6', H-6", H-6"', $\mathrm{H}-6^{\prime \prime \prime \prime}$ ), 1.11 (s, 3H, H-27), 0.96 (m, 9H, H-30, $\mathrm{H}-25, \mathrm{H}-23$ ), 0.88 (d, $J=6.4 \mathrm{~Hz}, 3 \mathrm{H}, \mathrm{H}-29), 0.84$ (s, 3H, H-26), 0.81 (s, 3H, H-24). ${ }^{13} \mathrm{C}$ NMR (101 MHz, $\mathrm{CD}_{3} \mathrm{OD} / \mathrm{CDCl}_{3} 1: 1$ ) $\delta 181.5$ (C-28), 138.9 (C-13), 126.0 (C-12), 103.6 (C-1"' ), 102.9 (C-

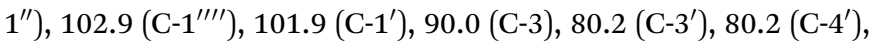
79.1 (C-2'), $73.2\left(\mathrm{C}-4^{\prime \prime \prime \prime}\right), 73.1\left(\mathrm{C}-4^{\prime \prime \prime}\right), 72.9\left(\mathrm{C}-4^{\prime \prime}\right), 71.8\left(\mathrm{C}-3^{\prime \prime}\right), 71.7$ $\left(\mathrm{C}-3^{\prime \prime \prime}\right), 71.6\left(\mathrm{C}-2^{\prime \prime}\right), 71.6\left(\mathrm{C}-3^{\prime \prime \prime \prime}\right), 71.3\left(\mathrm{C}-2^{\prime \prime \prime \prime}\right), 71.3\left(\mathrm{C}-2^{\prime \prime \prime}\right), 69.9$ $\left(\mathrm{C}-5^{\prime \prime}\right), 69.9\left({\mathrm{C}-5^{\prime \prime \prime \prime}}^{\prime \prime}\right), 69.6\left(\mathrm{C}-5^{\prime \prime \prime}\right), 68.3\left(\mathrm{C}-5^{\prime}\right), 55.9(\mathrm{C}-5), 53.6(\mathrm{C}-$ 18), 48.3 (C-17), 48.2 (C-9), 42.7 (C-14), 40.1 (C-8), 39.7 (C-19), 39.6 (C-20), 39.6 (C-4), 39.1 (C-1), 37.5 (C-22), 37.3 (C-10), 33.6 (C-7), 31.2 (C-21), 28.7 (C-23), 28.6 (C-15), 26.1 (C-2), 24.8 (C-16), 23.9 (C-27), 23.8 (C-11), 21.4 (C-30), 18.8 (C-6), 18.3 (C-6"), 17.8 $\left({\mathrm{C}-6^{\prime \prime \prime \prime}}^{\prime \prime}\right), 17.7$ (C-6'), $17.5\left(\mathrm{C}-6^{\prime \prime \prime}\right), 17.4$ (C-26), 17.4 (C-29), 16.8 (C24), 15.8 (C-25). HRMS calcd for $\mathrm{C}_{54} \mathrm{H}_{88} \mathrm{O}_{19} \mathrm{Na}[\mathrm{M}+\mathrm{Na}]^{+}$ 1063.5812, found 1063.5845.

Cell culture. Human skin fibroblasts WS1 (ATCC CRL-1502), human colon adenocarcinoma DLD-1 (ATCC CCL-221), and murine macrophage RAW 264.7 (ATCC TIB-71) were obtained from the American Type Culture Collection (Manassas, VA, USA). Cells were grown in a humidified atmosphere at $37{ }^{\circ} \mathrm{C}$ in $5 \% \mathrm{CO}_{2}$, in Dulbecco's Minimum Essential Medium supplemented with $10 \%$ fetal calf serum (Hyclone, Logan, UT, USA), $1 \times$ vitamins, $100 \mathrm{IU}$ of penicillin and $100 \mu \mathrm{g} \mathrm{mL}{ }^{-1}$ streptomycin (Cellgro®, Mediatech, Manassas, VA, USA).

Cytotoxicity assay. Human skin fibroblasts (WS1) and colon adenocarcinoma (DLD-1) were seeded in transparent flatbottom 96-well microplates (Costar, Corning Inc., Lowell, MA, USA) at a density of $5 \times 10^{3}$ cells per well in a volume of $100 \mu \mathrm{L}$ of culture medium. Cells were allowed to adhere for $16 \mathrm{~h}$ before 
treatment. Cells were then treated with rhamnosides 1-10 in DMSO. The final concentration of DMSO in the culture medium was $0.5 \%(\mathrm{v} / \mathrm{v})$ to avoid solvent toxicity. After $48 \mathrm{~h}$, we assessed the cytotoxicity using Hoechst test. ${ }^{38}$ Fluorescence was measured on an automated Fluoroskan Ascent FL $^{\mathrm{TM}}$ plate reader (Labsystems, Milford, MA, USA) using an excitation wavelength of $355 \mathrm{~nm}$ and an emission wavelength of $460 \mathrm{~nm}$. Cytotoxicity was expressed as the concentration that inhibited cell growth by $50 \%\left(\mathrm{IC}_{50}\right)$.

Anti-inflammatory assay. Murine macrophage RAW 264.7 cells were incubated with rhamnosides 1-10 in DMSO and then stimulated with $100 \mathrm{ng} \mathrm{mL}{ }^{-1}$ LPS and incubated at $37{ }^{\circ} \mathrm{C}$. Final DMSO concentration was maintained under $0.5 \%$ to avoid solvent toxicity. $N^{\omega}$-Nitro-L-arginine methyl ester hydrochloride (L-NAME), a known iNOS inhibitor, was used as positive control. After $24 \mathrm{~h}$, the cell-free supernatants were collected and NO concentration was immediately determined using the Griess reaction. ${ }^{39}$ The absorbance was measured at $550 \mathrm{~nm}$ using an automated Varioskan Ascent plate reader (Labsystems, Milford, MA, USA), to quantify the presence of nitrite by comparing with a $\mathrm{NaNO}_{2}$ standard curve.

\section{Authors contribution}

A. P., B. S., and C. G. designed the experiments. B. S. and J. L. performed the experiments. B. S. and S. L. analyzed the NMR data. B. S., C. G., and J. L. analyzed the data and wrote the paper. A. P. and J. L. secured funding. A. P., J. L., and C. G. directed the students.

\section{Conflicts of interest}

The authors have no conflict of interest to declare.

\section{Acknowledgements}

This work was supported by operating grants 311906 and 326086 from the Canadian Institutes of Health Research (CIHR, to A. P. and J. L.) and by a Discovery grant from the Natural Sciences and Engineering Research Council of Canada (NSERC) under award number RGPIN-2016-04950 (to C. G.). C. G. holds a Fonds de recherche du Québec - Santé (FRQS) Research Scholars Junior 2 Career Award. We thank Karl Lalancette and Catherine Dussault for the biological assays.

\section{References}

1 C. Gauthier, J. Legault, M. Piochon-Gauthier and A. Pichette, Phytochem. Rev., 2011, 10, 521-544.

2 M. Ali-Seyed, I. Jantan, K. Vijayaraghavan and S. N. A. Bukhari, Chem. Biol. Drug Des., 2016, 87, 517-536.

3 M. Grymel, M. Zawojak and J. Adamek, J. Nat. Prod., 2019, 82, 1719-1730.

4 J. L. C. Sousa, C. S. R. Freire, A. J. D. Silvestre and A. M. S. Silva, Molecules, 2019, 24, E355.

5 H. Chen, Y. Gao, A. Wang, X. Zhou, Y. Zheng and J. Zhou, Eur. J. Med. Chem., 2015, 92, 648-655.
6 D. Kashyap, H. S. Tuli and A. K. Sharma, Life Sci., 2016, 146, 201-213.

7 H. J. Jeong, H. B. Chai, S. Y. Park and D. S. H. L. Kim, Bioorg. Med. Chem. Lett., 1999, 9, 1201-1204.

8 M. Kvasnica, J. Sarek, E. Klinotova, P. Dzubak and M. Hajduch, Bioorg. Med. Chem., 2005, 13, 3447-3454.

9 H. Kommera, G. N. Kaluderović, S. Dittrich, J. Kalbitz, B. Dräger, T. Mueller and R. Paschke, Bioorg. Med. Chem. Lett., 2010, 20, 3409-3412.

10 C. Suresh, H. Zhao, A. Gumbs, C. S. Chetty and H. S. Bose, Bioorg. Med. Chem. Lett., 2012, 22, 1734-1738.

11 Q. Michaudel, G. Journot, A. Regueiro-Ren, A. Goswami, Z. Guo, T. P. Tully, L. Zou, R. O. Ramabhadran, K. N. Houk and P. S. Baran, Angew. Chem., Int. Ed., 2014, 53, 1209112096.

12 C. Gauthier, J. Legault, K. Girard-Lalancette, V. Mshvildadze and A. Pichette, Bioorg. Med. Chem., 2009, 17, 2002-2008.

13 C. Gauthier, J. Legault, S. Lavoie, S. Rondeau, S. Tremblay and A. Pichette, Tetrahedron, 2008, 64, 7386-7399.

14 C. Gauthier, J. Legault, S. Lavoie, S. Rondeau, S. Tremblay and A. Pichette, J. Nat. Prod., 2009, 72, 72-81.

15 C. Gauthier, J. Legault, M. Lebrun, P. Dufour and A. Pichette, Bioorg. Med. Chem., 2006, 14, 6713-6725.

16 C. Gauthier, J. Legault and A. Pichette, Mini-Rev. Org. Chem., 2009, 6, 321-344.

17 C. Gauthier, J. Legault, M. Piochon, S. Lavoie, S. Tremblay and A. Pichette, Bioorg. Med. Chem., 2009, 19, 2310-2314.

18 C. Gauthier, J. Legault, S. Rondeau and A. Pichette, Tetrahedron Lett., 2009, 50, 988-991.

19 Y. Li, J. Sun and B. Yu, Org. Lett., 2011, 13, 5508-5511.

20 P. Cmoch, Z. Pakulski, J. Swaczynová and M. Strnad, Carbohydr. Res., 2008, 343, 995-1003.

21 K. Kuczynska, P. Cmoch, L. Rárová, J. Oklešťková, A. Korda, Z. Pakulski and M. Strnad, Carbohydr. Res., 2016, 423, 49-69.

22 K. Sidoryk, L. Rárová, J. Oklešťková, Z. Pakulski, M. Strnad, P. Cmoch and R. Luboradzki, Org. Biomol. Chem., 2016, 14, 10238-10248.

23 A. Korda, Z. Pakulski, P. Cmoch, K. Gwardiak and R. Karczewski, Carbohydr. Res., 2018, 461, 32-37.

24 M. Mihoub, A. Pichette, B. Sylla, C. Gauthier and J. Legault, PLoS One, 2018, 13, e0193386.

25 P. Tomsik, T. Soukup, E. Cermakova, S. Micuda, M. Niang, L. Sucha and M. Rezacova, Cent. Eur. J. Biol., 2011, 6, 1-9.

26 A. Martín, T. D. Butters and G. W. J. Fieet, Chem. Commun., 1998, 2119-2120.

27 L. Moreno Y Banuls, A. Katz, W. Miklos, A. Cimmino, D. M. Tal, E. Ainbinder, M. Zehl, E. Urban, A. Evidente, B. Kopp, W. Berger, O. Feron, S. Karlish and R. Kiss, Mol. Cancer, 2013, 12.

28 H. Y. L. Wang, W. Xin, M. Zhou, T. A. Stueckle, Y. Rojanasakul and G. A. O'Doherty, ACS Med. Chem. Lett., 2011, 2, 73-78.

29 H. Y. L. Wang, Y. Rojanasakul and G. A. O'Doherty, ACS Med. Chem. Lett., 2011, 2, 264-269.

30 Y. Wang, J. Gao, G. Gu, G. Li, C. Cui, B. Sun and H. Lou, ChemBioChem, 2011, 12, 2418-2420. 
31 Y. L. Ku, G. V. Rao, C. H. Chen, C. Wu, J. H. Guh and S. S. Lee, Helv. Chim. Acta, 2003, 86, 697-702.

32 D. Thibeault, C. Gauthier, J. Legault, J. Bouchard, P. Dufour and A. Pichette, Bioorg. Med. Chem., 2007, 15, 6144-6157.

33 M. Tamigney Kenfack, M. Mazur, T. Nualnoi, T. L. Shaffer, A. Ngassimou, Y. Blériot, J. Marrot, R. Marchetti, K. Sintiprungrat, N. Chantratita, A. Silipo, A. Molinaro, D. P. AuCoin, M. N. Burtnick, P. J. Brett and C. Gauthier, Nat. Commun., 2017, 8, 115.

34 S. O. Bajaj, E. U. Sharif, N. G. Akhmedoz and G. A. O'Doherty, Chem. Sci., 2014, 5, 2230-2234.
35 R. R. Schmidt and A. Toepfer, Tetrahedron Lett., 1991, 32, 3353-3356.

36 Y. Zhang, Y. Li, T. Guo, H. Guan, J. Shi, Q. Yu and B. Yu, Carbohydr. Res., 2005, 340, 1453-1459.

37 S. C. B. Gnoatto, A. Dassonville-Klimpt, S. Da Nascimento, P. Galéra, K. Boumediene, G. Gosmann, P. Sonnet and S. Moslemi, Eur. J. Med. Chem., 2008, 43, 1865-1877.

38 R. Rago, J. Mitchen and G. Wilding, Anal. Biochem., 1990, 191, 31-34.

39 S. J. Green, M. S. Meltzer, J. B. Hibbs Jr and C. A. Nacy, J. Immunol., 1990, 144, 278-283. 